Dissertação apresentada como parte dos requisitos para obtenção do Grau de Mestre em Ciências na Área de Tecnologia Nuclear - Aplicações

Orientadora:

Profa. Dra. Carmen Cecília Bueno Tobias 


\section{INSTITUTO DE PESQUISAS ENERGÉTICAS E NUCLEARES}

Autarquia associada à Universidade de São Paulo

MEDIDAS DO COEFICIENTE DE MULTIPLICAÇÃO GASOSA NO

ISOBUTANO PURO

\section{IARA BATISTA DE LIMA}

Dissertação apresentada como parte dos requisitos para obtenção do Grau de Mestre em Ciências na Área de Tecnologia Nuclear - Aplicações

Orientadora:

Profa. Dra. Carmen Cecília Bueno Tobias 
Aos meus pais, 


\section{AGRADECIMENTOS}

Agradeço à orientadora Profa. Dra. Carmen Cecília Bueno Tobias, com quem muito aprendi ao longo destes anos, pelo exemplo de pesquisadora, seriedade e dedicação ao longo do projeto.

À Profa. Dra. Josemary Angélica Correa Gonçalves, pelo contínuo apoio, valiosos ensinamentos e auxílios prestados para compreensão da técnica experimental e aquisição de dados.

À Profa. Dra. Suzana Botelho, que muito acrescentou com sua experiência científica, pelas inestimáveis discussões sobre os conceitos envolvidos no trabalho e incondicionais auxílios durante o projeto.

À Profa. Dra. Maria Margarida F. R. Fraga, do Laboratório de Instrumentação e Física Experimental de Partículas da Universidade de Coimbra, pela atenção dedicada e pelos ensinamentos na área de parâmetros de transporte de elétrons em gases.

Ao Dr. Alessio Mangiarotti, do Laboratório de Instrumentação e Física Experimental de Partículas da Universidade de Coimbra, pelas valiosas discussões e presteza nas simulações em Monte Carlos utilizadas no trabalho.

Ao Prof. Dr. Paulo Fonte, do Laboratório de Instrumentação e Física Experimental de Partículas da Universidade de Coimbra, pelas contribuições no aparato experimental e auxílio na utilização da simulação de campo elétrico empregada no projeto.

Ao Prof. Dr. Jiro Takahashi, do Laboratório do Acelerador Linear da Universidade de São Paulo, pela construção e montagem da câmara utilizada no projeto. 
Ao Eng. Jair S. do Nascimento-Singer, pelas valiosas contribuições e alteração do circuito eletrônico de aquisição de sinais, que foram imprescindíveis para o desenvolvimento do projeto e para a confiabilidade das medidas.

Ao colega de mestrado e companheiro Túlio Cearamicoli Vivaldini, pelo auxílio durante o desenvolvimento do projeto e contribuições com críticas e sugestões.

Ao Prof. Dr. Paulo Reginaldo Pascholati e ao colega de mestrado Marco Antônio Ridenti, do Laboratório do Acelerador Linear da Universidade de São Paulo, pelas valiosas sugestões ao longo do trabalho.

Ao Dr. Wilson Aparecido Parejo Calvo, diretor do Centro de Tecnologia das Radiações (CTR) do IPEN-CNEN/SP, por ter permitido a utilização das instalações e da infra-estrutura do Centro durante a realização deste projeto.

À Fundação de Amparo a Pesquisa de São Paulo, pela concessão da bolsa de estudos sob processo no 2007/06773-0. 


\title{
MEDIDAS DO COEFICIENTE DE MULTIPLICAÇÃO GASOSA NO ISOBUTANO PURO
}

\author{
Iara Batista de Lima
}

\section{RESUMO}

Neste trabalho são apresentadas as medidas do coeficiente de multiplicação gasosa $(\alpha)$ no isobutano puro obtidas com uma câmara de placas paralelas protegida contra descargas por um eletrodo de vidro (anodo) de elevada resistividade ( $\rho=2 \times 10^{12} \Omega . \mathrm{cm}$ ). $\mathrm{O}$ método empregado foi o de Townsend pulsado, onde a ionização primária é produzida pela incidência de um feixe de laser de nitrogênio em um eletrodo metálico (catodo). As correntes elétricas medidas com a câmara operando em regime de ionização e de avalanche foram utilizadas para o cálculo do coeficiente de multiplicação gasosa pela solução da equação de Townsend para campos elétricos uniformes. A técnica utilizada foi validada pelas medidas do coeficiente de multiplicação gasosa no nitrogênio, um gás amplamente estudado, e para o qual se tem dados bem estabelecidos na literatura. Os coeficientes de multiplicação gasosa do isobutano foram medidos em função do campo elétrico reduzido no intervalo de $139 \mathrm{Td}$ a $208 \mathrm{Td}$. Os valores obtidos foram comparados com os simulados pelo programa Imonte (versão 4.5) e com os únicos dados existentes na literatura, recentemente obtidos pelo nosso grupo. Esta comparação demonstrou que os resultados são concordantes dentro dos erros experimentais. 


\title{
MEASUREMENTS OF GASEOUS MULTIPLICATION COEFFICIENT IN PURE ISOBUTANE
}

\author{
Iara Batista de Lima
}

\begin{abstract}
In this work it is presented measurements of gaseous multiplication coefficient $(\alpha)$ in pure isobutane obtained with a parallel plate chamber, protected against discharges by one electrode (anode) of high resistivity glass $\left(\rho=2 \times 10^{12} \Omega . \mathrm{cm}\right)$. The method applied was the Pulsed Townsend, where the primary ionization is produced through the incidence of a nitrogen laser beam onto a metallic electrode (cathode). The electric currents measured with the chamber operating in both ionization and avalanche regimes were used to calculate the gaseous multiplication coefficient by the solution of the Townsend equation for uniform electric fields. The validation of the technique was provided by the measurements of gaseous multiplication coefficient in pure nitrogen, a widely studied gas, which has well-established data in literature. The $\alpha$ coefficients in isobutane were measured as a function of the reduced electric field in the range of 139Td up to 208Td. The obtained values were compared with those simulated by Imonte software (version 4.5) and the only experimental results available in the literature, recently obtained in our group. This comparison showed that the results are concordant within the experimental errors.
\end{abstract}




\section{SUMÁRIO}

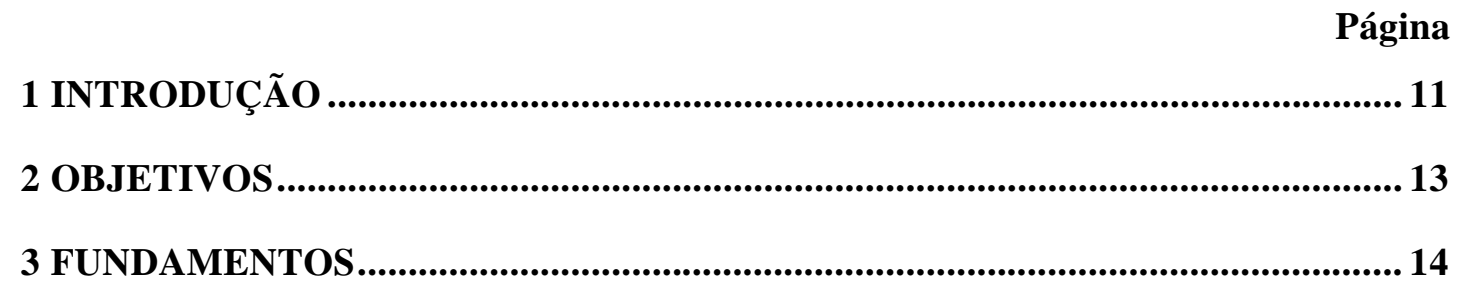

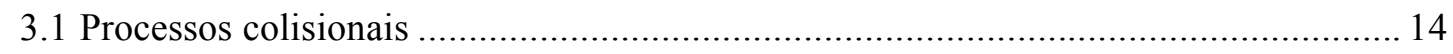

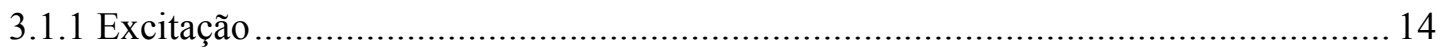

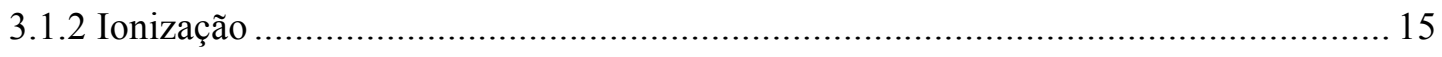

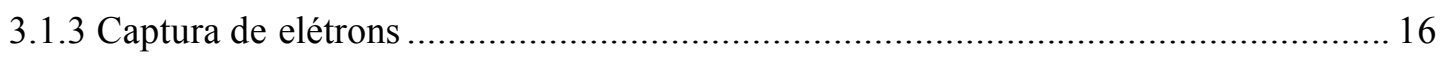

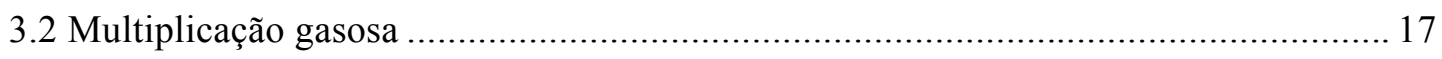

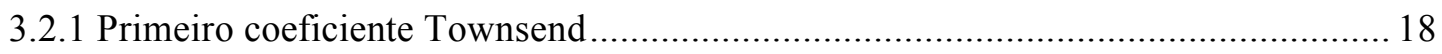

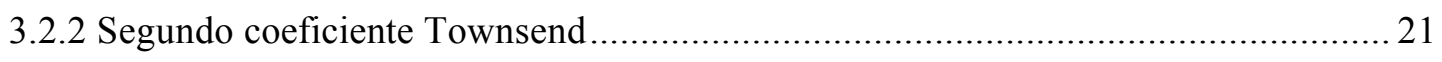

3.2.3 Disruptura para campos elétricos uniformes.................................................. 24

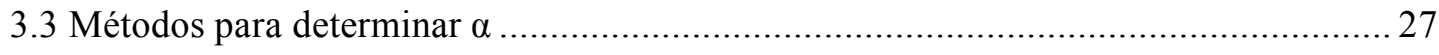

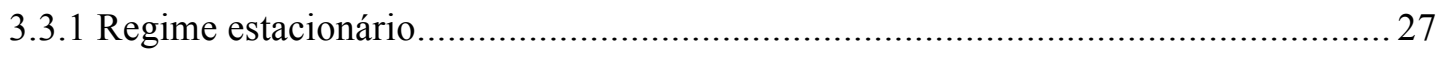

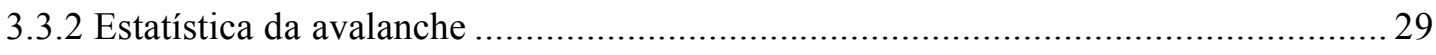

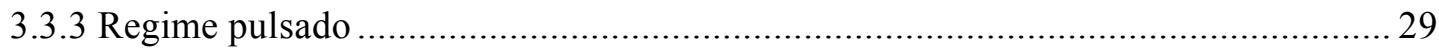

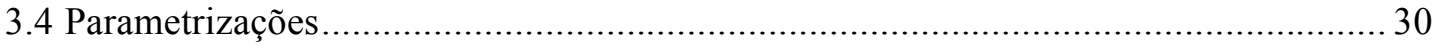

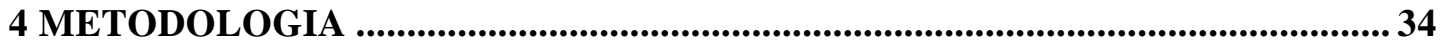

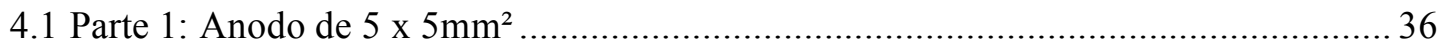

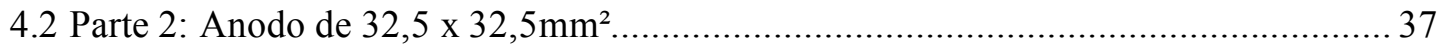




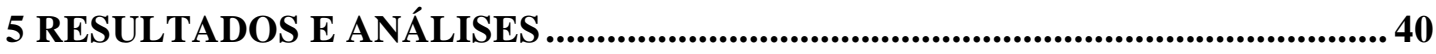

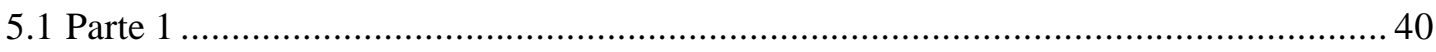

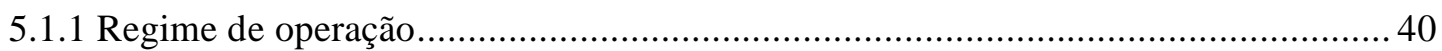

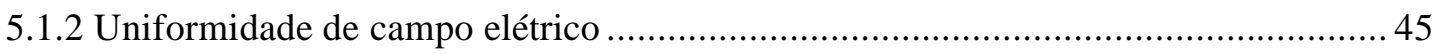

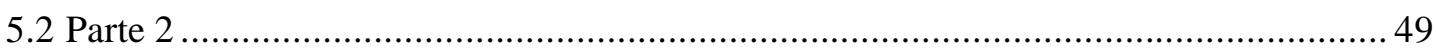

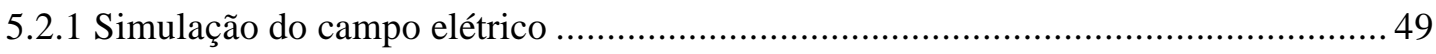

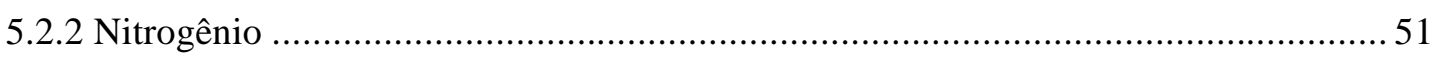

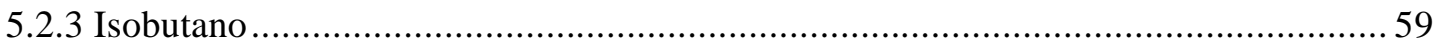

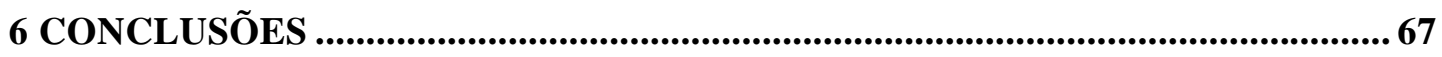

ANEXO I ........................................................................................................................69 69

REFERÊNCIAS BIBLIOGRÁFICAS ........................................................................... 71 


\section{ÍNDICE DE FIGURAS}

FIGURA 1: Processos de colisão em gases em função da energia do elétron [3]............... 14

FIGURA 2: Seção de choque total de ionização para gases nobres [2] ........................... 15

FIGURA 3: (a) Fotografia de avalanches em uma câmara de nuvens [6]; (b) Esquema de uma avalanche.

FIGURA 4: Produção de elétrons primários no catodo por meio da incidência de radiação ultravioleta [2]......

FIGURA 5: Coeficiente de ionização em função de $\mathrm{E} / \mathrm{N}$ para gases nobres [2]................ 20

FIGURA 6: Coeficiente $\gamma$ efetivo no $\mathrm{N}_{2}$ para diferentes catodos [19] .............................. 22

FIGURA 7: Valores calculados de $\gamma$ em função de E/N para Ar [20] ............................. 23

FIGURA 8: Valores de $\gamma / \alpha$ em função de $\mathrm{E} / \mathrm{N}$ para o $\mathrm{N}_{2}$, sendo $\mathrm{E} / \mathrm{P}_{20} \mathrm{o}$ campo elétrico

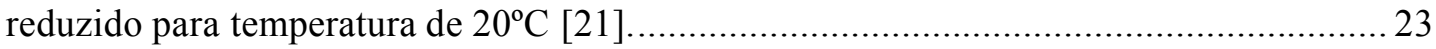

FIGURA 9: Curvas de Paschen para diferentes gases [2] .............................................. 25

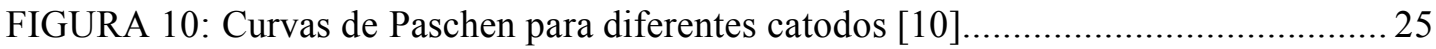

FIGURA 11: Variação da corrente em função do espaçamento entre os eletrodos.............2 28

FIGURA 12: Esquema de aparato empregado para determinar parâmetros de transporte por

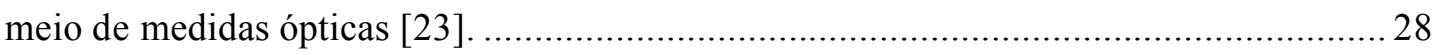

FIGURA 13: Comportamento da função de parametrização de Williams e Sara [2]......... 32

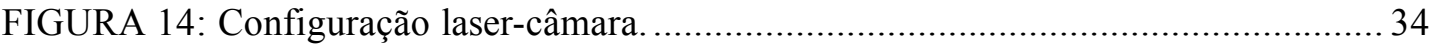

FIGURA 15: (a) Detalhes do parafuso micrométrico conectado ao catodo; (b) parafusos

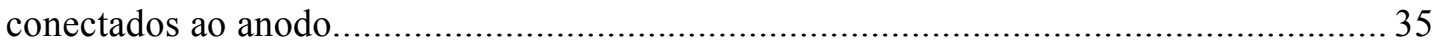

FIGURA 16: Aparato experimental sobre a bancada óptica. .......................................... 36

FIGURA 17: Anodo empregado na primeira parte do projeto......................................... 37

FIGURA 18: (a) Eletrodo de vidro; (b) Placa de latão de polarização do anodo................ 38

FIGURA 19: (a) Fotos do interior da câmara; (b) Esquema do circuito da câmara............ 38

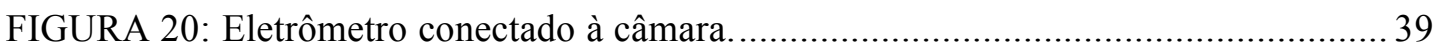

FIGURA 21: Média do sinal de menor amplitude para o nitrogênio................................ 42

FIGURA 22: Média do sinal de maior amplitude para o nitrogênio.................................. 42

FIGURA 23: Sinal de menor amplitude para o isobutano................................................. 43

FIGURA 24: Sinal de maior amplitude para o isobutano............................................... 43 
FIGURA 25: Amplitude média do sinal em função da tensão aplicada para o nitrogênio. 44

FIGURA 26: Amplitude média do sinal em função da tensão para o isobutano................ 44

FIGURA 27: Amplitude em função do campo elétrico reduzido para o nitrogênio............ 45

FIGURA 28: Amplitude em função do campo elétrico reduzido para o isobutano............. 46

FIGURA 29: Simulação do campo elétrico para o espaçamento de $0,50 \mathrm{~mm}$ - parte $1 \ldots . . .47$

FIGURA 30: Simulação do campo elétrico para o espaçamento de $1,00 \mathrm{~mm}$ - parte $1 \ldots . . .47$

FIGURA 31: Simulação do campo elétrico para o espaçamento de $1,50 \mathrm{~mm}$ - parte $1 \ldots . . .48$

FIGURA 32: Simulação do campo elétrico para o espaçamento de $1,75 \mathrm{~mm}$ - parte $1 \ldots . . .48$

FIGURA 33: Simulação do campo elétrico para a configuração de eletrodos da

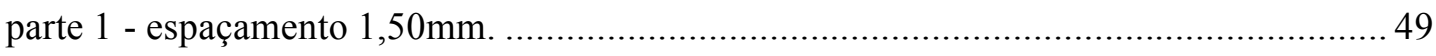

FIGURA 34: Simulação do campo elétrico para a configuração de eletrodos da

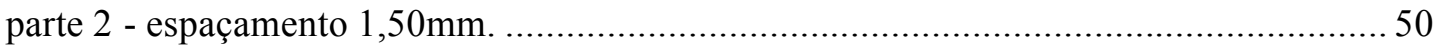

FIGURA 35: Simulação do campo elétrico para o espaçamento de $1,25 \mathrm{~mm}$ - parte 2 ...... 50

FIGURA 36: Simulação do campo elétrico para o espaçamento de $1,50 \mathrm{~mm}$ - parte 2 ......51

FIGURA 37: Variação da corrente em função da tensão................................................ 53

FIGURA 38: Coeficiente de multiplicação gasosa do nitrogênio...................................... 54

FIGURA 39: Corrente em função da tensão, para 1,25mm entre os eletrodos.................. 56

FIGURA 40: Coeficiente de multiplicação para os espaçamentos estudados.................... 57

FIGURA 41: $\alpha / \mathrm{N}$ em função do inverso do campo elétrico reduzido para o nitrogênio. ... 58

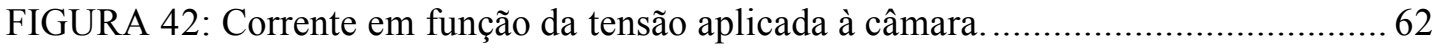

FIGURA 43: Corrente em função da tensão para $1,25 \mathrm{~mm}$ de espaçamento....................... 63

FIGURA 44: Coeficiente de multiplicação gasosa no isobutano. ..................................... 64

FIGURA 45: Coeficiente de multiplicação do nitrogênio e do isobutano. ........................ 65

FIGURA 46: Coeficiente $\alpha$ reduzido em função de N/E no isobutano.............................. 66

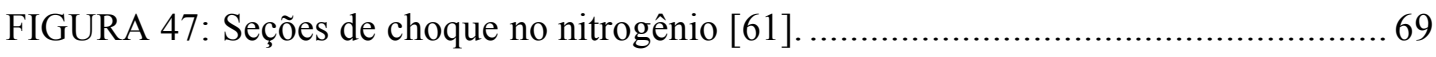

FIGURA 48: Porcentagem de energia perdida por elétrons em $\mathrm{N}_{2}$ em função de $E / N[62] .69$

FIGURA 49: Seções de choque no isobutano [63] ..................................................... 70

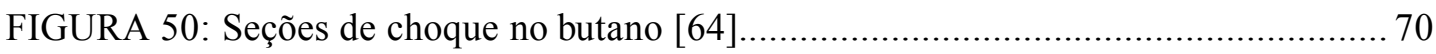




\section{INTRODUÇÃO}

O parâmetro de transporte empregado para descrever o crescimento de cargas em um detector operando em regime de avalanche é conhecido como primeiro coeficiente de Townsend de ionização, $\alpha$, (ou coeficiente de multiplicação gasosa), em homenagem a John Sealy Edward Townsend, aluno de Joseph John Thomson e precursor dos estudos sobre descargas elétricas em gases.

No início do século 20, Townsend em seus experimentos introduziu o coeficiente $\alpha$ para representar o número de elétrons secundários criados por elétron primário ao longo de uma unidade de trajetória, na direção do campo elétrico. Desde então, o coeficiente $\alpha$ de ionização tem sido largamente estudado para vários gases e misturas, em diferentes regiões de campo elétrico.

Contudo, nas últimas décadas, os experimentos em Física de Altas Energias têm motivado o desenvolvimento de detectores gasosos operando com estabilidade em regime de elevado ganho em carga, e o estudo de gases de enchimento com tais características. Neste contexto, os parâmetros de transporte de elétrons em gases, além de serem relevantes para validar as secções de choque envolvidas nas colisões com elétrons, contribuem com informações importantes para a construção de detectores.

Este projeto de mestrado tem como objetivo medir o coeficiente de multiplicação gasosa no isobutano, com uma câmara de placas paralelas, sendo um dos eletrodos constituído por um vidro de elevada resistividade $\left(2 \times 10^{12} \Omega . \mathrm{cm}\right)$. A técnica experimental baseia-se na medida da corrente produzida pela ionização do gás por elétrons emitidos a partir da incidência de um laser de nitrogênio em um catodo metálico. A razão entre a corrente elétrica com a câmara operando em regime de avalanche de cargas, e a corrente de ionização primária, com a câmara operando em regime de câmara ionização, fornece o coeficiente $\alpha$.

Para validar as medidas e o método empregado, as etapas iniciais contemplaram medidas do coeficiente $\alpha$ para o nitrogênio, já que os parâmetros de transporte desse gás são amplamente estudados e se dispõe de dados experimentais 
precisos na literatura. Após esta etapa de validação da metodologia, estendeu-se o estudo para o isobutano puro $\left(\mathrm{iC}_{4} \mathrm{H}_{10}\right)$. A escolha do isobutano deve-se à sua importância no domínio dos detectores gasosos como componente inibidor de descargas e a escassez de dados na literatura para este gás. Neste sentido, os resultados obtidos devem contribuir para a compreensão dos fenômenos físicos envolvidos nas avalanches gasosas.

Esta dissertação divide-se em seis capítulos. No capítulo 3 são discutidos os fundamentos teóricos do processo de descargas em gases, incluindo os principais tipos de colisões com elétrons, o processo de multiplicação de cargas em gases e os métodos experimentais para determinar o parâmetro $\alpha$.

No capítulo 4 são descritos os métodos experimentais adotados na aquisição das medidas, compreendendo os procedimentos de alinhamento dos eletrodos e focalização do laser. Este capítulo está dividido em duas partes, de acordo com a configuração de eletrodos empregada e tipo de estudo realizado. Na parte 1 são descritos os procedimentos utilizando-se um anodo de vidro de $25 \mathrm{~mm}^{2}$ de área, com o qual foram feitas medidas de amplitude de sinais para diferentes espaçamentos entre os eletrodos. Já na parte 2 são descritos os métodos utilizando-se um anodo de maior área efetiva $\left(1,06 \times 10^{3} \mathrm{~mm}^{2}\right)$, com o qual foram realizadas medidas sistemáticas de corrente elétrica.

No capítulo 5 são apresentados os resultados obtidos no trabalho e, assim como o capítulo 4, este capítulo divide-se em duas partes. Na parte 1 são apresentados estudos relativos ao regime de operação da câmara e uniformidade do campo elétrico entre os eletrodos. A partir dos resultados obtidos nessa parte 1 do trabalho, procederam-se análises com um anodo de vidro de maior área efetiva, que permitiram a determinação do coeficiente $\alpha$ no nitrogênio e no isobutano, e que são apresentados na parte 2 do capítulo. Merecem destaque nesta parte, os estudos de parametrização do coeficiente $\alpha$, que embasaram as análises e conclusões do projeto. 


\section{OBJETIVOS}

Determinar o coeficiente de multiplicação gasosa no isobutano puro com uma câmara de placas paralelas, sendo um dos eletrodos constituído por um material resistivo, operando em regime de ionização e de avalanche, por meio de medidas de corrente elétrica, e estudar a influência de efeitos de não uniformidade de campo elétrico entre os eletrodos. 


\section{FUNDAMENTOS}

\subsection{Processos colisionais}

As colisões de elétrons com os átomos ou moléculas de um gás podem ser divididas em colisões elásticas, quando não há variação na energia interna dos envolvidos, inelásticas, quando a energia interna é alterada, ou superelásticas, quando as colisões envolvem átomos ou moléculas excitadas e elétrons.

Cerca de $90 \%$ das colisões são do tipo elástica, porém colisões inelásticas, além de possibilitarem estudos da estrutura atômica, são de interesse no domínio dos detectores gasosos. Os principais tipos de colisões inelásticas são: excitação, ionização e captura eletrônica. Uma breve descrição destes processos colisionais é apresentada nas subseções a seguir. Maiores detalhes das interações envolvidas e das técnicas experimentais para medir as seções de choque de colisão podem ser encontrados em [1-4].

\subsubsection{Excitação}

Colisões que resultem em excitação podem ocorrer com moléculas do gás (excitação molecular) ou com átomos (excitação atômica). Considerando os níveis de energia envolvidos, as excitações moleculares podem ser classificadas em rotacionais ou vibracionais. Já as excitações atômicas com elétrons, por exemplo, ocorrem para energias maiores (FIG.1) e podem ser escritas como:

$$
\mathrm{A}+\mathrm{e} \rightarrow \mathrm{A}^{*}+\mathrm{e}
$$

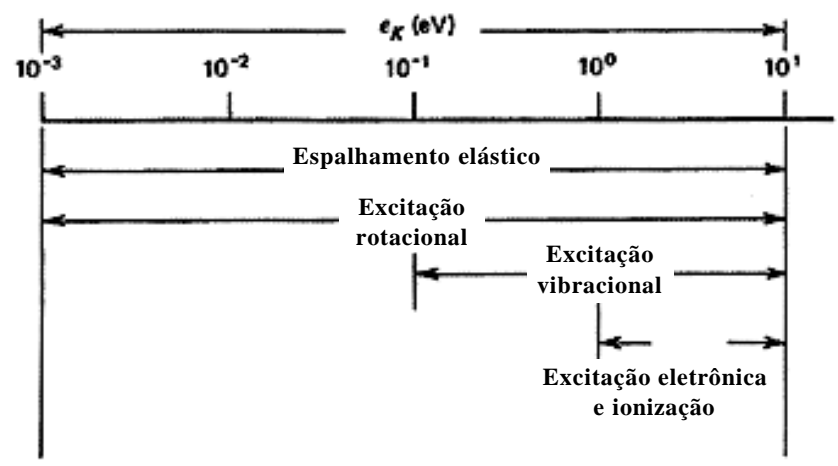

FIGURA 1: Processos de colisão em gases em função da energia do elétron [3]. 
Além das colisões com elétrons, para misturas gasosas com dois tipos de gases, podem ocorrer excitações do tipo:

- Excitação por impacto atômico: $\mathrm{A}+\mathrm{B} \rightarrow \mathrm{A}^{*}+\mathrm{B}$

- Excitação por átomos excitados: $\mathrm{A}^{*}+\mathrm{B} \rightarrow \mathrm{A}+\mathrm{B}^{*}$

Ainda, excitações por colisão com partículas, íons positivos ou átomos excitados em estados metaestáveis são possíveis processos, que dependem se a energia desses é superior ao potencial de excitação do átomo ou molécula.

\subsubsection{Ionização}

Para colisões envolvendo maiores energias, processos de geração de cargas, como ionização, tornam-se consideráveis. Assim como a excitação, a secção de choque para ionização é nula para energias inferiores ao potencial de ionização, aumenta até um máximo em seguida diminui lentamente com a energia.

Considerando um elétron como partícula incidente, à medida que sua energia aumenta o tempo de interação com o átomo ou molécula diminui, implicando em um decréscimo da seção de choque de ionização. Este comportamento pode ser visto na FIG.2, onde são apresentadas as curvas de seção eficaz de ionização para gases nobres. Nesta figura nota-se também o aumento da seção de choque com a massa atômica.

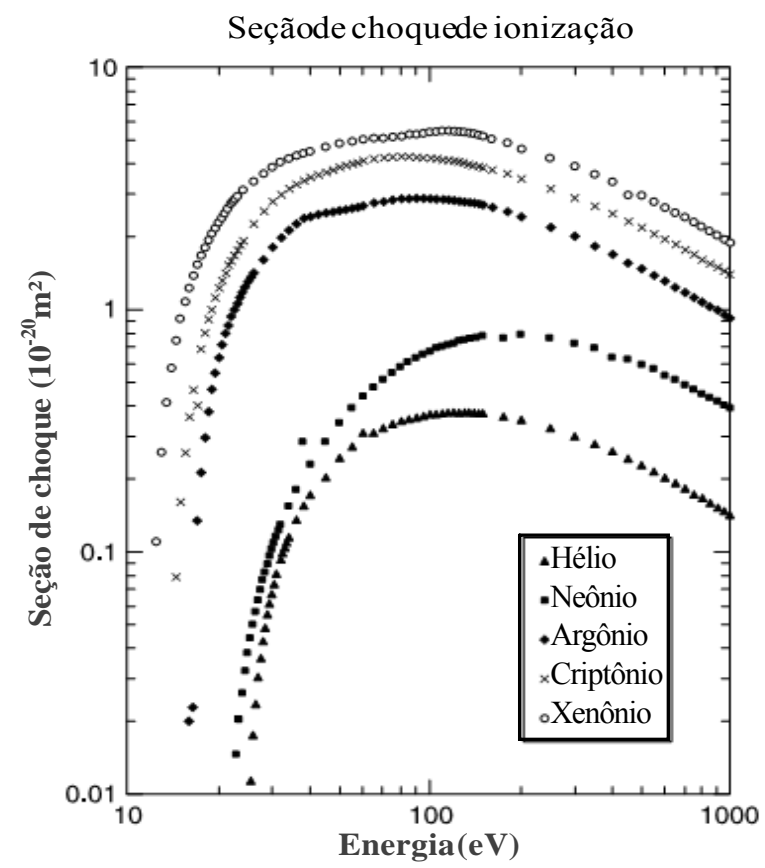

FIGURA 2: Seção de choque total de ionização para gases nobres [2]. 
Analogamente à excitação, o processo de ionização ocorre para diferentes tipos de colisões com átomos ou moléculas. Os principais são:

- Ionização por colisão com elétron: $\mathrm{A}+\mathrm{e} \rightarrow \mathrm{A}^{+}+\mathrm{e}+\mathrm{e}$

- Ionização por colisão com átomo: $\mathrm{A}+\mathrm{B} \rightarrow \mathrm{A}^{+}+\mathrm{e}+\mathrm{B}$

- Ionização por colisão com íon positivo: $\mathrm{A}^{+}+\mathrm{B} \rightarrow \mathrm{A}^{+}+\mathrm{B}^{+}+\mathrm{e}$

- Fotoionização: $\mathrm{A}+\mathrm{h} v \rightarrow \mathrm{A}^{+}+\mathrm{e}$

- Ionização de Penning: $\mathrm{A}^{*}+\mathrm{B} \rightarrow \mathrm{A}+\mathrm{B}^{+}+\mathrm{e}$

- Ionização associativa: $\mathrm{A}+\mathrm{A}^{*} \rightarrow \mathrm{A}_{2}^{+}+\mathrm{e}$

\subsubsection{Captura de elétrons}

Elétrons podem ser capturados por átomos ou moléculas neutras, dependendo da eletronegatividade desses, formando íons negativos. O processo é representado pela reação:

$$
\mathrm{e}+\mathrm{AB} \rightarrow \mathrm{AB}^{-}
$$

Para moléculas diatômicas ou poliatômicas a energia liberada na captura de elétrons pode conduzir à dissociação molecular. Este é um dos tipos mais eficientes de interação para formar íons negativos e pode ser representado por:

$$
\mathrm{e}+\mathrm{A}_{2} \rightarrow \mathrm{A}+\mathrm{A}^{-}
$$

A estabilidade de um íon negativo é medida pela afinidade eletrônica da molécula neutra em questão, que representa a energia fornecida para que um elétron de energia zero é arrancado de um íon negativo. Afinidade eletrônica positiva indica que o íon negativo é estável, além disso, quanto maior o valor da afinidade, maior a estabilidade do íon. Na TAB.1 a seguir são apresentados valores de afinidade eletrônica $\left(E_{a}\right)$ de alguns átomos e moléculas.

TABELA 1: Valores de afinidade eletrônica para alguns átomos e moléculas [5].

\begin{tabular}{cccc}
\hline Átomo & $\mathbf{E}_{\mathbf{a}}(\mathbf{e V})$ & Molécula & $\mathbf{E}_{\mathbf{a}}(\mathbf{e V})$ \\
\hline $\mathrm{F}$ & 3,40 & $\mathrm{~F}_{2}$ & 3,08 \\
$\mathrm{Cl}$ & 3,61 & $\mathrm{Cl}_{2}$ & 2,38 \\
$\mathrm{Br}$ & 3,36 & $\mathrm{Br}_{2}$ & 2,51 \\
$\mathrm{I}$ & 3,07 & $\mathrm{I}_{2}$ & 2,58 \\
$\mathrm{O}$ & 1,46 & $\mathrm{O}_{2}$ & 0,44 \\
$\mathrm{~S}$ & 2,08 & $\mathrm{SF}_{6}$ & 0,60 \\
$\mathrm{C}$ & 1,26 & $\mathrm{CF}_{2}$ & 2,10 \\
\hline
\end{tabular}




\subsection{Multiplicação gasosa}

O regime de avalanche, ou multiplicação gasosa, ocorre quando elétrons produzidos na ionização primária do gás adquirem energia suficiente para ionizar as moléculas do gás devido ao campo elétrico a que estão submetidos. Os elétrons adicionais produzidos também adquirem energia para ionizar moléculas neutras e assim por diante. Essa produção de cargas em cascata é conhecida como avalanche Townsend. Devido à mobilidade dos elétrons ser maior do que a dos íons positivos (cerca de 1000 vezes), a avalanche tem o formato de uma gota, com todos os elétrons contidos na parte mais extensa da gota e os íons positivos decrescendo em número à medida que a extensão lateral da gota diminui.

Na FIG.3 é mostrada uma fotografia de avalanches produzidas em uma câmara de nuvens por meio de gotículas condensadas ao redor de íons. Os métodos empregados para observar avalanches e as técnicas experimentais para medir parâmetros de transporte em gases são apresentados em Raether [6].
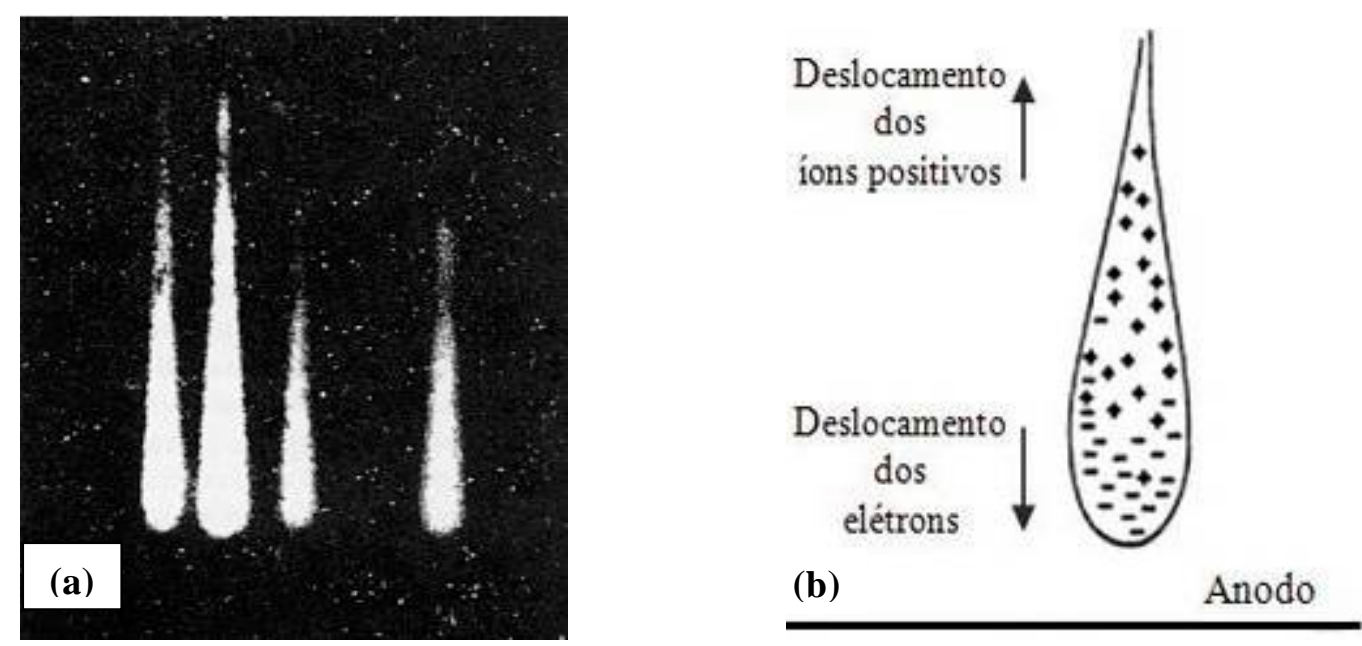

FIGURA 3: (a) Fotografia de avalanches em uma câmara de nuvens [6]; (b) Esquema de uma avalanche.

Dois parâmetros de suma importância para descrever o processo de ionização e o crescimento de cargas em regime de avalanche são os chamados coeficientes de Townsend de ionização. Uma descrição desses coeficientes, juntamente com suas implicações no processo de disruptura gasosa, é apresentada nas subseções a seguir. 


\subsubsection{Primeiro coeficiente Townsend}

Townsend em seus estudos relativos à variação da corrente entre eletrodos de placas paralelas, com o catodo sendo irradiado com luz ultravioleta, observou que com o aumento da tensão entre os eletrodos a corrente inicialmente cresce até uma região de valor constante, correspondente à corrente fotoelétrica gerada no catodo, e após essa região a corrente elétrica aumenta exponencialmente com a tensão.

Neste contexto, Townsend introduziu o coeficiente $\alpha_{i}$ para representar o número de elétrons secundários produzidos por elétron primário percorrendo uma unidade de trajetória, na direção do campo elétrico. Por esta razão, o coeficiente $\alpha_{\mathrm{i}}$ é conhecido como primeiro coeficiente Townsend de ionização, ou primeiro coeficiente de multiplicação gasosa. Resumos dos experimentos de Townsend e dos fatores envolvidos nas descargas em gases são apresentados nas referências [7-10].

Sendo $n$ o número de elétrons produzidos em uma dada posição, então o número de elétrons criados por unidade de trajetória em regime de avalanche, desconsiderando a captura de elétrons, é dado pela equação de Townsend:

$$
\frac{\mathrm{dn}}{\mathrm{dx}}=\alpha_{\mathrm{i}} \mathrm{n}
$$

Considerando uma região de campo elétrico uniforme (geometria de eletrodos paralelos) a solução da equação anterior é obtida por integração simples que resulta em:

$$
\mathrm{n}=\mathrm{n}_{0} \mathrm{e}^{\alpha_{\mathrm{i}} \mathrm{x}}
$$

sendo $n_{0} \mathrm{o}$ número de elétrons primários e $x$ a distância percorrida pelos elétrons do ponto de interação até o eletrodo coletor. Se todos os elétrons primários forem produzidos no catodo (FIG.4) o comprimento da avalanche será igual ao espaçamento entre os eletrodos, $d$.

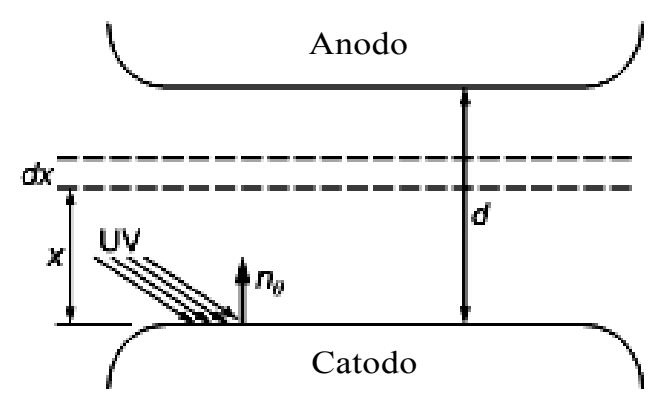

FIGURA 4: Produção de elétrons primários no catodo por meio da incidência de radiação ultravioleta [2]. 
Em termos da corrente elétrica, a Eq. (2) pode ser reescrita como sendo

$$
\mathrm{I}=\mathrm{I}_{0} \mathrm{e}^{\alpha_{\mathrm{i}} \mathrm{x}}
$$

onde $I$ é a corrente medida em regime de avalanche e $I_{0}$ a corrente de ionização primária.

Para gases com eletronegatividade considerável, define-se o coeficiente de ionização efetivo $(\alpha)$ como sendo a diferença entre o coeficiente de ionização $\left(\alpha_{i}\right)$ e o coeficiente de captura de elétrons por moléculas neutras do gás $(\mu)$. Na literatura, e principalmente em trabalhos experimentais, o coeficiente de ionização efetivo $(\alpha)$ é chamado simplesmente de coeficiente de ionização.

Para uma configuração de campo elétrico não uniforme, como é o caso para eletrodos com geometria cilíndrica ou esférica, a solução da Eq.(2) é dada pela relação (4) a seguir. Com uma geometria de eletrodos paralelos, os valores medidos do coeficiente $\alpha$ são influenciados por efeitos que resultem em distorções do campo elétrico, por exemplo, efeitos de borda ou de carga espacial.

$$
I=I_{0} e^{\int_{x_{1}}^{x_{2}} \alpha d x}
$$

O coeficiente $\alpha$ relaciona-se com o fator de multiplicação do gás $M$, parâmetro diretamente ligado à construção de detectores operando em regime de avalanche e a escolha do gás de enchimento. Para geometria cilíndrica,o fator $M$ é definido como

$$
M=\frac{I}{I_{0}}=e^{\int_{x_{1}}^{x_{2}} \alpha d x}
$$

O primeiro coeficiente de Townsend é função da intensidade do campo elétrico $(E)$ e da distância que o elétron percorre entre duas colisões sucessivas, ou seja, do livre caminho médio $(\lambda)$ :

$$
\alpha=\frac{f(E, \lambda)}{\lambda}
$$

Como o livre caminho médio é inversamente proporcional a pressão $(P)$, a equação anterior pode ser reescrita como

$$
\frac{\alpha}{P}=f\left(\frac{E}{P}\right)
$$

Baseando-se na relação anterior, os valores de $\alpha$ publicados antes de 1970 são apresentados nas unidades $\alpha / P\left(\mathrm{~cm}^{-1} \mathrm{Torr}^{-1}\right)$ e $E / P\left(\mathrm{~V} \mathrm{~cm}^{-1} \mathrm{Torr}^{-1}\right)$. Contudo, valores de $\alpha / P$ 
obtidos para o mesmo $E / P$ não concordavam, dentro do erro experimental, devido a diferentes condições de temperatura.

Por essa razão, e para melhor representar o processo físico, a densidade de gás $(N)$ foi introduzida para substituir $P$ nos estudos de variação do coeficiente $\alpha$ em função do campo elétrico. A densidade de gás é obtida a partir da lei dos gases perfeitos e é dada pela relação:

$$
\mathrm{N}=\mathrm{N}_{0} \frac{\mathrm{P}(\text { Torr })}{760} \frac{273,15}{\mathrm{~T}}
$$

com $N_{0}=2,687 \times 10^{25} \mathrm{~m}^{-3}$ (número de Loschmidt) e T a temperatura em kelvin.

Na FIG.5 é mostrado o comportamento de $\alpha / \mathrm{N}$ em função do campo elétrico reduzido. A unidade especial para $E / N$ é o townsend, definida como $1 \mathrm{Td}=10^{-21} \mathrm{Vm}^{2}$.

O coeficiente $\alpha$ aumenta com o campo, porém a partir de determinado valor, processos secundários, como geração de avalanches por fótons, originam disruptura do gás. O limite para este fenômeno ocorrer é dado pela condição de Raether [6]:

$$
\alpha \mathrm{x}<20
$$

Além de relacionar-se com grandezas importantes para o desenvolvimento de detectores gasosos, o coeficiente $\alpha$ está indiretamente ligado com a probabilidade de ionização. Como esta probabilidade é dada para elétrons monoenergéticos e em descargas gasosas os elétrons possuem uma distribuição de energia, apenas conhecendo a forma desta distribuição, é possível com os dados de seção de choque determinar o parâmetro $\alpha$.

É importante salientar que os valores medidos de parâmetros de transporte variam ligeiramente com a técnica experimental adotada, como discutido por Sakai et al. [11] e Tagashira et al. [12]. Na seção 3.3 alguns métodos de medida serão apresentados.

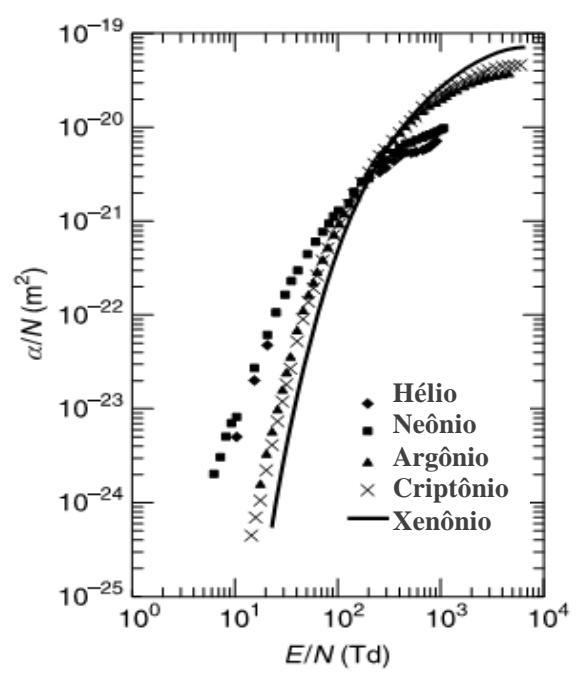

FIGURA 5: Coeficiente de ionização em função de E/N para gases nobres [2]. 
Apesar do coeficiente de ionização $\alpha$ ser um parâmetro amplamente estudado (desde 1900, com Townsend), e da existência de valores precisos na literatura para muitos gases, o desenvolvimento de novos detectores gasosos, operando em regiões de elevado $E / N$, tem motivado o estudo de parâmetros de transporte em misturas gasosas que favoreçam essa condição.

Entre esses detectores gasosos estão as câmaras de placas paralelas resistivas (RPCs) e os detectores de microestrutura, nos quais a resolução está ligada à flutuações no número de elétrons da avalanche, ou seja, ao coeficiente $\alpha$ [13-17].

\subsubsection{Segundo coeficiente Townsend}

Durante a propagação da avalanche as colisões inelásticas dos elétrons com as moléculas do gás não produzem apenas cargas por meio do processo de ionização. Outras colisões inelásticas podem ocorrer como: excitações de moléculas, que se desexcitam emitindo fótons, ou ainda, excitações de moléculas para estados metaestáveis. Com isso, íons positivos, fótons e átomos metaestáveis poderão produzir cargas no gás, ou no catodo, e dar início a novas avalanches.

Esses processos secundários de geração de cargas são responsáveis por um aumento na corrente, que não pode ser descrito pela Eq.(3). Considera-se que esses processos são majoritariamente devido à ação de fótons, gerados na avalanche primária, no catodo. Nestas condições, o coeficiente $\gamma$ (conhecido como segundo coeficiente de Townsend) é introduzido para representar o número de elétrons secundários produzidos por elétron da avalanche primária.

Considerando $n_{0}$ elétrons liberados do catodo (por radiação UV, por exemplo), $n_{0}$ ' elétrons produzidos no catodo por todas as fontes e $n$ elétrons chegando ao anodo, $\left(n_{0}{ }^{\prime}-n_{0}\right)$ representa o número de elétrons liberados do catodo por processos secundários e $\left(n-n_{0}{ }^{\prime}\right)$ o número de elétrons produzidos por ionização entre os eletrodos. Assim,

$$
\left(\mathrm{n}_{0}^{\prime}-\mathrm{n}_{0}\right)=\left(\mathrm{n}-\mathrm{n}_{0}^{\prime}\right) \gamma
$$

Isolando $n_{0}$,

$$
\mathrm{n}_{0}^{\prime}=\frac{\mathrm{n}_{0}+\mathrm{n} \gamma}{1+\gamma}
$$

Como

$$
n=n_{0}^{\prime} e^{\alpha d}
$$


Substituindo a Eq. (11) na Eq.(12), tem-se

$$
\mathrm{n}=\frac{\mathrm{n}_{0}+\mathrm{n} \gamma}{1+\gamma} \mathrm{e}^{\alpha \mathrm{d}}
$$

Em termos de $n$

$$
\mathrm{n}=\frac{\mathrm{n}_{0} \mathrm{e}^{\alpha \mathrm{d}}}{1-\gamma\left(\mathrm{e}^{\alpha \mathrm{d}}-1\right)}
$$

Reescrevendo a Eq.(14) em termos da corrente elétrica, tem-se

$$
\mathrm{I}=\frac{\mathrm{I}_{0} \mathrm{e}^{\alpha \mathrm{d}}}{1-\gamma\left(\mathrm{e}^{\alpha \mathrm{d}}-1\right)}
$$

Esta equação é válida para baixas pressões e gases não eletronegativos. Para $\gamma=0$, ou seja, se a emissão secundária for desprezível, a Eq.(15) se reduz à Eq. (3).

Vale ressaltar que, além de depender do campo elétrico reduzido e do gás, o coeficiente $\gamma$ depende do material do catodo [18] como mostrado na FIG.6, e é sensível às condições da superfície do catodo.

Como comentado anteriormente, a emissão secundária de elétrons pode ocorrer não apenas por fótons de desexcitação como também por colisão de íons positivos e átomos metaestáveis no catodo. Em um gás esses processos competem, e muitas vezes não é possível identificar quais estão agindo em uma descarga.

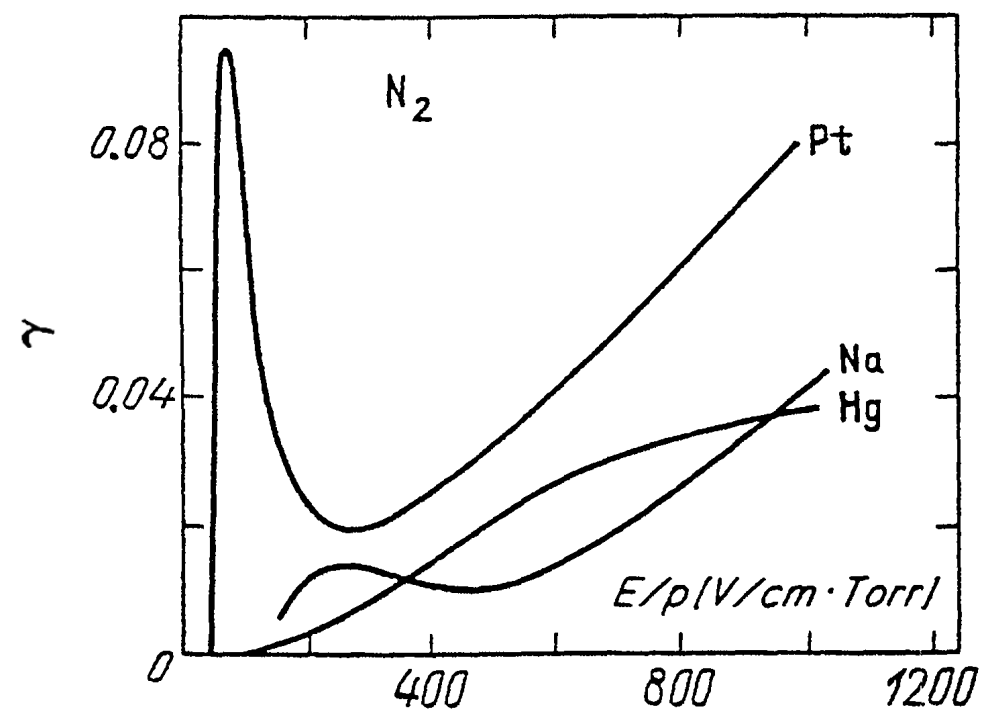

FIGURA 6: Coeficiente $\gamma$ efetivo no $\mathrm{N}_{2}$ para diferentes catodos [19].

Para utilizar a Eq.(15) deve-se considerar o coeficiente $\gamma$ como sendo um coeficiente efetivo, no qual a contribuição de cada um desses processos é considerada. $\mathrm{Na}$ FIG.7 são apresentadas curvas de coeficiente de emissão secundária para diferentes 
processos em função do campo elétrico reduzido. Na FIG.7, $\gamma_{i}$ representa elétrons produzidos no catodo por íons; $\gamma_{\mathrm{a}}$ elétrons produzidos por átomos rápidos; $\gamma_{\mathrm{ph}}$ elétrons produzidos por fótons $\mathrm{UV}$; e $\gamma_{\mathrm{m}}$ elétrons produzidos por átomos metaestáveis.

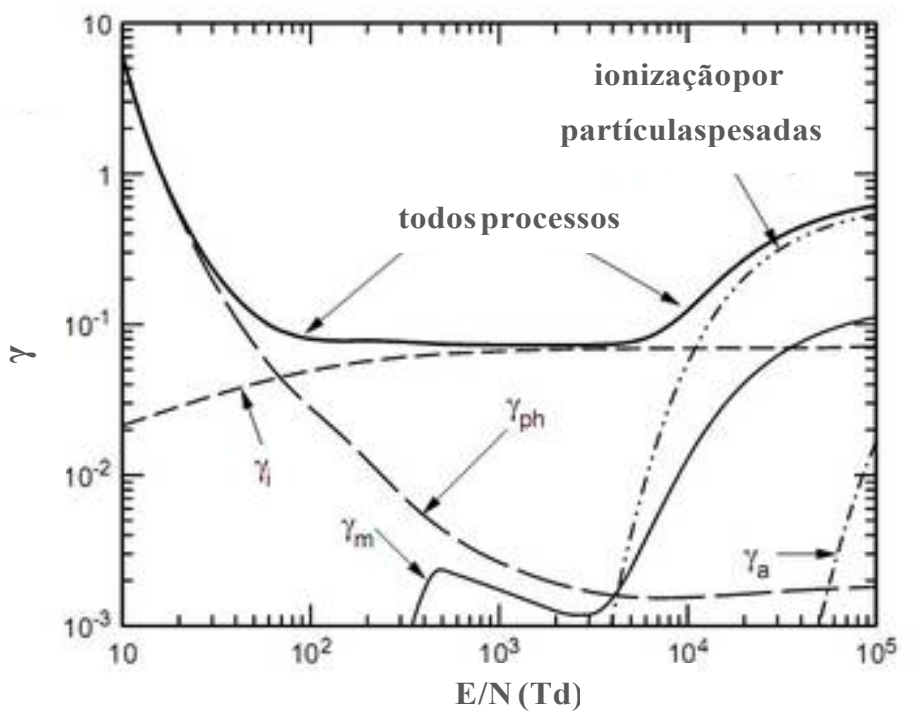

FIGURA 7: Valores calculados de $\gamma$ em função de E/N para Ar [20].

Além de gráficos do coeficiente $\gamma$ em função do campo elétrico reduzido, para estudar a contribuição de efeitos secundários em processos primários de ionização são comuns gráficos de $\gamma / \alpha$ em função de E/N na literatura, FIG.8.

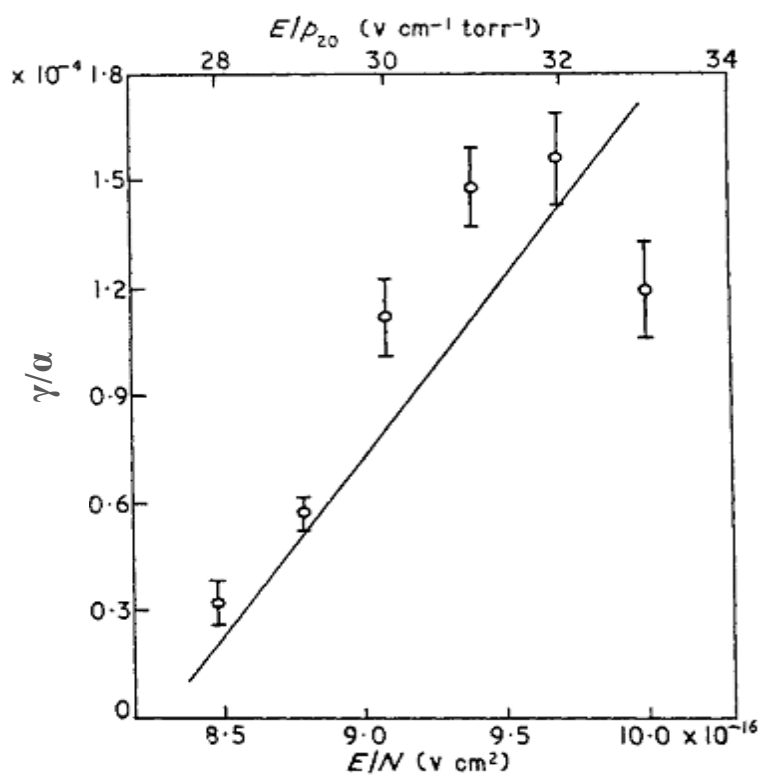

FIGURA 8: Valores de $\gamma / \alpha$ em função de $\mathrm{E} / \mathrm{N}$ para o $\mathrm{N}_{2}$, sendo $\mathrm{E} / \mathrm{P}_{20}$ o campo elétrico reduzido para temperatura de $20^{\circ} \mathrm{C}$ [21]. 


\subsubsection{Disruptura para campos elétricos uniformes}

No processo de disruptura gasosa tem-se a transformação de um material não condutor (como gás) em um material condutor como resultado do elevado campo elétrico aplicado. A ionização é tão intensa, que geralmente este processo é acompanhado de luz visível (faísca).

Considerando a corrente gerada em regime de avalanche, Eq.(15):

$$
I=\frac{I_{0} e^{\alpha d}}{1-\gamma\left(e^{\alpha d}-1\right)}
$$

Para baixas intensidades de campo elétrico $\gamma\left(\mathrm{e}^{\alpha \mathrm{d}}-1\right)$ é zero. Contudo, com o aumento do campo elétrico pode-se atingir a condição:

$$
\gamma\left(\mathrm{e}^{\alpha \mathrm{d}}-1\right)=1
$$

Assim, o denominador da Eq. (15) é nulo e a corrente $I$ indeterminada. Segundo a teoria de descargas em gases, essa condição define o critério para disruptura. Como para elevados valores de campo elétrico $\mathrm{e}^{\alpha \mathrm{d}}>>1$ a Eq. (16) pode ser reescrita como:

$$
\gamma \mathrm{e}^{\alpha \mathrm{d}}=1
$$

A interpretação física desta equação é que cada íon positivo da avalanche primária gera elétrons secundários também no catodo. Ainda com a Eq. (16), a distância de disruptura $(d)$ pode ser expressa como:

$$
\mathrm{d}=\frac{1}{\alpha} \ln \left(1+\frac{1}{\gamma}\right)
$$

Como discutido anteriormente, para um dado gás ou mistura, $\alpha / N$ é função do campo elétrico reduzido $E / N$ :

$$
\frac{\alpha}{N}=f\left(\frac{E}{N}\right)
$$

Assumindo que $\gamma$ também é função de $E / N$, ou seja, $\gamma=\phi(E / N)$, a Eq.(18)

fica:

$$
\mathrm{d}=\frac{1}{\mathrm{Nf}(\mathrm{E} / \mathrm{N})} \ln \left(1+\frac{1}{\phi(\mathrm{E} / \mathrm{N})}\right)
$$

Para uma configuração de placas paralelas, sem influência de cargas espaciais, o campo elétrico é uniforme. Na condição de disruptura o campo elétrico é dado pela razão $V_{s} / d$, sendo $V_{s}$ a tensão de disruptura. Então,

$$
\mathrm{Nd}=\frac{1}{\mathrm{f}\left(\mathrm{V}_{\mathrm{s}} / \mathrm{Nd}\right)} \ln \left(1+\frac{1}{\phi\left(\mathrm{V}_{\mathrm{s}} / \mathrm{Nd}\right)}\right)
$$


Com a equação anterior verifica-se que, para cada valor de $N d$ existe uma tensão de disruptura $V_{s}$. Ou seja,

$$
\mathrm{V}=\mathrm{g}(\mathrm{Nd})
$$

Esta é conhecida como lei de Paschen e sua validade foi verificada para uma variedade de gases [10]. As curvas de $V=g(N d)$ são chamadas de curvas de Paschen e algumas dessas são mostradas na FIG.9.

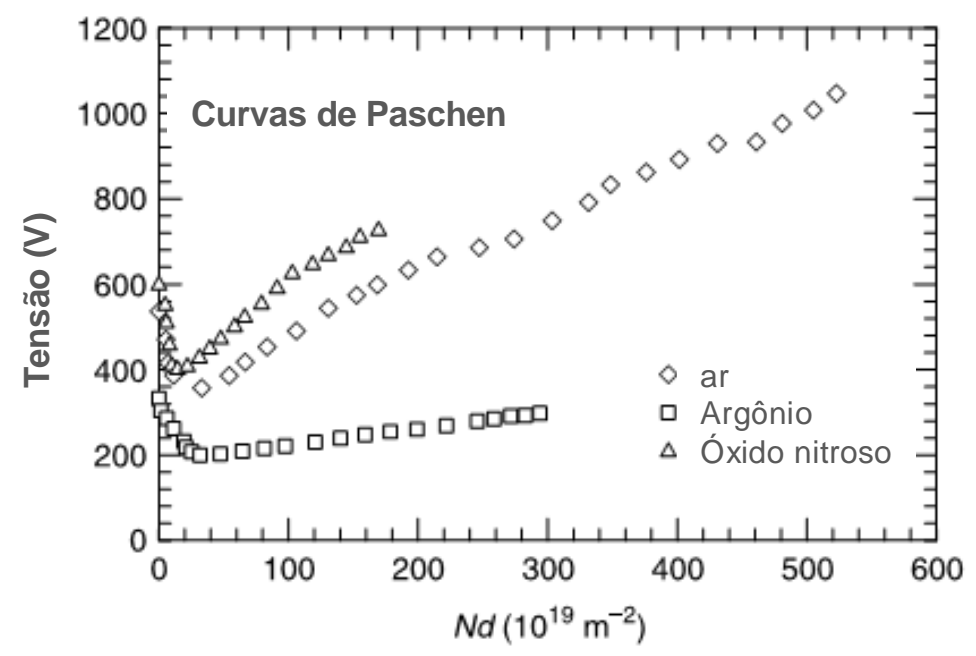

FIGURA 9: Curvas de Paschen para diferentes gases [2].

Além de serem função do gás, as curvas de Paschen dependem do material do catodo, dada a influência do segundo coeficiente de ionização $\gamma$, FIG.10.

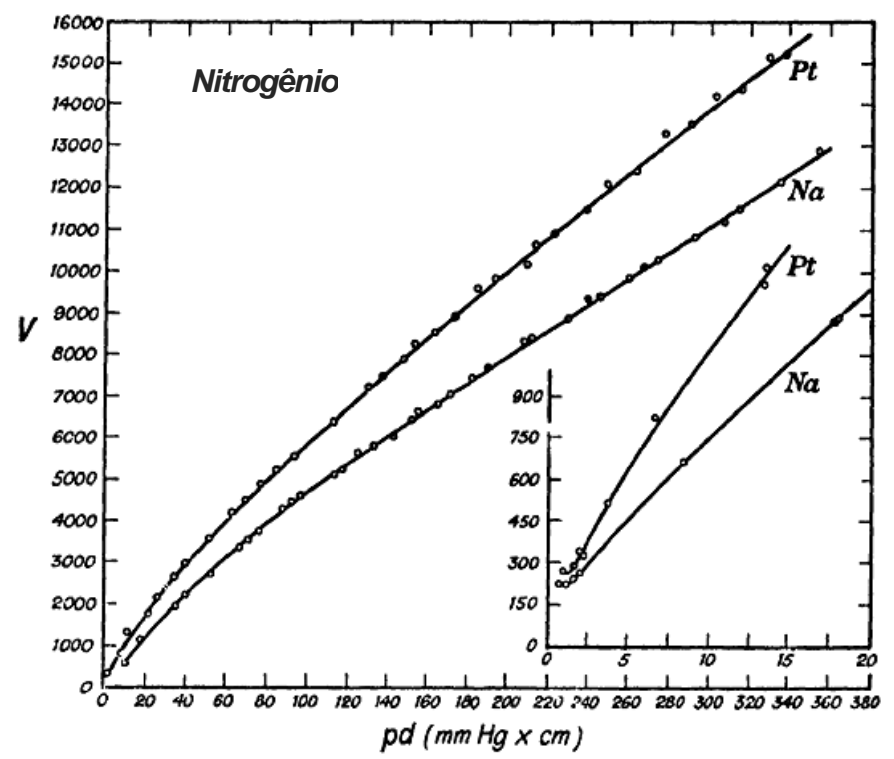

FIGURA 10: Curvas de Paschen para diferentes catodos [10]. 
Como será discutido na seção 3.4, o coeficiente $\alpha$ varia com o campo elétrico reduzido segundo a função a seguir:

$$
\frac{\alpha}{N}=\mathrm{Ae}^{-B \frac{N}{\mathrm{E}}}
$$

sendo $A$ e $B$ parâmetros determinados empiricamente e que dependem do tipo de gás e região de $E / N$ considerada.

Substituindo a Eq. (22) na Eq. (18), lembrando que $E=V_{s} / d$, tem-se:

$$
\mathrm{V}_{\mathrm{s}}=\frac{\mathrm{BNd}}{\ln \left(\frac{\mathrm{ANd}}{\ln (1+1 / \gamma)}\right)}
$$

A fim de obter o valor de tensão mínimo para que ocorra disruptura, a Eq. (23) é derivada e igualada à zero. Com isso, o valor mínimo do produto $N d$ é:

$$
\mathrm{Nd}_{\text {min }}=\frac{2,718}{\mathrm{~A}} \ln \left(1+\frac{1}{\gamma}\right)
$$

Substituindo a Eq. (24) na Eq. (23) tem-se que a tensão de disruptura é:

$$
\mathrm{V}_{\mathrm{s}, \min }=2,718 \frac{\mathrm{B}}{\mathrm{A}} \ln \left(1+\frac{1}{\gamma}\right)
$$

Vale destacar que o coeficiente $\gamma$ é uma quantidade não reprodutível e depende das condições da superfície do catodo como material, uniformidade, oxidação, se o catodo já sofreu descargas, limpeza do eletrodo, etc. $[9,10]$. Desta maneira, $V_{s, \min }$ e $N d_{\text {min }}$ também variam com as condições citadas, porém, com diferente proporção.

Dividindo a Eq.(25) pela Eq.(24) tem-se o mínimo campo elétrico reduzido para que ocorra o processo de disruptura:

$$
\left(\frac{\mathrm{E}}{\mathrm{N}}\right)_{\min }=\mathrm{B}
$$

Diferentemente das equações para $V_{s, \min }$ e $N d_{\min }$, a razão $(E / N)_{\min }$ depende das características do gás e é independente das propriedades do catodo. A determinação dos fatores $A$ e $B$ será discutida na seção 3.4.

As equações anteriores podem ser utilizadas para estimar as condições de disruptura. Valores típicos de tensão mínima de disruptura e do produto $N d_{\min }$ são apresentados na TAB.2 a seguir 
TABELA 2: Condições para o mínimo de Paschen em alguns gases [2].

\begin{tabular}{ccc}
\hline $\mathbf{G a ́ s}$ & $\mathbf{V}_{\mathbf{s}, \text { min }}(\mathbf{V})$ & $\mathbf{N d}_{\mathbf{m i n}}\left(\mathbf{1 0}^{\mathbf{2 0}} \mathbf{m}^{-\mathbf{2}}\right)$ \\
\hline $\mathrm{N}_{2}$ & 270 & 2,20 \\
ar & 330 & 1,83 \\
$\mathrm{O}_{2}$ & 435 & 2,25 \\
$\mathrm{H}_{2}$ & 275 & 3,70 \\
$\mathrm{He}$ & 161 & 2,10 \\
$\mathrm{CO}_{2}$ & 418 & 1,64 \\
$\mathrm{Ar}$ & 245 & 1,90 \\
$\mathrm{~N}_{2} \mathrm{O}$ & 420 & 1,61 \\
\hline
\end{tabular}

\subsection{Métodos para determinar $\alpha$}

Essencialmente, as medidas do coeficiente $\alpha$ baseiam-se em três métodos experimentais: método estacionário (ou experimentos em SST, Steady State Townsend), método estatístico da avalanche, e método pulsado. Detalhes destas são apresentados a seguir.

\subsubsection{Regime estacionário}

Caracterizado pela produção contínua de elétrons por uma fonte externa, este método requer uma fonte muito estável de elétrons primários. Existem basicamente duas variações deste método com relação aos parâmetros medidos (corrente elétrica ou fótons de desexcitação).

Medida de corrente em regime estacionário é o método mais antigo para determinação do coeficiente $\alpha$. Neste, analisa-se o crescimento desta em função do espaçamento entre os eletrodos $(d)$, para um dado valor de campo elétrico reduzido $E / N$. Considerando o logaritmo neperiano da Eq. (3) tem-se

$$
\ln \mathrm{I}=\ln \mathrm{I}_{0}+\alpha \mathrm{d}
$$

Ou seja, o logaritmo da corrente medida em regime de avalanche depende linearmente do espaçamento $d$. Na FIG.11 a relação entre a corrente e o espaçamento é apresentada. Para a região linear da curva, o coeficiente angular fornece o coeficiente $\alpha$, e o linear a corrente de ionização primária, já a parte não linear fornece informações do coeficiente $\gamma$. 


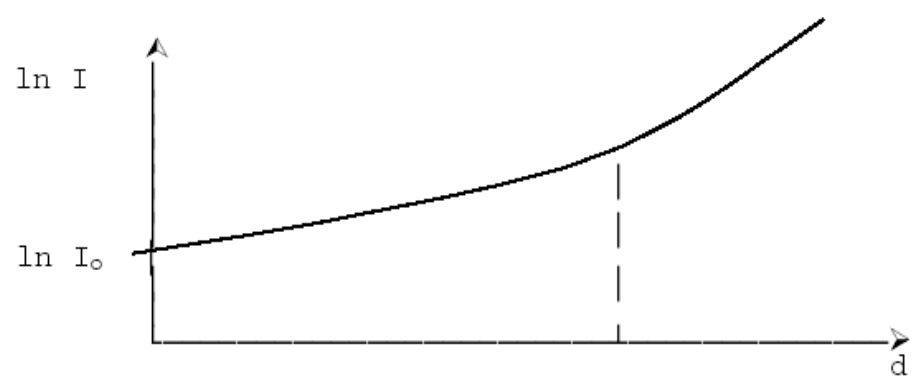

FIGURA 11: Variação da corrente em função do espaçamento entre os eletrodos.

Outra técnica menos utilizada para determinar $\alpha$ parte do estudo da variação de corrente em função da densidade de gás $N$, para valores fixos de $E / N$ e espaçamento $d$. Para isto, utiliza-se a Eq.(3) reescrita na forma

$$
\mathrm{I}=\mathrm{I}_{0} \mathrm{e}^{\left(\frac{\alpha}{\mathrm{N}} \times \mathrm{Nd}\right)}
$$

Medidas por meios ópticos fundamentam-se no fato que a quantidade de fótons de desexcitação produzida em uma avalanche é maior do que o número de elétrons. Estas técnicas permitem determinar parâmetros de transporte em gases, além de contribuírem para estudos de regiões de não uniformidade de campo.

Com a distribuição espacial de luz de uma descarga é possível determinar o coeficiente $\alpha$ [22-23]. Na FIG.12 é apresentado um esquema de aparato empregado em tais medidas.

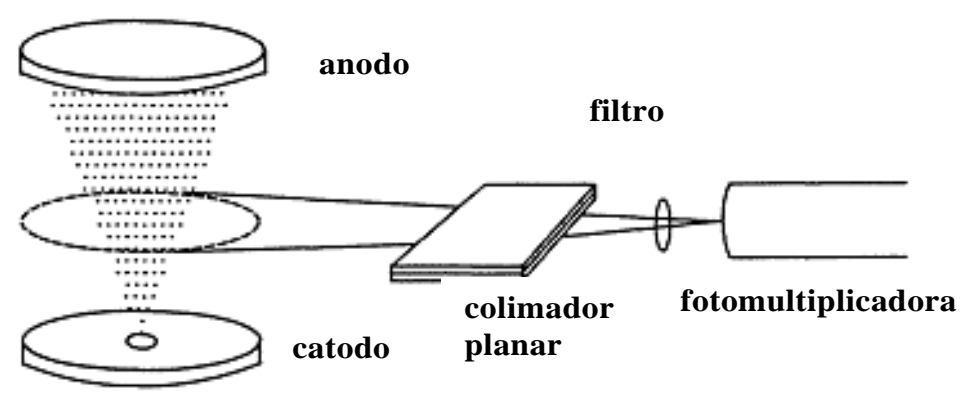

fonte de elétrons

FIGURA 12: Esquema de aparato empregado para determinar parâmetros de transporte por meio de medidas ópticas [23]. 


\subsubsection{Estatística da avalanche}

Este método baseia-se no fato de que cada elétron primário sofre multiplicação gasosa, que resulta no processo de avalanche, o qual segue um comportamento estatístico [24]. A probabilidade $q(n, d) \delta n$ de que um elétron liberado do catodo resulte em $n$ e $n+1$ elétrons no anodo é dada pela relação

$$
q(n, d)=\frac{1}{\bar{n}} e^{-\left(\frac{n}{\bar{n}}\right)}
$$

sendo $\overline{\mathrm{n}}$, o número médio de elétrons, dado por

$$
\overline{\mathrm{n}}=\mathrm{e}^{\alpha \mathrm{d}}
$$

Adquirindo-se uma quantidade suficientemente grande de avalanches com um

analisador de altura de pulsos é possível determinar experimentalmente a função distribuição $q(n, d)$. Com isso, por meio da Eq. (18), o coeficiente $\alpha$ pode ser obtido de três maneiras:

1. A partir do coeficiente angular $\left(e^{-a d}\right)$ do gráfico $(\ln q, n)$;

2. Extrapolando para o limite $\mathrm{n}=0$, no qual $q(0, d)=e^{-\alpha d}$;

3. A partir do valor médio da distribuição, $\mathrm{e}^{\alpha \mathrm{d}}$.

\subsubsection{Regime pulsado}

O regime pulsado (ou técnica pulsada de Townsend, PT) é caracterizado pelo uso de uma fonte pulsada para gerar os elétrons primários. A vantagem deste regime está em permitir a determinação, não somente do coeficiente $\alpha$, como também de parâmetros de difusão e deriva de cargas em gases por meio da análise de sinais.

$\mathrm{Na}$ literatura são apresentados inúmeros métodos experimentais derivados desta técnica. Contudo, existem duas principais variações de medidas em regime pulsado, relacionadas com características do circuito, chamadas de medidas em modo diferencial ou modo integral $[2,6]$.

No modo diferencial a constante de tempo do circuito de extração do sinal é escolhida para ser menor do que o tempo de trânsito dos elétrons. Entre os autores que empregam esta técnica para determinar o coeficiente $\alpha$ estão J. Urquijo et al. [25] e J. L. Hernández-Ávila et al. [26].

Já na técnica pulsada em modo integral a constante de tempo do circuito deve ser maior do que o tempo de trânsito dos elétrons, ou dos íons. Considerações teóricas e 
descrições do aparato experimental deste método podem ser encontradas em Blevin et al. [27] e Hunter et al. [28.]

É importante salientar, que as três técnicas experimentais discutidas anteriormente (SST, estatística da avalanche e PT) representam os principais experimentos utilizados para determinação de parâmetros de transporte em gases. Todavia, os avanços em armazenamento e análise de dados têm impulsionado o surgimento de novas técnicas, além de variações destas.

\subsection{Parametrizações}

Dada a importância do coeficiente $\alpha$ para descrição do regime de avalanche, o comportamento deste, para diferentes gases, é largamente estudado e modelos são apresentados na literatura. A validade de cada modelo depende basicamente do tipo de gás e da região de campo elétrico estudada.

Durante as décadas de 40 e 70, a extensa utilização de detectores gasosos motivou estudos sobre o ganho (ou fator de multiplicação $M$ ) de contadores proporcionais cilíndricos. Para geometria cilíndrica o coeficiente $\alpha$ não é constante para um valor de tensão, já que o campo nesta configuração varia inversamente com a distância radial. Porém, a fim de determinar o ganho, são propostas algumas expressões aproximadas na literatura, que dependem de modelos para $\alpha / \mathrm{N}=\mathrm{f}(\mathrm{E} / \mathrm{N})$.

Entre as parametrizações mais utilizadas está a semi-empírica proposta por Williams e Sara [29], que considera um crescimento exponencial de $\alpha / \mathrm{N}$ com o campo, já citada anteriormente no texto, Eq.(22).

$$
\frac{\alpha}{N}=A e^{-B \frac{N}{E}}
$$

As constantes $A$ e $B$ relacionam-se com parâmetros característicos do gás. A distância mínima $(l)$ que um elétron tem que percorrer na direção do campo elétrico $(E)$ para ionizar o gás é dada por

$$
1=\frac{\mathrm{V}_{\mathrm{i}}}{\mathrm{E}}
$$

sendo $V_{i}$ o potencial de ionização do gás. A fração de colisões $(z / / z)$ que excedem o livre caminho médio $(\lambda)$, obtida por meio da distribuição estatística de livres caminhos médios é

$$
\frac{\mathrm{z}_{1}}{\mathrm{z}}=\mathrm{e}^{-1 / \lambda}
$$


Considerando uma unidade de trajetória, o número de colisões sofridas é $\lambda^{-1}$, e, portanto, o número de colisões ionizantes por unidade de trajetória na direção do campo é

$$
\alpha=\frac{1}{\lambda} \mathrm{e}^{-1 / \lambda}
$$

O livre caminho médio depende do número de moléculas do gás por unidade de volume, $\operatorname{logo}, \operatorname{com} \lambda=\lambda_{1} / N$, e considerando a Eq.(31), a Eq.(33) pode ser reescrita como

$$
\frac{\alpha}{\mathrm{N}}=\frac{1}{\lambda_{1}} \mathrm{e}^{-\mathrm{V}_{\mathrm{i}} \frac{\mathrm{N}}{\mathrm{E}}}
$$

Igualando a Eq.(22) e a Eq. (34) tem-se

$$
\mathrm{A}=\frac{1}{\lambda_{\mathrm{i}}}
$$

$\mathrm{e}$

$$
\mathrm{B}=\frac{\mathrm{V}_{\mathrm{i}}}{\lambda_{1}}
$$

Portanto, dividindo a Eq. (36) pela Eq.(35)

$$
\frac{\mathrm{B}}{\mathrm{A}}=\mathrm{V}_{\mathrm{i}}
$$

Para obtenção das relações anteriores assume-se que:

(1) Cada elétron inicia o livre caminho médio com baixa energia, em comparação com a energia de ionização;

(2) A probabilidade de um elétron com energia maior do que $e V_{i}$ ionizar o gás é $100 \%$;

(3) O número de colisões efetuadas em uma unidade de trajetória na direção do campo elétrico é $\lambda^{-1}$.

Entretanto, as considerações anteriores não correspondem a situações reais. Em condições experimentais típicas, o número de elétrons com energia superior ao potencial de ionização é grande, e mesmo com energia superior a $e V_{i}$, somente uma fração das colisões resultam em ionização, pois parte da energia é perdida em colisões inelásticas de excitação. Além disso, em uma unidade de trajetória o número de colisões é maior do que $\lambda^{-1}$, já que muitas colisões entre elétrons e átomos são do tipo elástica.

Por essa razão, $V_{i}$ obtido a partir dos parâmetros $A$ e $B$ corresponde a um potencial de ionização efetivo $\left(V_{e f}\right)$, maior do que o potencial de ionização do gás, que 
inclui perdas por excitação [30]. O significado físico da constante $A\left(\mathrm{~m}^{2}\right)$ é que $\alpha / N$ tende a uma saturação com o aumento de $E / N$, já a constante $B\left(\mathrm{Vm}^{2}\right)$ é diretamente proporcional ao potencial de ionização efetivo.

O comportamento da função de Williams e Sara é apresentado na FIG.13 a seguir, considerando um gás hipotético $\left(A=4,22 \times 10^{-20} \mathrm{~m}^{2}\right.$ e $\left.B=7,30 \times 10^{-19} \mathrm{Vm}^{2}\right)$. A curva apresenta um ponto de inflexão e uma tangente, passando pela origem, intercepta a curva no ponto $E / N=B$ e $\alpha / \mathrm{N}=0,368 A$, também conhecido na literatura como ponto de Stoletow.

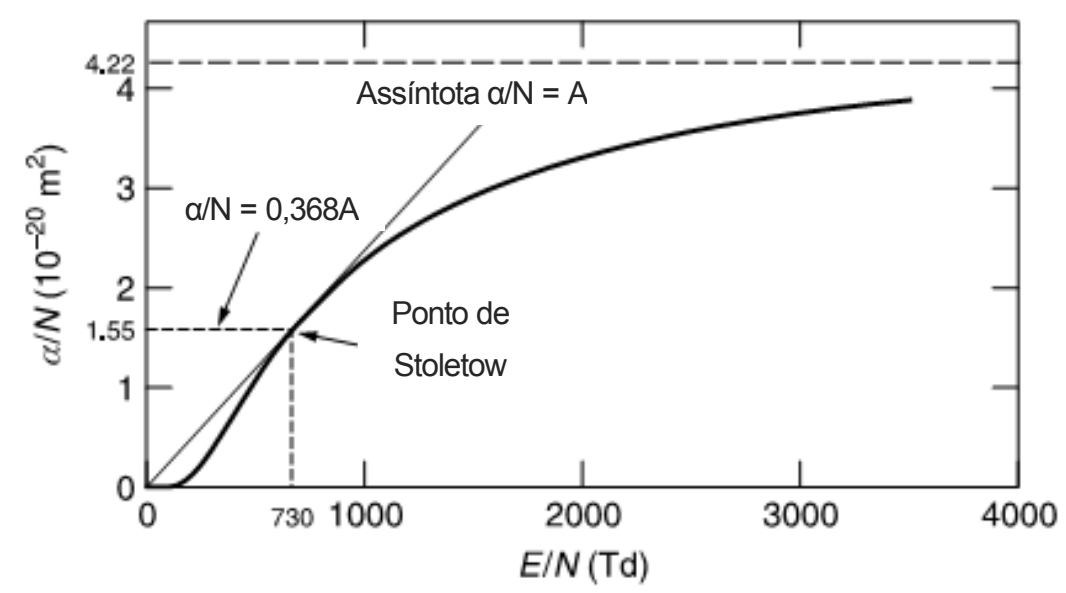

FIGURA 13: Comportamento da função de parametrização de Williams e Sara [2].

Na TAB.3 são apresentados valores para as constantes $A$ e $B$ de gases nobres, com a região de $E / N$ na qual foram obtidos.

TABELA 3: Parâmetros A e B, e região de $\mathrm{E} / \mathrm{N}$ em que foram obtidos [31].

\begin{tabular}{cccc}
\hline Gás & $\mathbf{A ~ ( \mathbf { 1 0 } ^ { - 2 0 } \mathbf { m } ^ { \mathbf { 2 } } )}$ & $\mathbf{B}(\mathbf{T d})$ & Região de E/N (Td) \\
\hline $\mathrm{He}$ & 0,85 & 96 & $60-420$ \\
$\mathrm{Ne}$ & 1,1 & 280 & $280-1100$ \\
$\mathrm{Ar}$ & 4,0 & 510 & $280-1700$ \\
$\mathrm{Kr}$ & 4,8 & 680 & $280-2800$ \\
$\mathrm{Xe}$ & 7,3 & 990 & $280-2300$ \\
\hline
\end{tabular}

Como comentado anteriormente, as medidas de coeficiente $\alpha$ antes de 1970 eram expressas em função da pressão $(P)$ e, consequentemente, os coeficientes $A^{\prime}$ e $B$ ' 
publicados nessa época apresentam valores diferentes dos expressos em função da densidade do gás $(N)$. Se a pressão for expressa em torricelli, a conversão é dada por

$$
\begin{aligned}
& \mathrm{A}=\frac{\mathrm{A}^{\prime}}{\mathrm{N}_{0}} \times 100 \quad\left(\mathrm{~m}^{2}\right) \\
& \mathrm{B}=\frac{\mathrm{B}^{\prime}}{\mathrm{N}_{0}} \times 100 \quad\left(\mathrm{Vm}^{2}\right)
\end{aligned}
$$

onde $\mathrm{N}_{0}=3,22 \times 10^{22} \mathrm{~m}^{-3} \operatorname{Torr}^{-1}$ para $A^{\prime}$ e $B^{\prime}$ determinados a $293 \mathrm{~K}$, e $\mathrm{N}_{0}=3,54 \times 10^{22} \mathrm{~m}^{-3} \operatorname{Torr}^{-1}$ para $A^{\prime}$ e $B$ ' determinados a $273 \mathrm{~K}$.

Além da parametrização de William e Sara existem outras expressões sugeridas na literatura, com diferentes constantes. As principais parametrizações, com o ano em que foram propostas, estão na TAB.4 abaixo.

TABELA 4: Principais parametrizações da literatura, sendo $\mathrm{S}=\mathrm{E} / \mathrm{N}$ [32].

\begin{tabular}{lcc}
\multicolumn{1}{c}{ Autor } & $\boldsymbol{\alpha} / \mathbf{N}$ & Ano \\
\hline Rose e Korff & $\mathrm{C} \sqrt{ } \mathrm{S}$ & 1941 \\
Diethorn & $\mathrm{DS}$ & 1956 \\
Williams e Sara & $\mathrm{A} \mathrm{e}$ & 1962 \\
Zastawny & $\mathrm{F}\left(\mathrm{S}-\mathrm{S}_{0}\right)$ & 1967 \\
Charles & $\mathrm{Ge}^{(-\mathrm{H} / \sqrt{\mathrm{S}})}$ & 1971 \\
\hline
\end{tabular}




\section{METODOLOGIA}

Entre os dispositivos desenvolvidos nas últimas décadas estão as câmaras de placas resistivas (RPCs), que possuem pelo menos um de seus eletrodos constituído por um material de elevada resistividade [33-35]. Os eletrodos da câmara empregada no projeto possuem configuração semelhante à de uma RPC. O catodo é constituído por uma placa de alumínio (40mm de diâmetro) e o anodo por uma placa de vidro com resistividade de $10^{12} \Omega \mathrm{cm}$.

A fim de produzir os elétrons primários que iniciarão o processo de avalanche, utilizou-se um laser de nitrogênio (LTB ${ }^{\circledR}$ modelo MNL200-LD), que atravessava uma janela de quartzo e incidia diretamente no catodo de alumínio, FIG.14. Esse feixe possui baixa divergência, $1 \times 2 \mathrm{~mm}^{2}$ (largura x altura) de área e comprimento de onda na região do ultravioleta $(337,1 \mathrm{~nm})$. Cada disparo do feixe produz um sinal elétrico com duração média de 700ps.

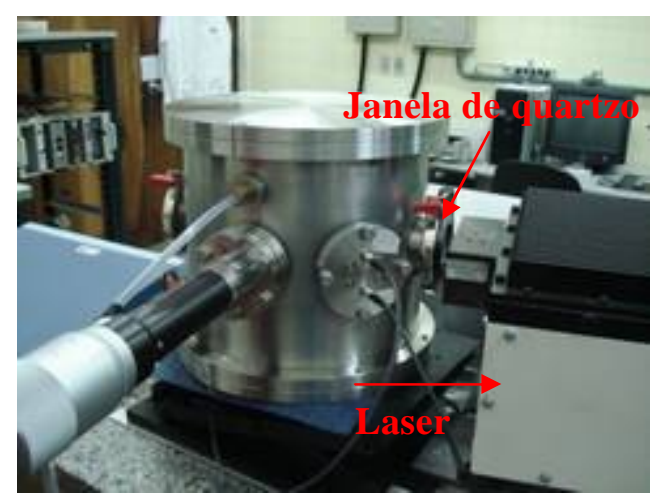

FIGURA 14: Configuração laser-câmara.

Todas as operações do laser, incluindo o condicionamento, são monitoradas por meio de uma interface com um computador. O software, fornecido pelo fabricante, permite ajustar o modo de operação, a quantidade de pulsos desejados ou a taxa de repetição (1 a 20Hz). Além disso, este software possibilita monitorar a estabilidade do feixe, por meio de medidas de energia, a temperatura interna do equipamento e a pressão do nitrogênio. 
Para acelerar os elétrons em direção ao anodo utilizou-se uma fonte de alta tensão (225-30R, Bertan $\left.{ }^{\circledR}\right)$, com ripple máximo de $400 \mathrm{mV}$, e que possibilita limitar a corrente elétrica em até $0,5 \mathrm{~mA}$ e ajustar valores de tensão até $30 \mathrm{kV}$.

O catodo é fixado a um parafuso micrométrico (L2241-2, Huntington ${ }^{\circledR}$ ) com $2 \mu \mathrm{m}$ de resolução de escala, que permite variar o espaçamento entre os eletrodos, FIG.15a. Já o anodo é fixado a três parafusos micrométricos (150-189, Mitutoyo $\left.{ }^{\circledR}\right)$, que auxiliam nos ajustes de paralelismo dos eletrodos, FIG.15b. Por se tratarem de medidas sensíveis ao alinhamento da câmara e do laser, este aparato é mantido sobre uma bancada ótica.

Como as condições do campo elétrico entre os eletrodos influenciam a exatidão das medidas, para cada espaçamento entre os eletrodos são realizados procedimentos de alinhamento do aparato e dos eletrodos.

A fim de garantir a incidência do feixe no catodo, o alinhamento da câmara e do laser segue um ajuste inicial da altura da câmara em relação ao feixe. Em seguida, com o auxílio de um amplificador e um osciloscópio, ajusta-se o laser para a posição angular que resulte em um sinal de tensão de maior amplitude. Já o paralelismo entre os eletrodos é verificado por meio de ajustes ópticos, com a ajuda de uma luz branca na parte inferior e na lateral dos eletrodos.
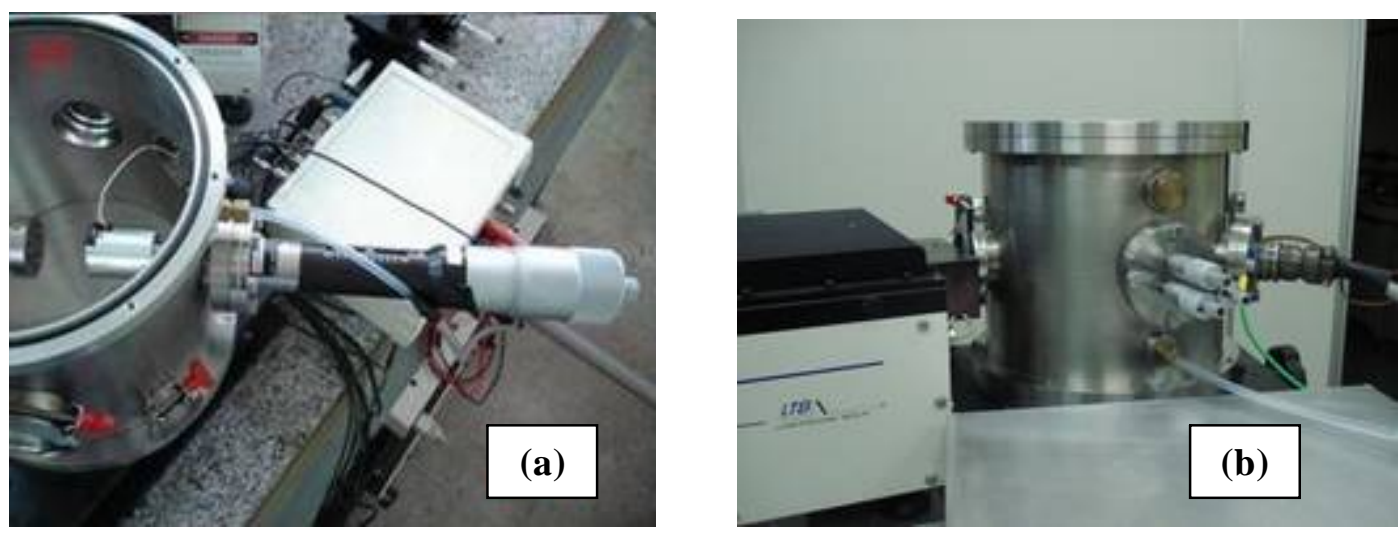

FIGURA 15: (a) Detalhes do parafuso micrométrico conectado ao catodo; (b) parafusos conectados ao anodo.

Para garantir que impurezas não comprometam os resultados nem a estabilidade de operação da câmara, o nitrogênio utilizado nas medidas possui pureza de 99,999\% e o isobutano 99,9\%. As medidas são realizadas em fluxo contínuo de gás e sob pressão atmosférica. Como discutido anteriormente, as condições de temperatura e pressão influenciam a densidade do gás, e consequentemente os resultados, por essa razão, em todas as aquisições de dados essas foram monitoradas. 
As atividades experimentais do projeto foram compostas por duas partes, uma inicial, incluindo análise de efeitos de não uniformidade de campo elétrico, a partir da análise de sinais, e uma segunda parte de medidas de corrente com um eletrômetro. Nas subseções a seguir são apresentadas descrições das atividades desenvolvidas em cada etapa do trabalho.

\subsection{Parte 1: Anodo de $5 \times 5 \mathrm{~mm}^{2}$}

As medidas preliminares compreendem análises de sinais para o nitrogênio e para o isobutano, estudo do regime de operação da câmara a partir de medidas de amplitude de sinais em função da tensão aplicada ao detector e análise de efeitos de não uniformidade de campo elétrico.

Nesta etapa, para analisar os sinais gerados no anodo individualmente, esses passavam por um amplificador de elevada largura de banda $(\approx \mathrm{GHz})$, baseado no circuito integrado BGM1013 da Philips ${ }^{\circledR}$, e que foi projetado e construído no Laboratório de Instrumentação e Física Experimental de Partículas (LIP) de Coimbra. Como os sinais provenientes da câmara possuem tempo de subida da ordem de nanosegundo este amplificador é apropriado para a análise de tais sinais.

Após amplificação, as características dos sinais foram medidas com um osciloscópio (WavePro 7000, Lecroy $^{\circledR}$ ) de largura de banda de $1 \mathrm{GHz}$ e taxa de amostragem de 20GS/s. Na FIG.16 são mostrados os equipamentos utilizados nesta etapa do projeto.

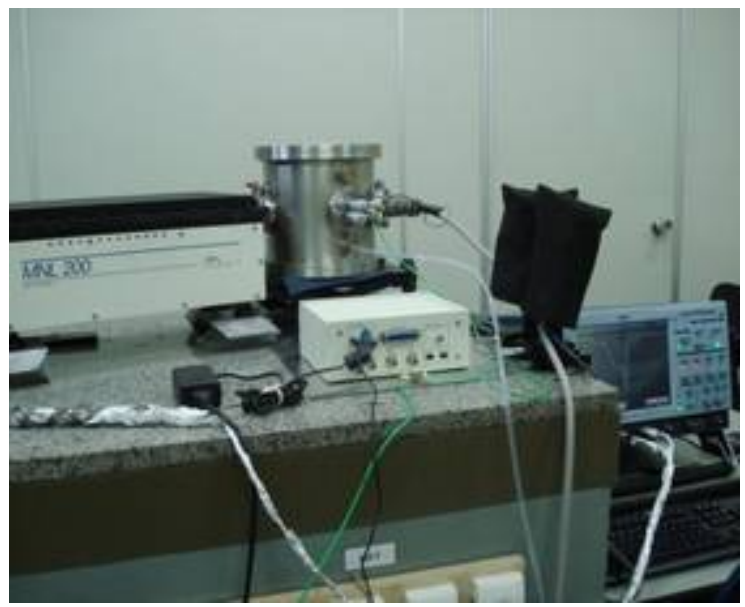

FIGURA 16: Aparato experimental sobre a bancada óptica.

$\mathrm{O}$ anodo era constituído por um vidro com área de $25 \mathrm{~mm}^{2}, 1 \mathrm{~mm}$ de espessura e resistividade $\rho=2 \times 10^{12} \Omega$.cm, FIG.17. A polarização do anodo era feita por meio de uma placa de alumínio colada na parte posterior do vidro. Além disso, uma fita de Kapton ${ }^{\circledR}$ 
revestia partes metálicas da placa de polarização e do suporte mecânico do anodo para prevenir faíscas no gás durante as medidas.

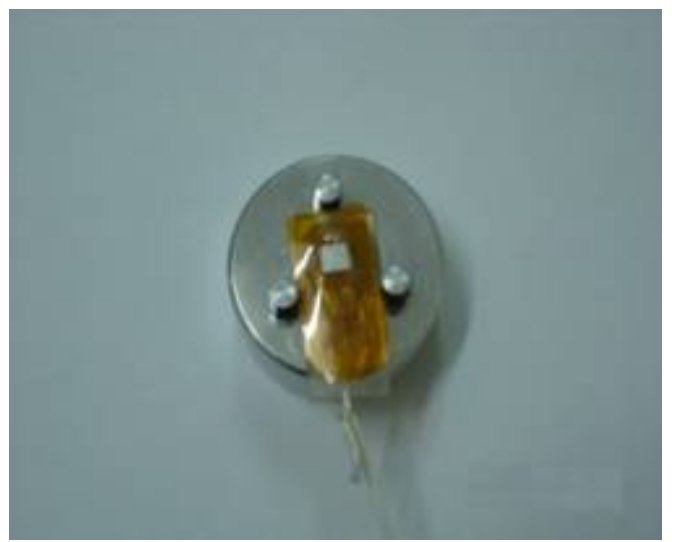

FIGURA 17: Anodo empregado na primeira parte do projeto.

Para cada valor de tensão, obtinha-se a média de 30 formas de onda no osciloscópio. Como a amplitude dos sinais relaciona-se com a carga produzida no gás, nesta etapa analisou-se o comportamento da amplitude em função do campo elétrico, para diferentes espaçamentos entre os eletrodos. Isto permitiu estudar o regime de operação da câmara (regime de ionização e avalanche).

Dada a relação entre a carga produzida em regime de avalanche e o coeficiente de multiplicação $\alpha$, Eq.(2), com a razão entre o logaritmo da amplitude e a distância entre os eletrodos, em função do campo elétrico reduzido, analisou-se a influência de efeitos de não uniformidade de campo.

Ainda, utilizou-se o software Comsol Multiphysics ${ }^{\circledR}$ v.3.5 para simular as linhas de campo elétrico entre os eletrodos e estudar a contribuição de efeitos não lineares durante as medidas do coeficiente $\alpha$. Com o programa simulou-se o campo elétrico, em duas dimensões, para os espaçamentos entre os eletrodos analisados nesta parte do projeto.

\subsection{Parte 2: Anodo de 32,5 x 32,5 $\mathrm{mm}^{2}$}

Com os estudos anteriores verificou-se que para espaçamento menor entre os eletrodos, efeitos de não-uniformidade de campo elétrico influenciavam as medidas. Como esses efeitos relacionam-se com as dimensões dos eletrodos em comparação com a distância entre os mesmos, nesta segunda parte de medidas o anodo de vidro de $25 \mathrm{~mm}^{2}$ foi substituído por um de $1056 \mathrm{~mm}^{2}$ (FIG.18a). Na FIG.18b é mostrada a placa de latão utilizada na polarização do vidro. 

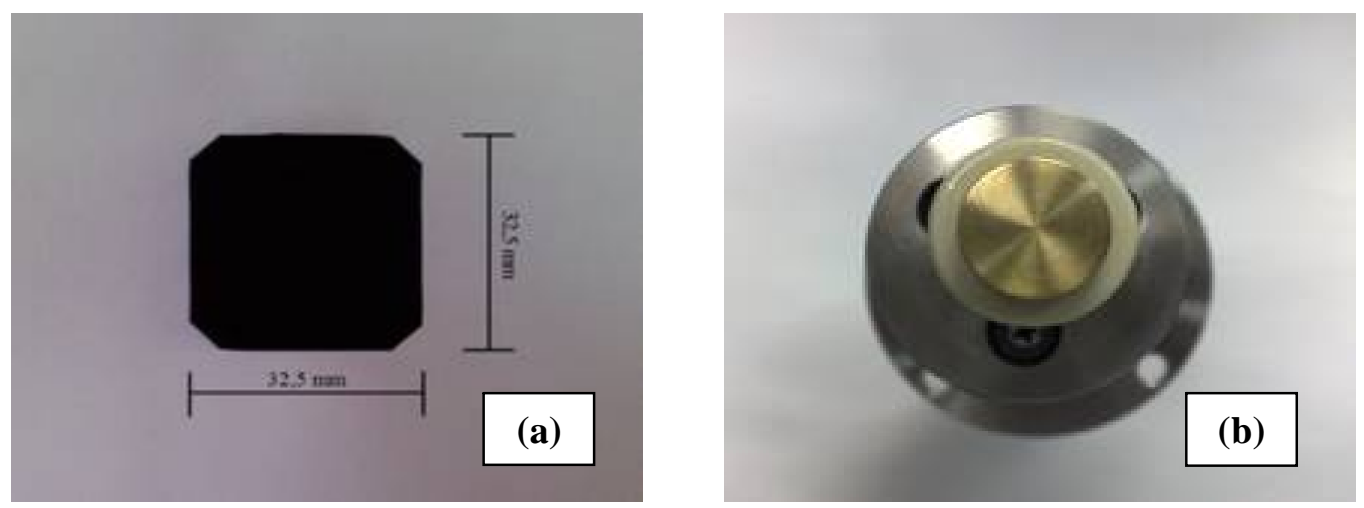

FIGURA 18: (a) Eletrodo de vidro; (b) Placa de latão de polarização do anodo.

Além disso, a fim de evitar possíveis impurezas provenientes de colas e fitas de isolamento elétrico, os componentes eletrônicos do interior da câmara foram substituídos por outros com melhores características elétricas (Fig19a), como capacitores a vácuo da Comet $^{\circledR}$ e resistores para alta tensão da Ohmite $^{\circledR}$ (R1 e R2), empregados na polarização do anodo e extração de sinal da câmara, Fig19b.
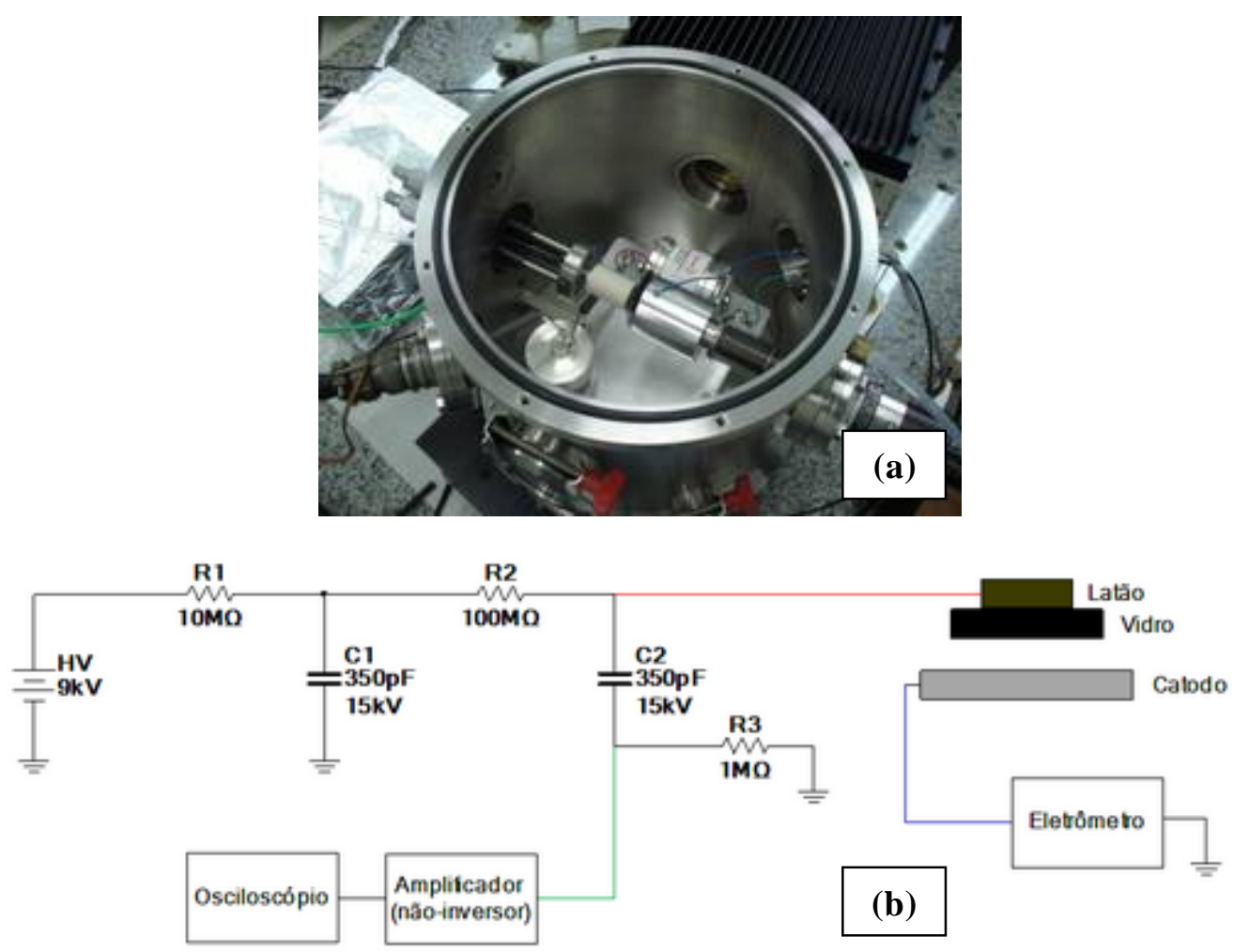

FIGURA 19: (a) Fotos do interior da câmara; (b) Esquema do circuito da câmara. 
Com esta configuração, para determinar o coeficiente de multiplicação gasosa $\alpha$, foram efetuadas medidas de corrente elétrica, em função da tensão aplicada à câmara, para diferentes espaçamentos entre os eletrodos. Nas medidas utilizou-se um eletrômetro (610C Keithley $\left.{ }^{\circledR}\right)$ conectado à saída direta do catodo (FIG.20).

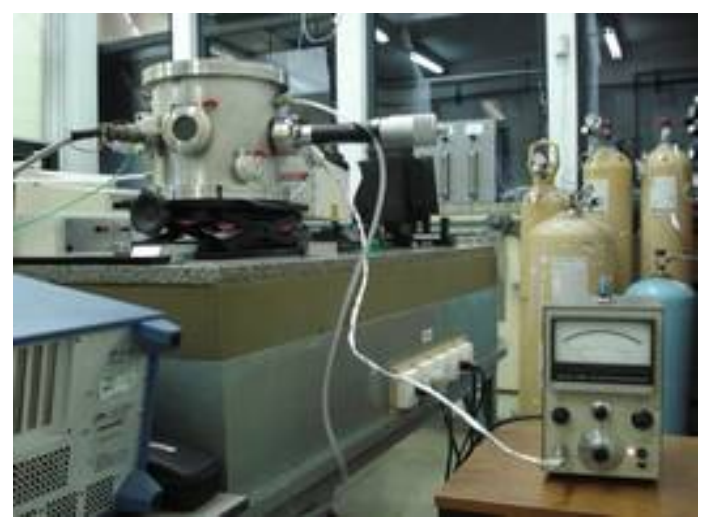

FIGURA 20: Eletrômetro conectado à câmara.

O método para determinar o coeficiente $\alpha$ baseou-se na solução da equação de Townsend para condição de campo elétrico uniforme. Como discutido anteriormente, a corrente em regime de avalanche (I) é dada pela Eq. (3)

$$
\mathrm{I}=\mathrm{I}_{0} \mathrm{e}^{\alpha \mathrm{d}}
$$

onde:

$\mathrm{I}_{0} \rightarrow$ corrente de ionização primária

$\mathrm{d} \rightarrow$ espaçamento entre os eletrodos, já que a ionização primária ocorre no catodo.

A corrente de ionização primária $I_{0}$ depende apenas da intensidade do laser que incide no catodo (a intensidade média do laser utilizado no trabalho é de $49 \mathrm{~kW} / \mathrm{mm}^{2}$ ), e é determinada a partir do valor médio de corrente, com a câmara operando em regime de saturação.

Isolando o coeficiente $\alpha$, tem-se

$$
\alpha=\frac{1}{\mathrm{~d}} \ln \left(\frac{\mathrm{I}}{\mathrm{I}_{0}}\right)
$$

Para validar a técnica experimental e verificar a reprodutibilidade dos dados, determinou-se o coeficiente $\alpha$ em função do campo elétrico reduzido para o nitrogênio, que é um gás amplamente estudado. As análises do comportamento do coeficiente $\alpha$ no nitrogênio ainda incluíram estudos das parametrizações para a região de campo elétrico analisada no trabalho. Em seguida, estendeu-se a técnica para o isobutano. 


\section{RESULTADOS E ANÁliSES}

\subsection{Parte 1}

Nas subseções a seguir são apresentadas algumas formas de onda obtidas para o nitrogênio e para o isobutano. Para verificar o regime de operação da câmara a partir das medidas preliminares, analisou-se a variação da amplitude em função da tensão aplicada para diferentes distâncias entre os eletrodos. Em seguida, para estudar efeitos de nãouniformidade de campo, analisou-se essa variação em função do campo elétrico reduzido.

\subsubsection{Regime de operação}

Nas TAB.5 e 6 a seguir são apresentados os valores utilizados de espaçamento entre os eletrodos, tensão aplicada à câmara, amplitude do sinal (considerando a média de 30 formas de onda) e campo elétrico reduzido $(E / N)$, para o nitrogênio e para o isobutano, respectivamente.

TABELA 5: Valores de espaçamento, tensão aplicada, campo elétrico reduzido (para temperatura de $19^{\circ} \mathrm{C}$ e pressão de $700 \mathrm{mmHg}$ ) e amplitude média dos sinais para o nitrogênio. As incertezas nos valores das amplitudes correspondem à metade da menor divisão da escala utilizada.

\begin{tabular}{cccc}
\hline \multicolumn{4}{c}{ Nitrogênio } \\
\hline Espaçamento (mm) & Tensão (V) & E/N (Td) & Amplitude (mV) \\
\hline 0,50 & 2250 & 194 & $13,80(20)$ \\
0,50 & 2500 & 216 & $43,0(6)$ \\
1,00 & 2500 & 108 & $5,02(13)$ \\
1,00 & 2750 & 119 & $7,92(13)$ \\
1,00 & 3000 & 130 & $9,37(14)$ \\
1,00 & 3250 & 140 & $13,62(20)$ \\
1,00 & 3500 & 151 & $30,1(4)$ \\
1,00 & 3750 & 162 & $34,1(5)$ \\
1,00 & 4000 & 173 & $107,0(16)$ \\
\hline
\end{tabular}


TABELA 6: Valores de espaçamento entre os eletrodos, tensão aplicada, campo elétrico reduzido (para temperatura de $19^{\circ} \mathrm{C}$ e pressão de $700 \mathrm{mmHg}$ ) e amplitude média dos sinais para o isobutano. As incertezas nos valores das amplitudes correspondem à metade da menor divisão da escala utilizada.

\begin{tabular}{|c|c|c|c|}
\hline \multicolumn{4}{|c|}{ Isobutano } \\
\hline Espaçamento (mm) & Tensão (V) & E/N (Td) & Amplitude (mV) \\
\hline 0,50 & 2750 & 238 & $29,2(5)$ \\
\hline 0,50 & 3000 & 259 & $98,6(16)$ \\
\hline 0,50 & 3250 & 281 & $219(4)$ \\
\hline 1,00 & 4500 & 194 & $9,89(15)$ \\
\hline 1,00 & 4750 & 205 & $21,9(4)$ \\
\hline 1,00 & 5000 & 216 & $58,8(10)$ \\
\hline 1,00 & 5250 & 227 & $119,8(18)$ \\
\hline 1,00 & 5500 & 238 & $241,1(4)$ \\
\hline 1,50 & 6000 & 173 & $12,4(22)$ \\
\hline 1,50 & 6250 & 180 & $22,2(4)$ \\
\hline 1,50 & 6500 & 187 & $42,8(22)$ \\
\hline 1,50 & 6750 & 194 & $76,2(12)$ \\
\hline 1,50 & 7000 & 202 & $121,0(19)$ \\
\hline 1,50 & 7250 & 209 & $149,0(29)$ \\
\hline 1,50 & 7500 & 216 & $234(4)$ \\
\hline 1,50 & 7540 & 217 & 253(4) \\
\hline 1,75 & 7000 & 173 & $13,7(26)$ \\
\hline 1,75 & 7250 & 179 & $22,1(6)$ \\
\hline 1,75 & 7500 & 185 & $46,0(15)$ \\
\hline 1,75 & 7750 & 191 & $65,4(15)$ \\
\hline 1,75 & 8000 & 198 & $135(4)$ \\
\hline 1,75 & 8250 & 204 & $139(4)$ \\
\hline
\end{tabular}

Por se tratar de um gás com estrutura complexa, com o isobutano atingem-se regiões de campo elétrico mais elevado, porém as amplitudes dos sinais obtidos nessas para um mesmo espaçamento entre os eletrodos são menores, em comparação com o nitrogênio, como é observado na TAB.6. Estas características favorecem a utilização do 
isobutano como gás de enchimento em detectores nos quais se pretende operar em regime estável, porém a utilização deste gás requer tensões de operação mais elevadas.

Os sinais de menor e maior amplitude obtidos para o nitrogênio, considerando a média de 30 formas de onda, são apresentados nas FIG.21 e 22 a seguir.

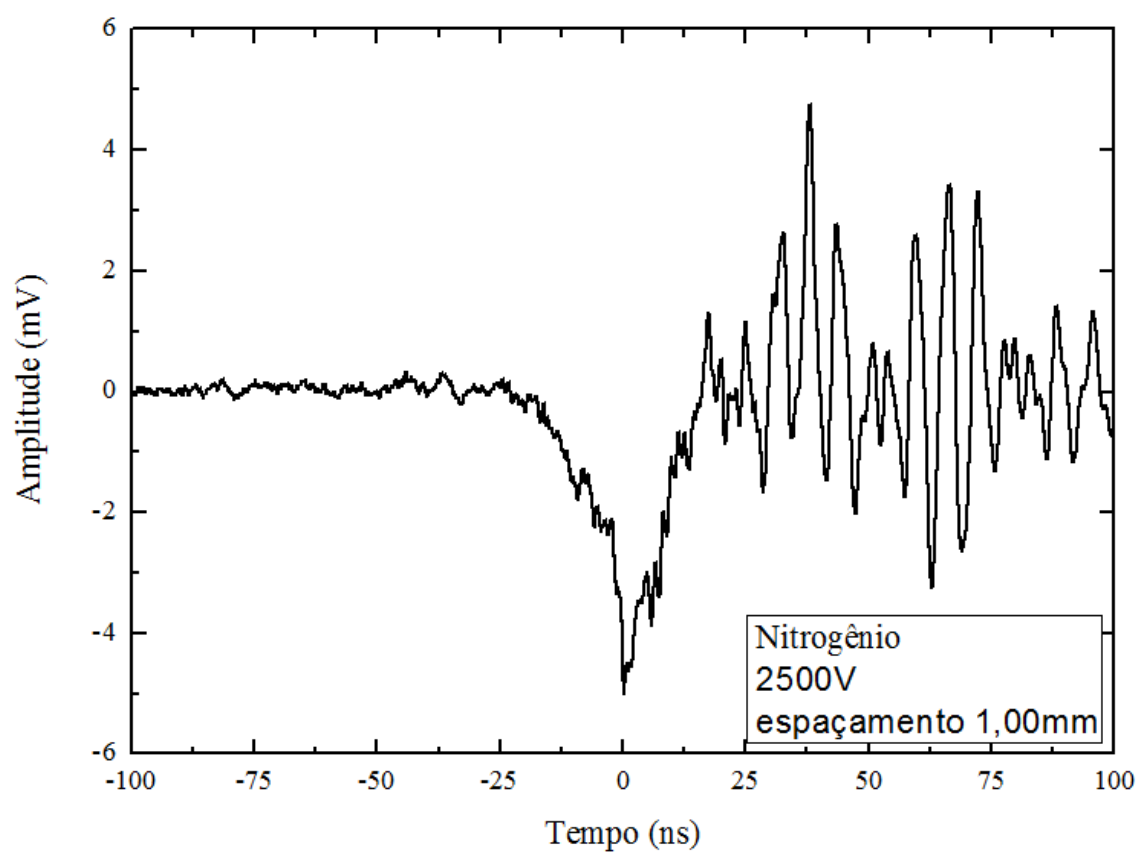

FIGURA 21: Média do sinal de menor amplitude para o nitrogênio.

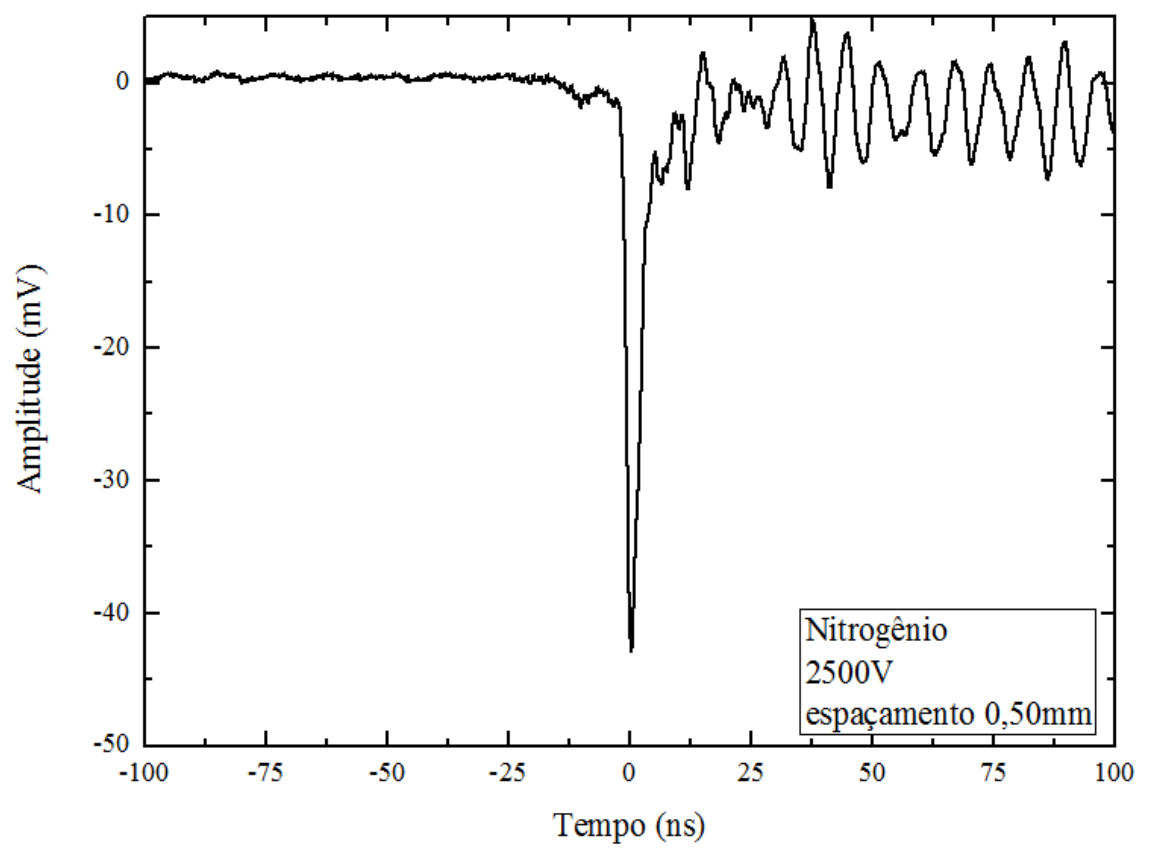

FIGURA 22: Média do sinal de maior amplitude para o nitrogênio. 
A seguir, nas FIG.23 e 24 são apresentados os sinais de menor e maior amplitude obtidos para o isobutano, considerando a média de 30 formas de onda.

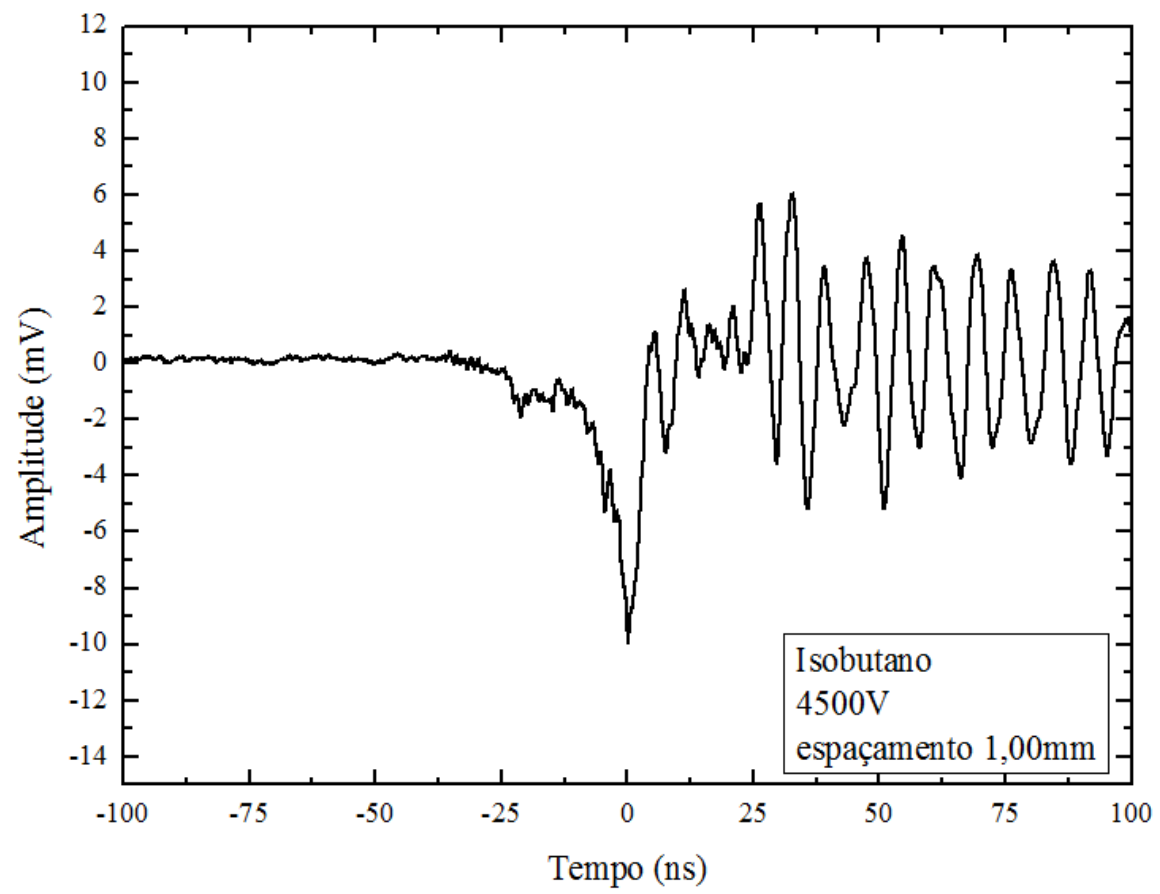

FIGURA 23: Sinal de menor amplitude para o isobutano.

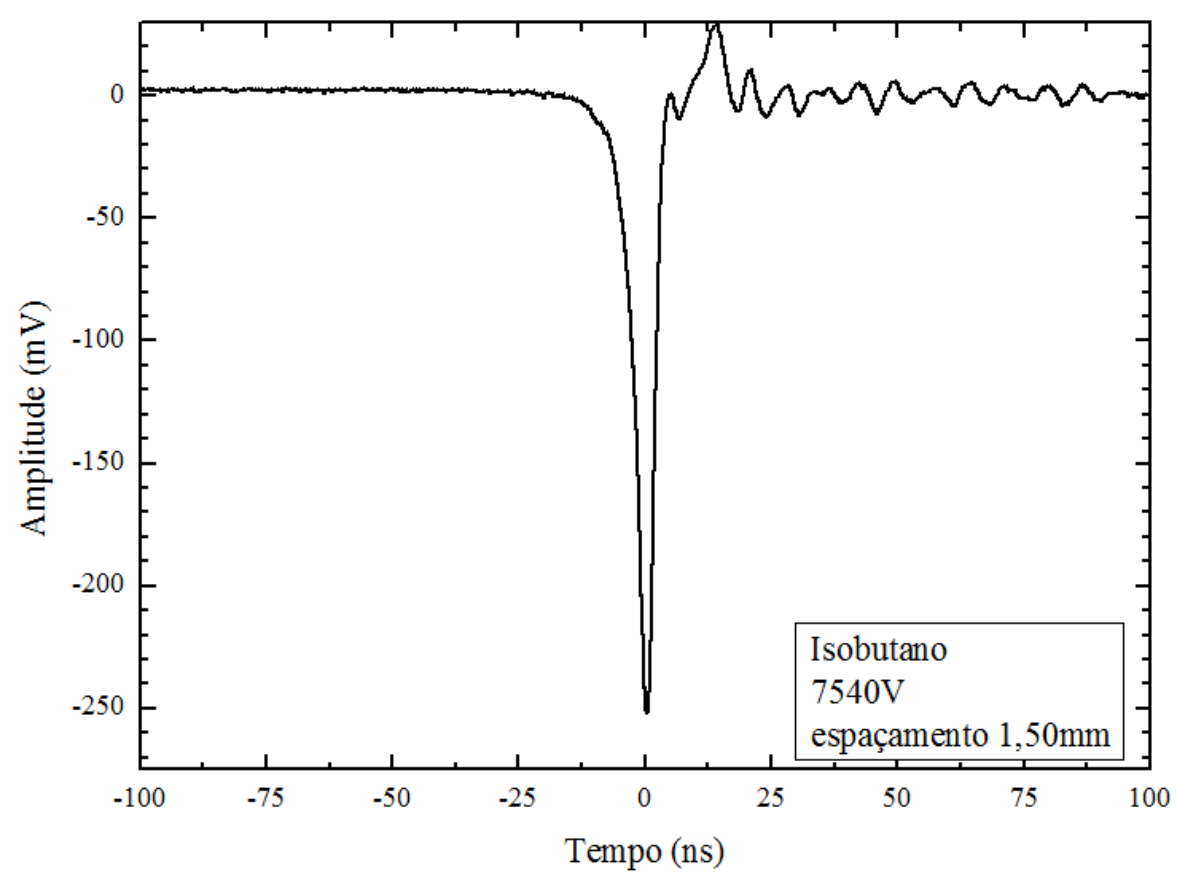

FIGURA 24: Sinal de maior amplitude para o isobutano. 
Por meio das formas de onda dos sinais verifica-se que a interferência do ruído eletrônico prejudica a definição dos sinais de menor amplitude. Como os valores de amplitude relacionam-se diretamente com a carga produzida no interior do detector, para análise do regime de operação do mesmo examinou-se a variação da amplitude dos sinais com a tensão aplicada para o nitrogênio e para o isobutano (FIG.25 e 26).

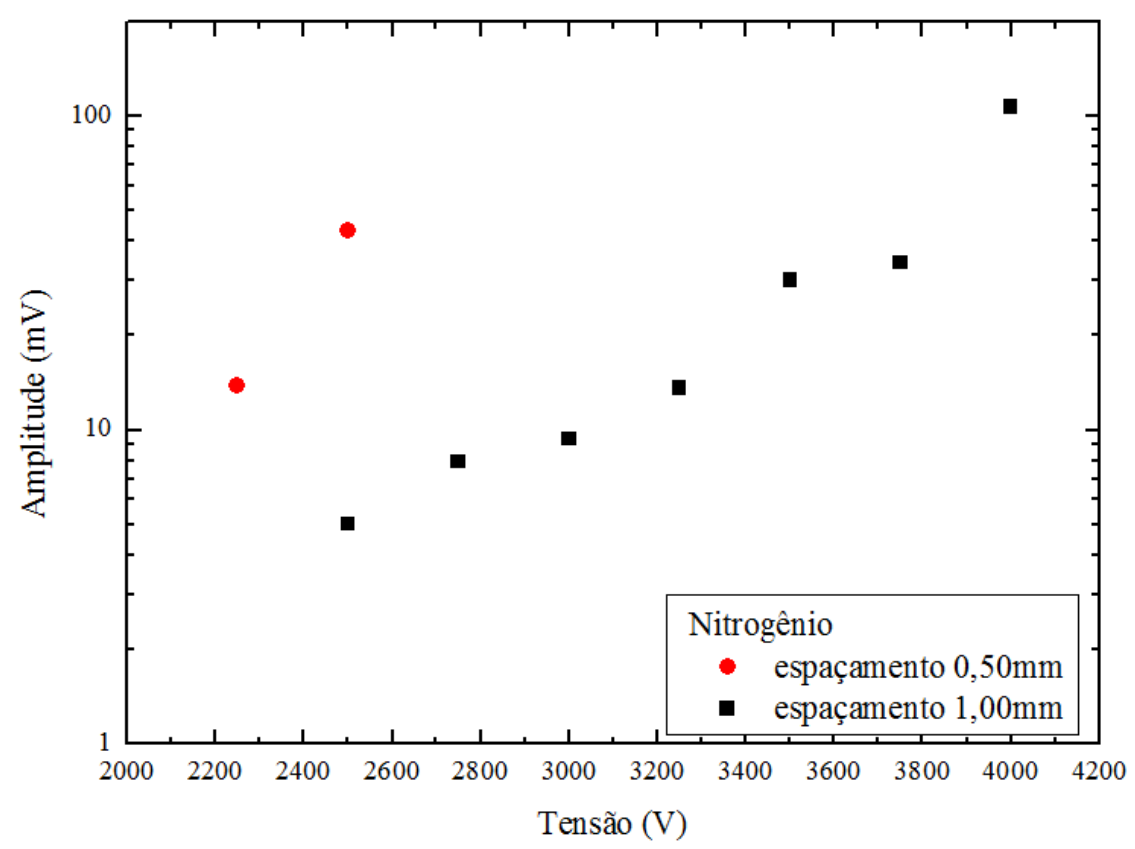

FIGURA 25: Amplitude média do sinal em função da tensão aplicada para o nitrogênio.

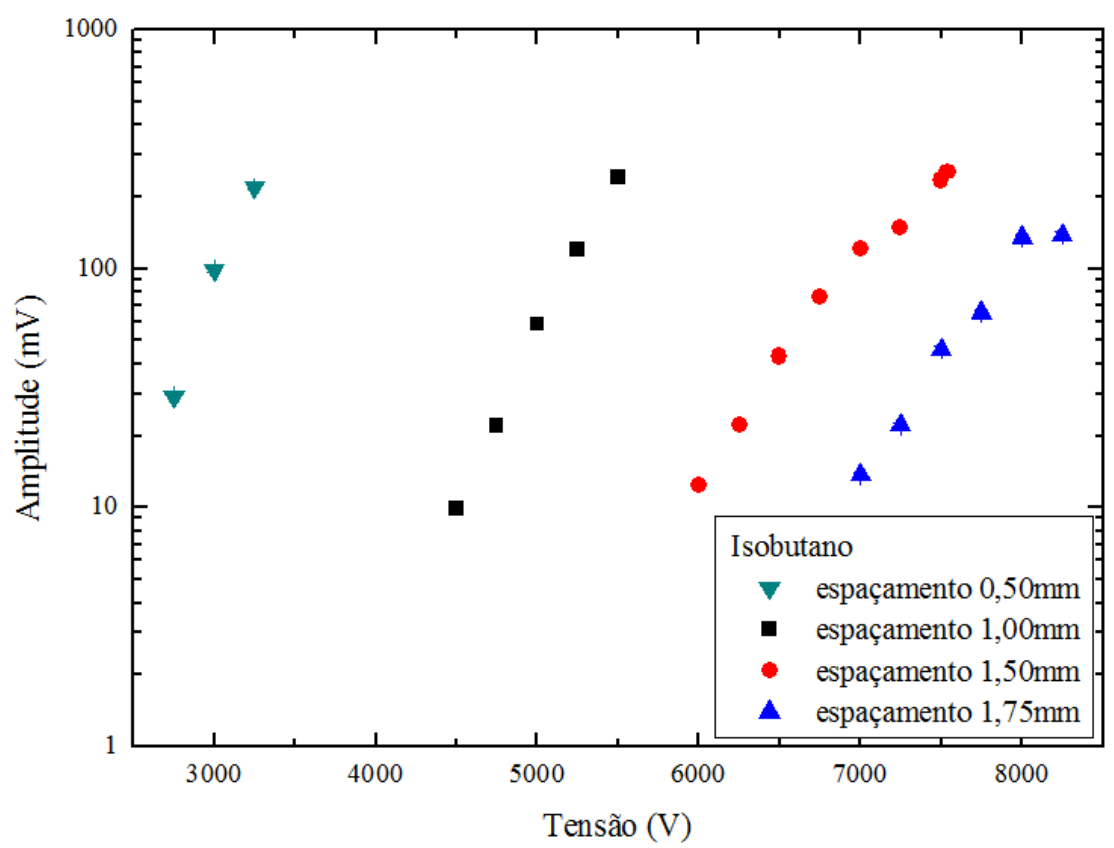

FIGURA 26: Amplitude média do sinal em função da tensão para o isobutano. 
Com os gráficos anteriores observa-se que a sensibilidade do sistema não permitiu distinguir o regime de ionização, que é caracterizado pela invariância da amplitude com a tensão aplicada, verificando-se somente o regime de avalanche.

Além disso, para o caso do isobutano, devido a limitações de isolamento elétrico da câmara, para o espaçamento de $1,75 \mathrm{~mm}$, verifica-se uma saturação dos sinais de maiores amplitudes (FIG.26).

\subsubsection{Uniformidade de campo elétrico}

Para estudo qualitativo do coeficiente de multiplicação gasosa e análise da uniformidade do campo elétrico examinou-se a variação da amplitude do sinal com o campo elétrico reduzido.

Dada a relação entre o coeficiente $\alpha$ e a carga produzida na avalanche, Eq.(40), estudou-se o logaritmo da amplitude, normalizado para o espaçamento entre os eletrodos (d), em função do campo elétrico reduzido para o nitrogênio e para o isobutano (FIG.27 e 28). Vale destacar que as condições de temperatura e pressão das medidas foram as mesmas $\left(19^{\circ} \mathrm{C}\right.$ e $\left.700 \mathrm{mmHg}\right)$.

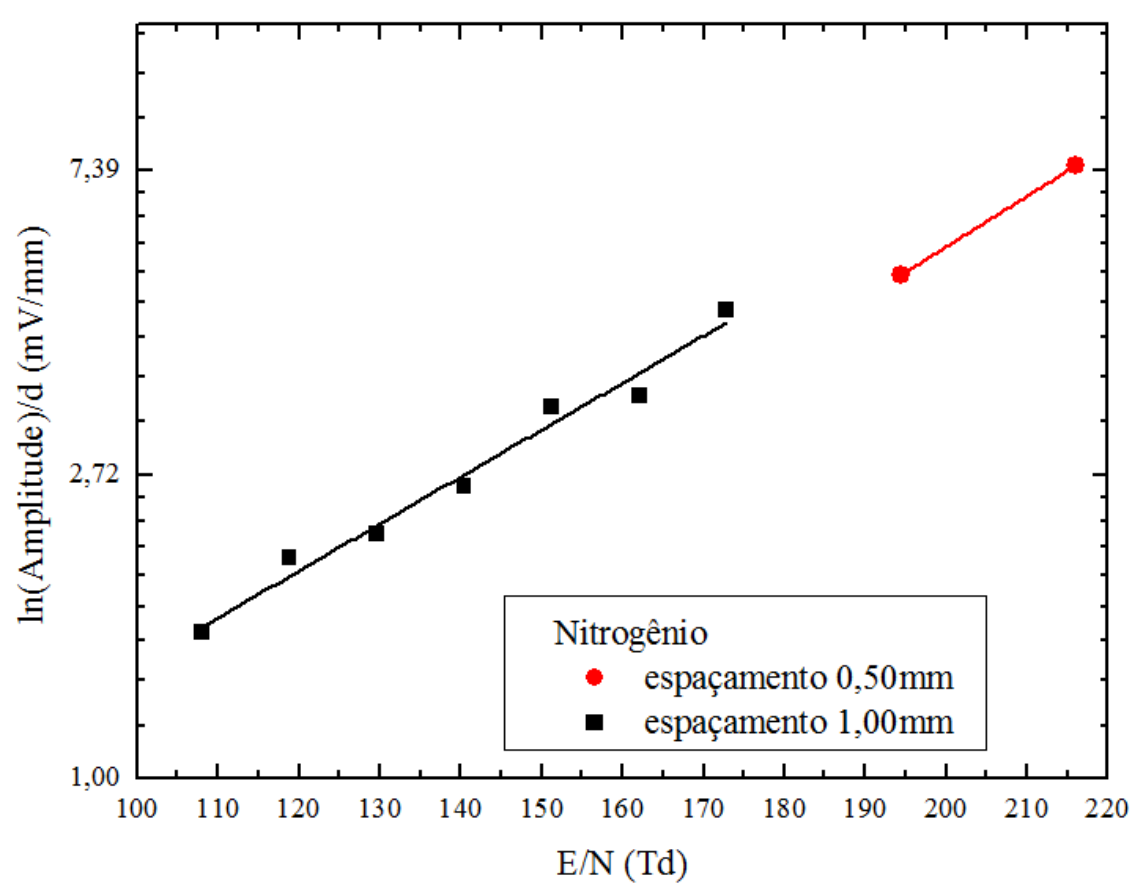

FIGURA 27: Amplitude em função do campo elétrico reduzido para o nitrogênio. 


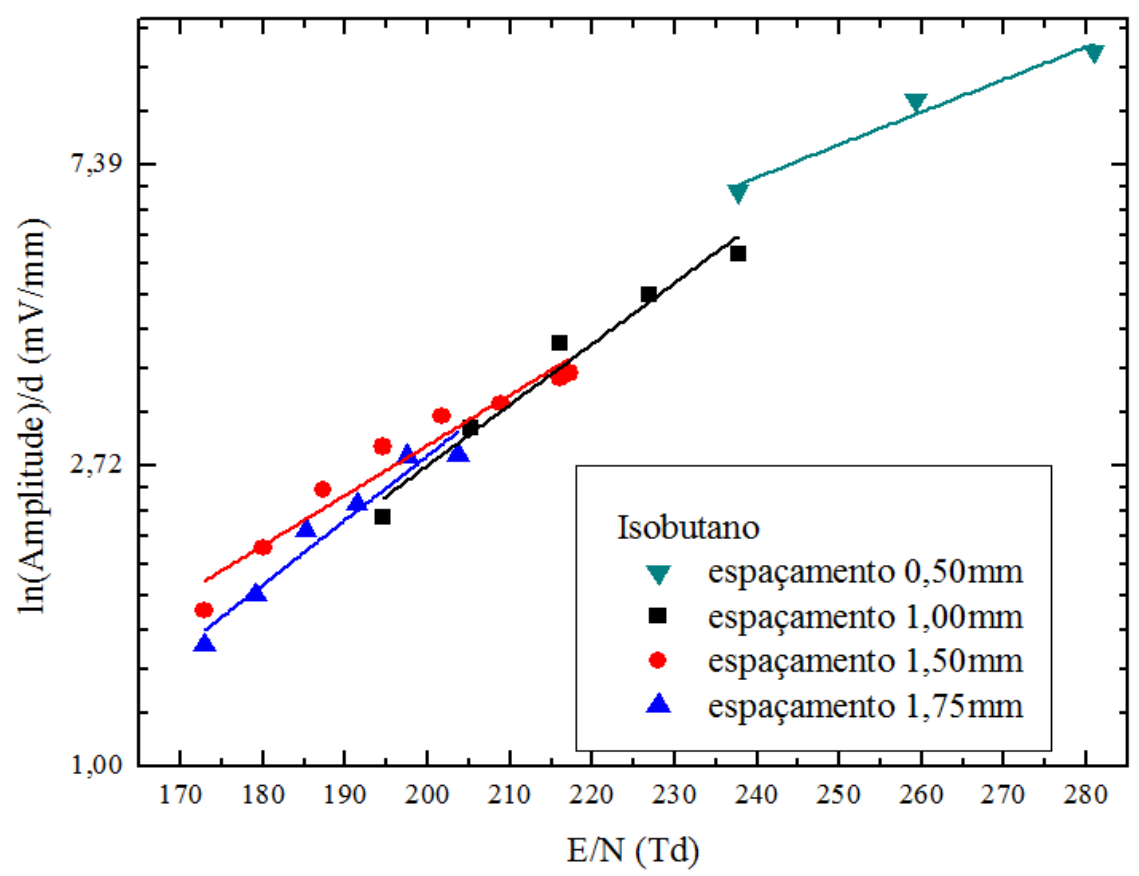

FIGURA 28: Amplitude em função do campo elétrico reduzido para o isobutano.

Como para o isobutano analisou-se uma faixa maior de campo elétrico, verifica-se com a FIG.28 que diferentes distâncias entre os eletrodos resultam em curvas com inclinações distintas. Como o coeficiente de multiplicação é função da intensidade do campo elétrico, do tipo de gás e do livre caminho médio dos elétrons, o resultado anterior indica a existência de efeitos de não uniformidade de campo elétrico.

Com o programa Comsol Multiphysics ${ }^{\circledR}$ v.3.5, que permite definir a geometria, os materiais e as condições de contorno utilizadas, simulou-se o campo elétrico entre os eletrodos em duas dimensões. Nas FIG.29 - 32 são apresentadas as simulações para os espaçamentos entre os eletrodos estudados, considerando a resistividade do vidro empregado $\rho=2 \times 10^{12} \Omega . \mathrm{cm}$, e campo elétrico esperado de $1 \times 10^{6} \mathrm{~V} / \mathrm{m}$. As escalas verticais e horizontais estão representadas na unidade metro, já as duas escalas graduadas, à direita das simulações, referem-se ao campo elétrico e às linhas de campo, respectivamente.

O esquema dos eletrodos corresponde a uma aproximação da configuração empregada nesta parte do projeto, não incluindo componentes isoladores, como a folha Kapton $^{\circledR}$, e o suporte mecânico do anodo, que não interferem nos resultados da simulação. Vale destacar que, por se tratar de uma configuração semelhante à de uma câmara de placas resistivas, para simular adequadamente o campo elétrico entre os eletrodos é necessário considerar o vidro como um meio condutor [33]. 


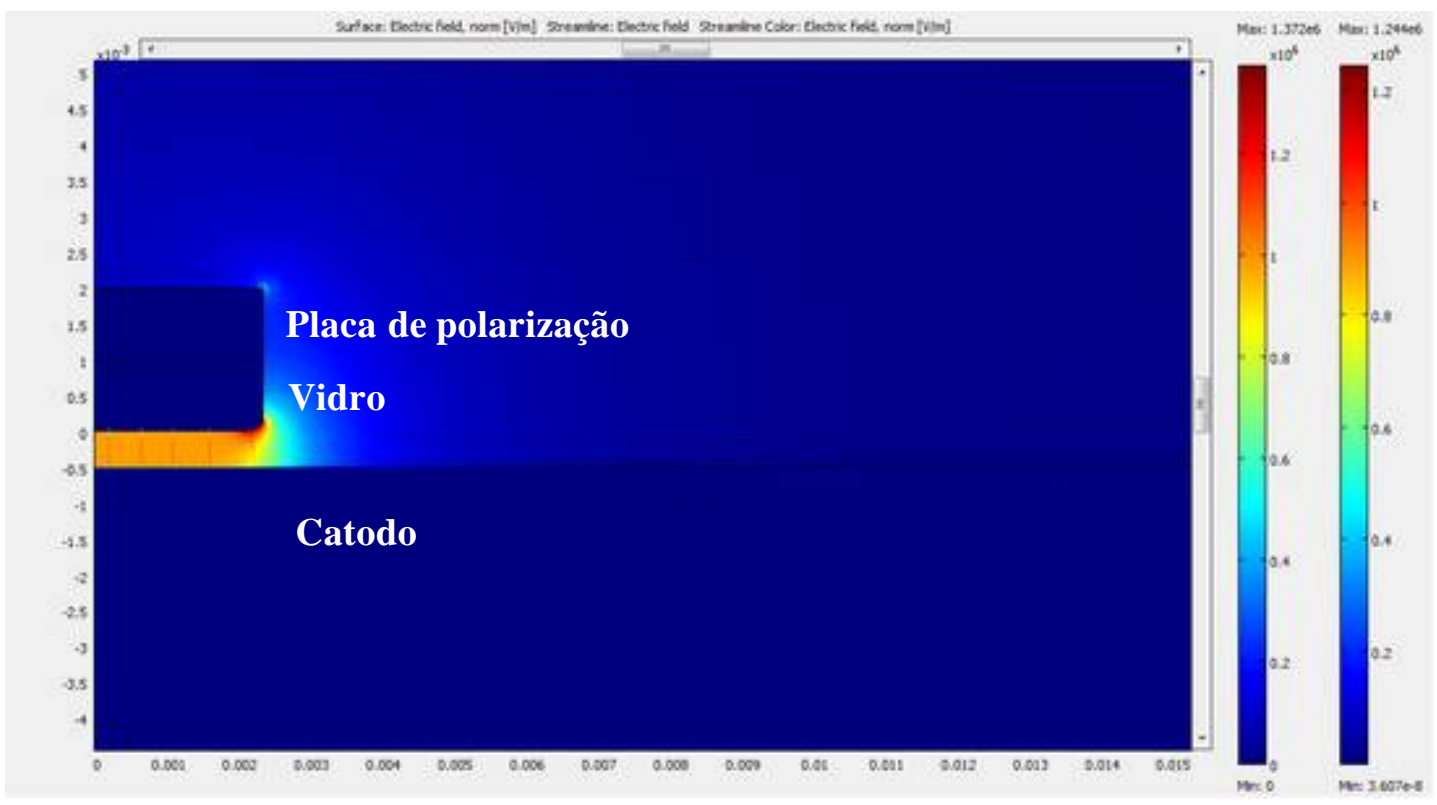

FIGURA 29: Simulação do campo elétrico para o espaçamento de 0,50mm - parte 1.

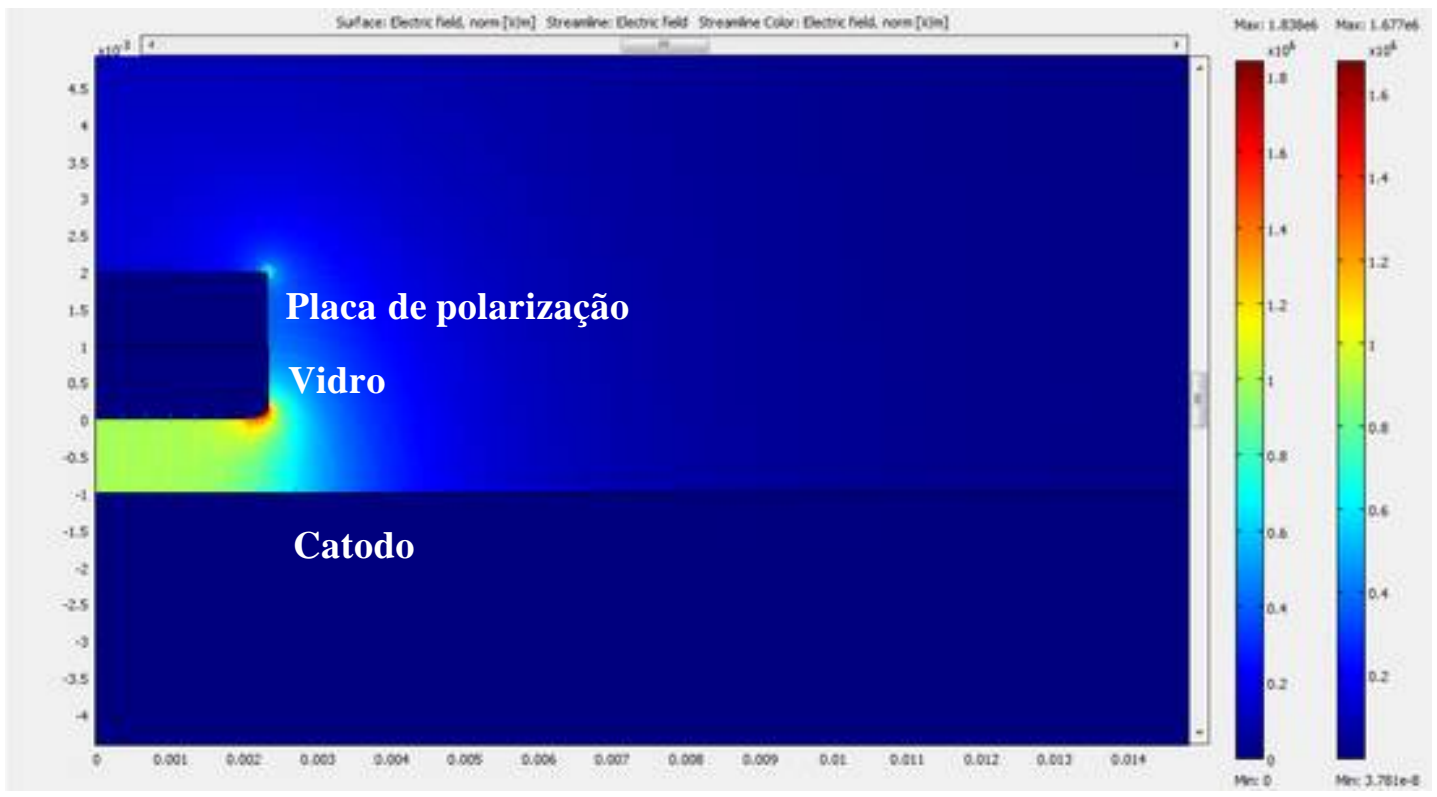

FIGURA 30: Simulação do campo elétrico para o espaçamento de 1,00mm - parte 1. 


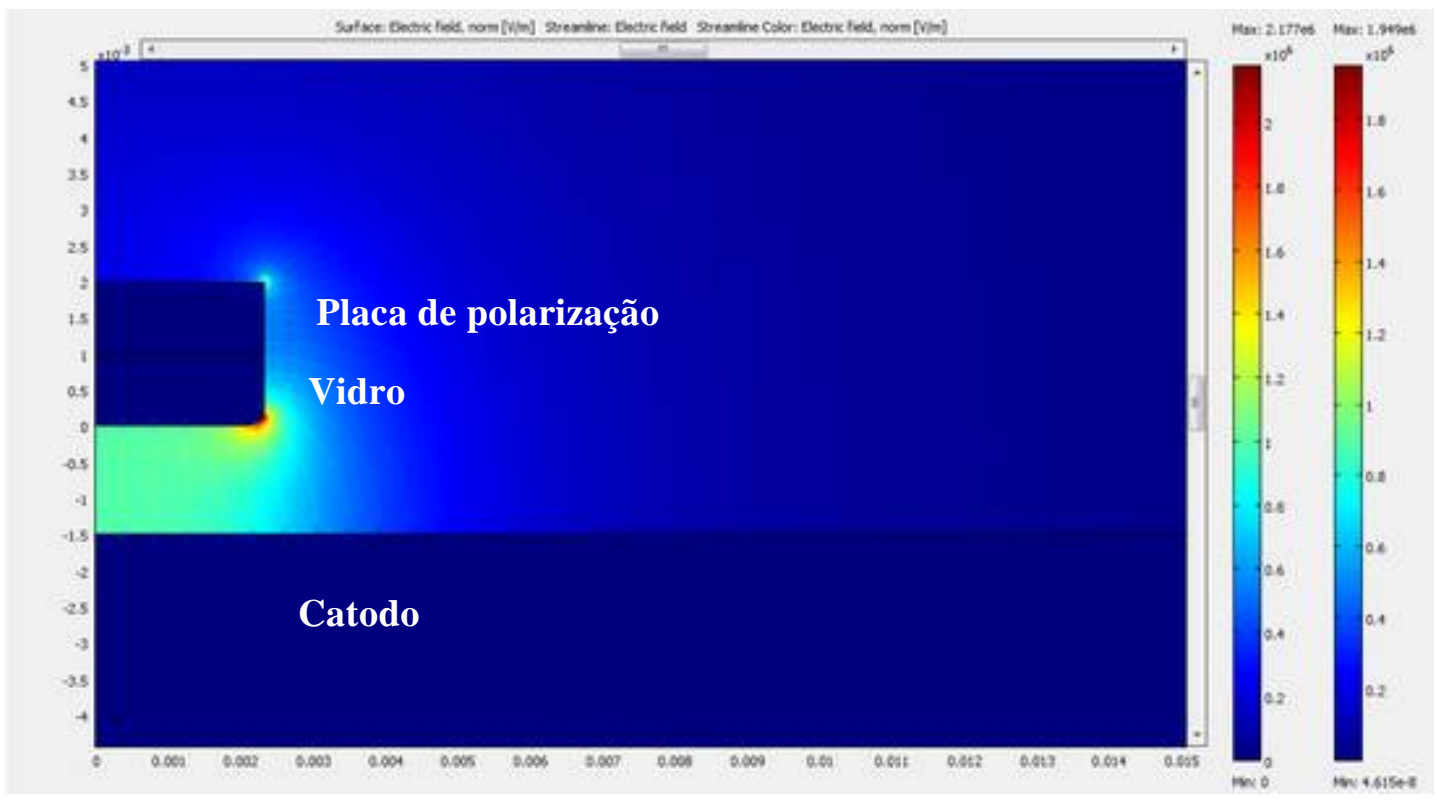

FIGURA 31: Simulação do campo elétrico para o espaçamento de 1,50mm - parte 1.

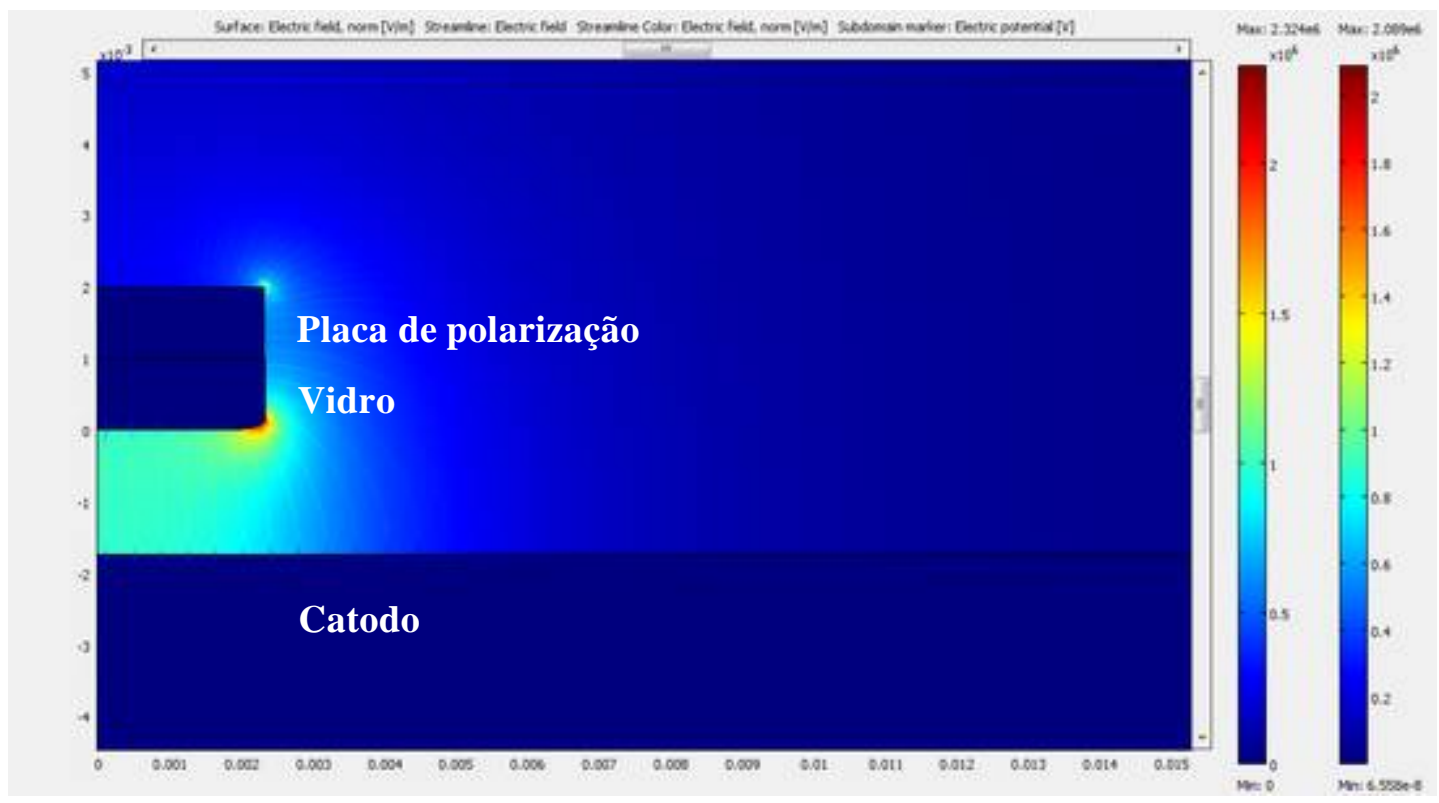

FIGURA 32: Simulação do campo elétrico para o espaçamento de $1,75 \mathrm{~mm}$ - parte 1. 


\subsection{Parte 2}

Como citado anteriormente, com as medidas preliminares observou-se a influência de efeitos de não uniformidade de campo elétrico, que estão relacionados com as dimensões dos eletrodos em comparação ao espaçamento entre eles. Assim, para esta etapa de medições o anodo de vidro de $25 \mathrm{~mm}^{2}$ foi substituído por um de área efetiva de $1056 \mathrm{~mm}^{2}$. Além disso, os componentes eletrônicos do interior da câmara foram substituídos por componentes com melhores características elétricas, como isoladores de esteatite, capacitores a vácuo e resistores para alta tensão, minimizando também a presença de contaminantes para o gás.

Com esta configuração foram efetuadas medidas de corrente de fundo e corrente devido à ionização do gás, para nitrogênio e isobutano, com espaçamentos de 1,50 e 1,25mm entre os eletrodos. Para estudar o campo elétrico nesta configuração, realizaramse simulações com o programa Comsol Multiphysics ${ }^{\circledR}$ v.3.5 para os espaçamentos estudados. Os resultados obtidos são apresentados a seguir.

\subsubsection{Simulação do campo elétrico}

A substituição do anodo de vidro por um com área efetiva maior favorece a focalização do laser em uma região de campo elétrico uniforme, condição esta fundamental para determinação do coeficiente de multiplicação gasosa. Além disso, a contribuição relativa de efeitos de borda é menor para eletrodos com maior área efetiva.

Nas FIG.33 e 34 são apresentadas simulações de campo elétrico para o espaçamento de $1,50 \mathrm{~mm}$, com as duas configurações empregadas no projeto, considerando um campo elétrico de $10^{6} \mathrm{~V} / \mathrm{m}$.

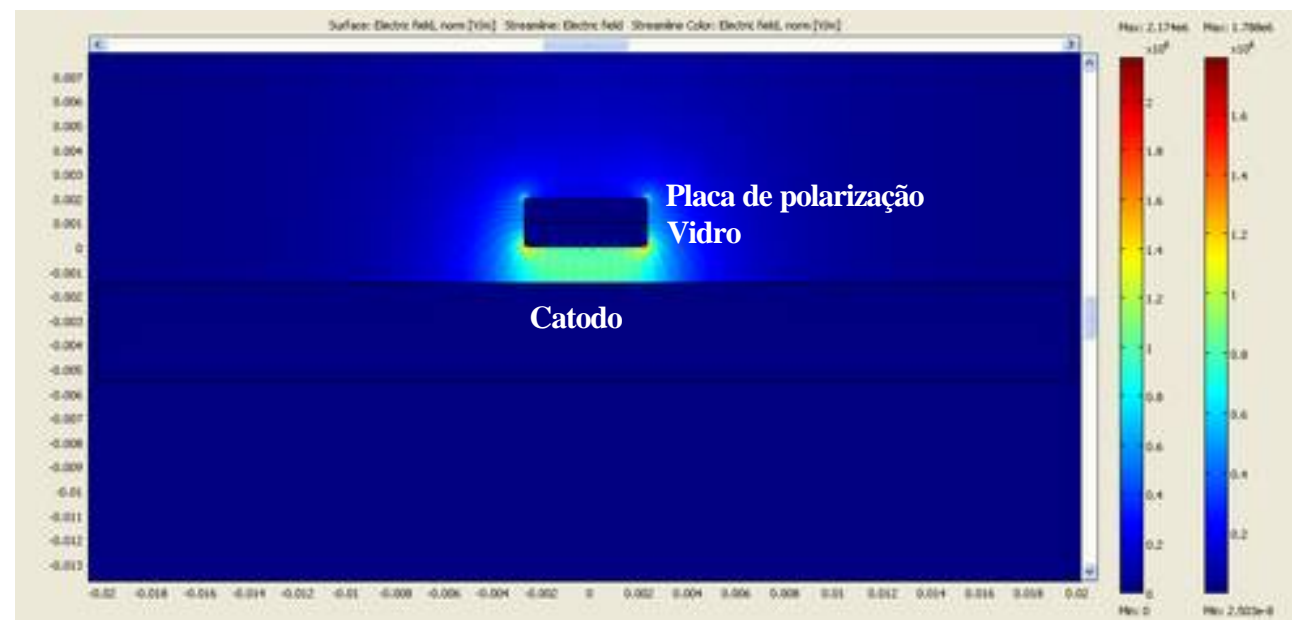

FIGURA 33: Simulação do campo elétrico para a configuração de eletrodos da parte 1 - espaçamento $1,50 \mathrm{~mm}$. 


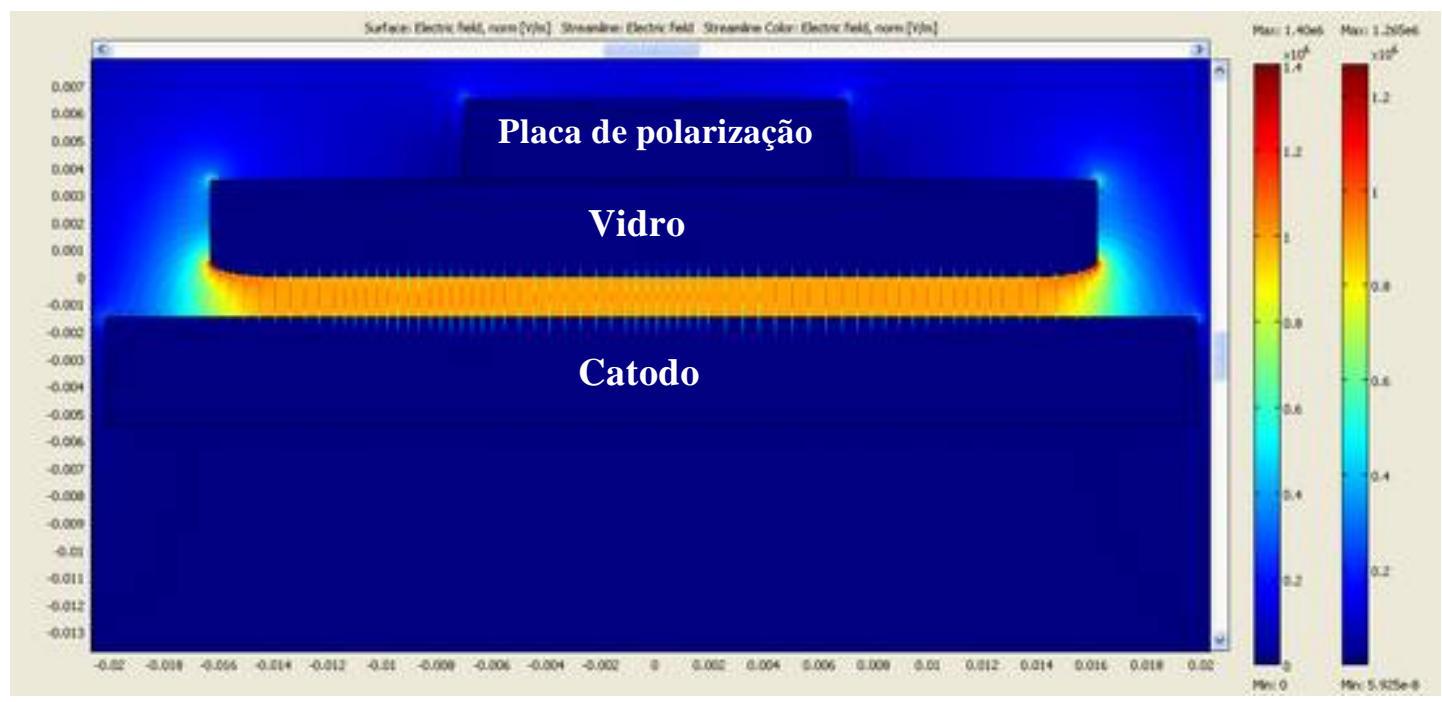

FIGURA 34: Simulação do campo elétrico para a configuração de eletrodos da parte 2 - espaçamento $1,50 \mathrm{~mm}$.

Nas FIG.35 e 36 a seguir são apresentadas as simulações para os espaçamentos de 1,25 e 1,50mm, empregados nesta etapa do trabalho. Em detalhe, a região central e bordas dos eletrodos.

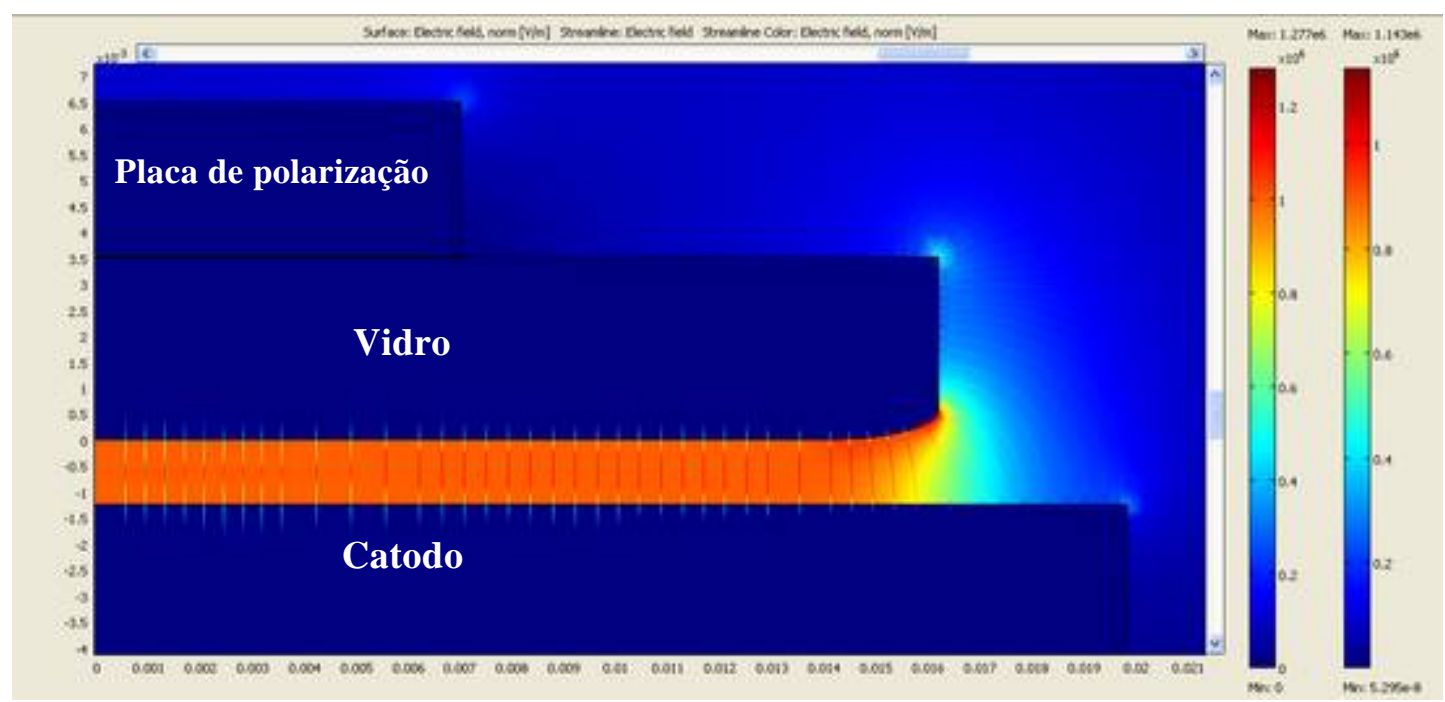

FIGURA 35: Simulação do campo elétrico para o espaçamento de 1,25mm - parte 2. 


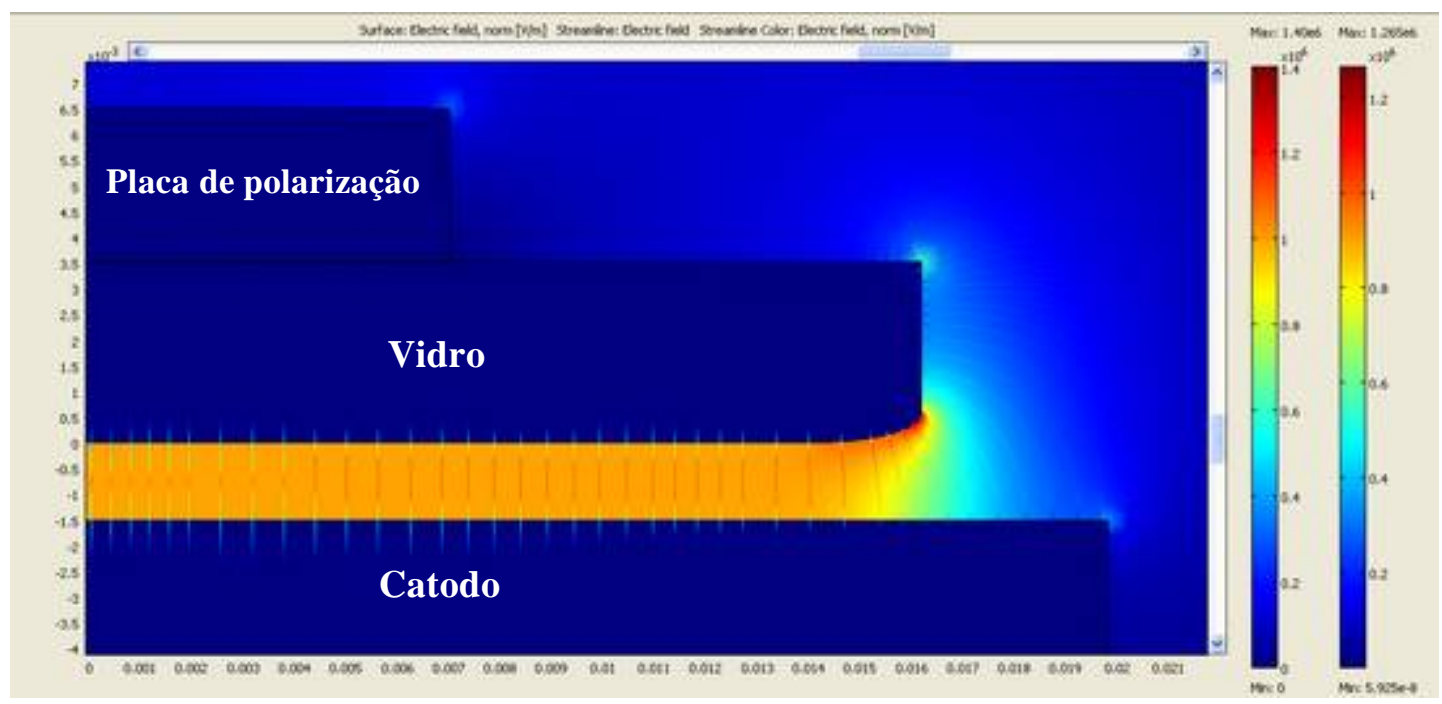

FIGURA 36: Simulação do campo elétrico para o espaçamento de 1,50mm - parte 2.

Com as figuras anteriores verifica-se que a contribuição de efeitos de não uniformidade de campo elétrico para as medidas efetuadas com esta nova configuração de eletrodos é pequena, em comparação com a geometria da parte 1, o que aumenta a confiabilidade das medidas do coeficiente de multiplicação.

\subsubsection{Nitrogênio}

O nitrogênio é um gás diatômico, quimicamente inerte e não eletronegativo, com potencial de ionização de $15,58 \mathrm{eV}$ [36]. A energia média para produzir um par de íons (W) em colisões com elétrons ou interações com fótons no nitrogênio é 36,5eV [37]. No ANEXO I são apresentados os gráficos de secção de choque do nitrogênio, com os principais processos colisionais e a porcentagem de energia perdida em diferentes colisões inelásticas em função do campo elétrico reduzido.

Inicialmente motivados pelas aplicações deste gás em sistemas de isolamento elétrico e em lasers, estudos de crescimento espacial de corrente e dos parâmetros de transporte no nitrogênio são extensivamente apresentados na literatura [38-47]. Por essa razão, se dispõe de valores bem estabelecidos de coeficiente de multiplicação, para uma ampla faixa de campo elétrico reduzido.

No presente trabalho a variação da corrente em função da tensão aplicada foi estudada para dois espaçamentos entre os eletrodos (1,50 e 1,25mm). Na TAB.7 a seguir são apresentados os valores obtidos de corrente elétrica medida na saída direta do catodo em função da tensão aplicada à câmara para 1,50mm de espaçamento entre os eletrodos. 
TABELA 7: Valores de tensão aplicada e corrente medida em três tomadas de dados. As incertezas nos valores de corrente correspondem a incertezas instrumentais.

Espaçamento 1,50mm

\begin{tabular}{llllll}
\hline & \multicolumn{2}{c}{ Dados 1 } & \multicolumn{2}{c}{ Dados 2 } & \multicolumn{2}{c}{ Dados 3 } \\
Tensão (V) & Corrente (pA) & Tensão $(\mathbf{V})$ & Corrente (pA) & Tensão (V) & Corrente (pA) \\
\hline 1000 & $0,0900(20)$ & 1000 & $0,0870(5)$ & 1000 & $0,1600(20)$ \\
1500 & $0,1200(20)$ & 1500 & $0,0940(5)$ & 1500 & $0,1600(20)$ \\
2000 & $0,1200(20)$ & 2000 & $0,1200(20)$ & 2000 & $0,1700(20)$ \\
2500 & $0,1250(20)$ & 2500 & $0,1200(20)$ & 2500 & $0,1700(20)$ \\
3000 & $0,1450(20)$ & 3000 & $0,1500(20)$ & 3000 & $0,1650(20)$ \\
3500 & $0,1600(20)$ & 3500 & $0,1700(20)$ & 3500 & $0,2500(20)$ \\
4000 & $0,260(5)$ & 4000 & $0,2500(20)$ & 4000 & $0,360(5)$ \\
4500 & $0,620(5)$ & 4500 & $0,590(5)$ & 4500 & $0,810(5)$ \\
5000 & $2,200(20)$ & 5000 & $2,050(20)$ & 5000 & $2,800(20)$ \\
5200 & $4,30(5)$ & 5200 & $3,90(5)$ & 5200 & $5,10(5)$ \\
5400 & $8,70(5)$ & 5400 & $7,80(5)$ & 5400 & $9,00(5)$ \\
5600 & $18,00(20)$ & 5600 & $16,00(20)$ & 5600 & $17,00(20)$ \\
5800 & $37,0(5)$ & 5800 & $32,0(5)$ & 5800 & $33,0(5)$ \\
6000 & $68,0(5)$ & 6000 & $62,0(5)$ & 6000 & $67,0(5)$ \\
\hline
\end{tabular}

Com os valores anteriores de corrente e tensão construiu-se o gráfico a seguir, FIG.37. Como é possível observar, para a faixa de tensão analisada, podem-se distinguir os regimes de ionização e de avalanche. As diferenças nas correntes para cada conjunto de dados devem-se às condições de temperatura e pressão de cada medição.

A corrente de ionização primária foi avaliada a partir da média aritmética dos valores de corrente medidos em regime de ionização. Para este espaçamento entre os eletrodos $(1,50 \mathrm{~mm})$ a corrente de fundo média foi de 0,0200(4)pA. Já o menor valor de corrente de ionização primária entre os conjuntos de dados foi de 0,1200(14)pA, para os "Dados1". Ou seja, a corrente de fundo é seis vezes menor do que a corrente de ionização primária. Por essa razão, os valores de corrente medidos não foram corrigidos para corrente de fundo. 


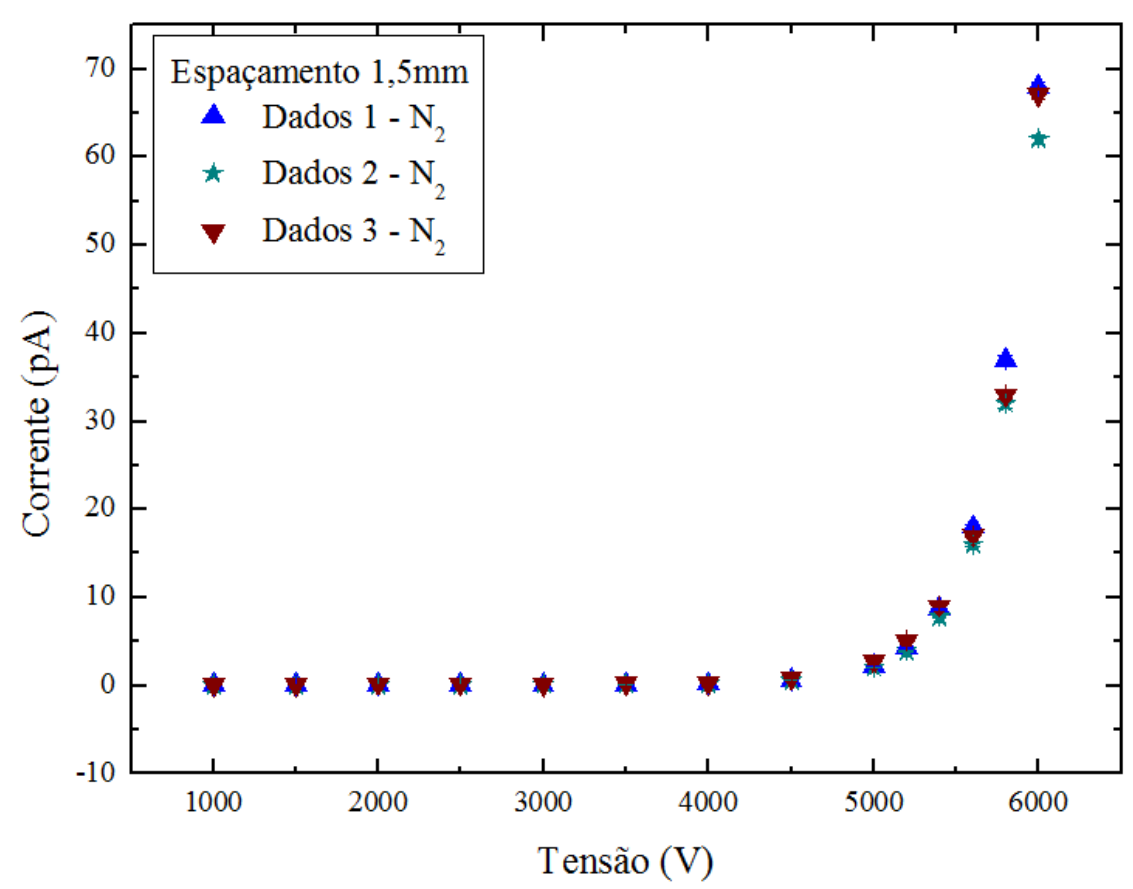

FIGURA 37: Variação da corrente em função da tensão.

A partir dos valores de corrente, com a Eq. (40), considerando as condições de temperatura e pressão das medidas, determinou-se o coeficiente de multiplicação gasosa para o nitrogênio, TAB.8.

TABELA 8: Coeficiente de multiplicação gasosa em função do campo elétrico reduzido para nitrogênio.

\begin{tabular}{|c|c|c|c|c|c|}
\hline \multicolumn{6}{|c|}{ Espaçamento 1,50mm } \\
\hline \multicolumn{2}{|c|}{ Dados 1} & \multicolumn{2}{|c|}{ Dados 2} & \multicolumn{2}{|c|}{ Dados 3} \\
\hline E/N (Td) & $\alpha / \mathbf{N}\left(10^{-20} \mathrm{~m}^{2}\right)$ & $\mathbf{E} / \mathbf{N}(\mathbf{T d})$ & $\alpha / \mathbf{N}\left(10^{-20} \mathrm{~m}^{2}\right)$ & E/N (Td) & $\alpha / N\left(10^{-20} \mathrm{~m}^{2}\right)$ \\
\hline 100 & $0,00083(5)$ & 100 & $0,00100(5)$ & 100 & $0,00111(3)$ \\
\hline 115 & $0,00222(6)$ & 115 & $0,00210(4)$ & 115 & $0,00215(5)$ \\
\hline 129 & $0,00471(4)$ & 129 & $0,00457(4)$ & 129 & $0,00448(3)$ \\
\hline 144 & $0,00835(4)$ & 143 & $0,00814(4)$ & 144 & $0,00804(3)$ \\
\hline 149 & $0,01027(5)$ & 149 & $0,00998(5)$ & 149 & $0,00976(4)$ \\
\hline 155 & $0,01230(4)$ & 155 & $0,01197(4)$ & 155 & $0,01139(3)$ \\
\hline 161 & $0,01438(5)$ & 161 & $0,01402(5)$ & 161 & $0,01322(4)$ \\
\hline 166 & $0,01645(5)$ & 166 & $0,01601(6)$ & 166 & $0,01512(5)$ \\
\hline 172 & $0,01820(4)$ & 172 & $0,01791(4)$ & 172 & $0,01716(3)$ \\
\hline
\end{tabular}


O gráfico do coeficiente de multiplicação em função do campo elétrico reduzido é apresentado a seguir, FIG.38. No gráfico também estão representados os dados de Haydon e Williams [44] e os simulados com o código Imonte 4.5. Este programa foi desenvolvido por S. F. Biagi e calcula os parâmetros de transporte de elétrons em gases por meio do método de Monte Carlo. Ou seja, são consideradas as trajetórias de cada elétron na avalanche, com as possíveis interações com o gás, a partir das seções de choque envolvidas nas colisões. O autor sugere a utilização deste código para obtenção de parâmetros de transporte mais precisos, para regiões de campo elevado $(E>50 \mathrm{kV} / \mathrm{cm})$ [48].

Os dados da simulação foram obtidos pelo Dr. Alessio Mangiarotti, pesquisador do Laboratório de Instrumentação e Física Experimental de Partículas (LIP) da Universidade de Coimbra, que colabora conosco.

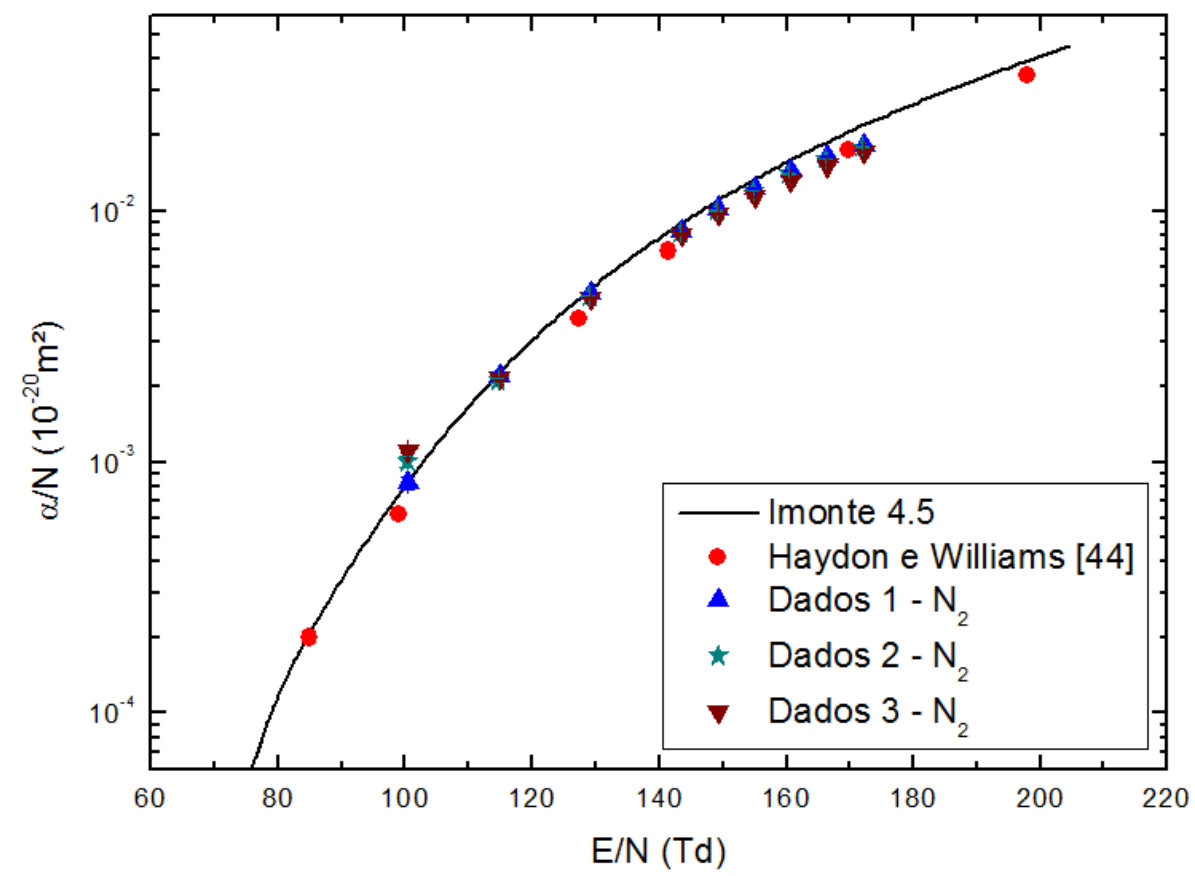

FIGURA 38: Coeficiente de multiplicação gasosa do nitrogênio.

Por meio da FIG.38, verifica-se que os resultados obtidos de coeficiente de multiplicação para o nitrogênio, para o intervalo de campo elétrico reduzido em estudo, apresentam comportamento reprodutível e compatível com a literatura e com a simulação.

Adotando os procedimentos anteriores, foram realizadas medidas para o espaçamento de $1,25 \mathrm{~mm}$ entre os eletrodos. Na TAB.9 a seguir são apresentados os valores de tensão aplicada à câmara e corrente medida para dois conjuntos de dados. 
TABELA 9: Valores de tensão aplicada e corrente medida em duas tomadas de dados. As incertezas nos valores de corrente correspondem a incertezas instrumentais.

\begin{tabular}{cccc}
\hline \multicolumn{4}{c}{ Espaçamento 1,25mm } \\
\hline Tensão (V) & Corrente (pA) & Tensão (V) & Corrente (pA) \\
\hline 1000 & $0,1250(20)$ & 1000 & $0,2000(20)$ \\
1500 & $0,1550(20)$ & 2000 & $0,2800(20)$ \\
2000 & $0,1600(20)$ & 3000 & $0,390(5)$ \\
2500 & $0,1900(20)$ & 4000 & $1,600(20)$ \\
3000 & $0,2300(20)$ & 4200 & $2,80(5)$ \\
3500 & $0,410(5)$ & 4400 & $5,70(5)$ \\
4000 & $1,100(20)$ & 4600 & $10,5(5)$ \\
4200 & $2,100(20)$ & 4800 & $20,00(20)$ \\
4400 & $3,80(5)$ & & \\
4600 & $7,80(5)$ & & \\
4800 & $16,00(20)$ & & \\
\hline
\end{tabular}

A partir dos dados anteriores, para analisar os regimes de operação da câmara, construiu-se a curva apresentada a seguir (FIG.39).

O valor médio da corrente de fundo, para a faixa de tensão analisada, foi de 0,0635(6)pA, enquanto que a menor corrente de ionização primária foi de 0,1467(12)pA. Por essa razão, assim como para o espaçamento de $1,50 \mathrm{~mm}$, os valores de corrente medidos não foram corrigidos para corrente de fundo. 


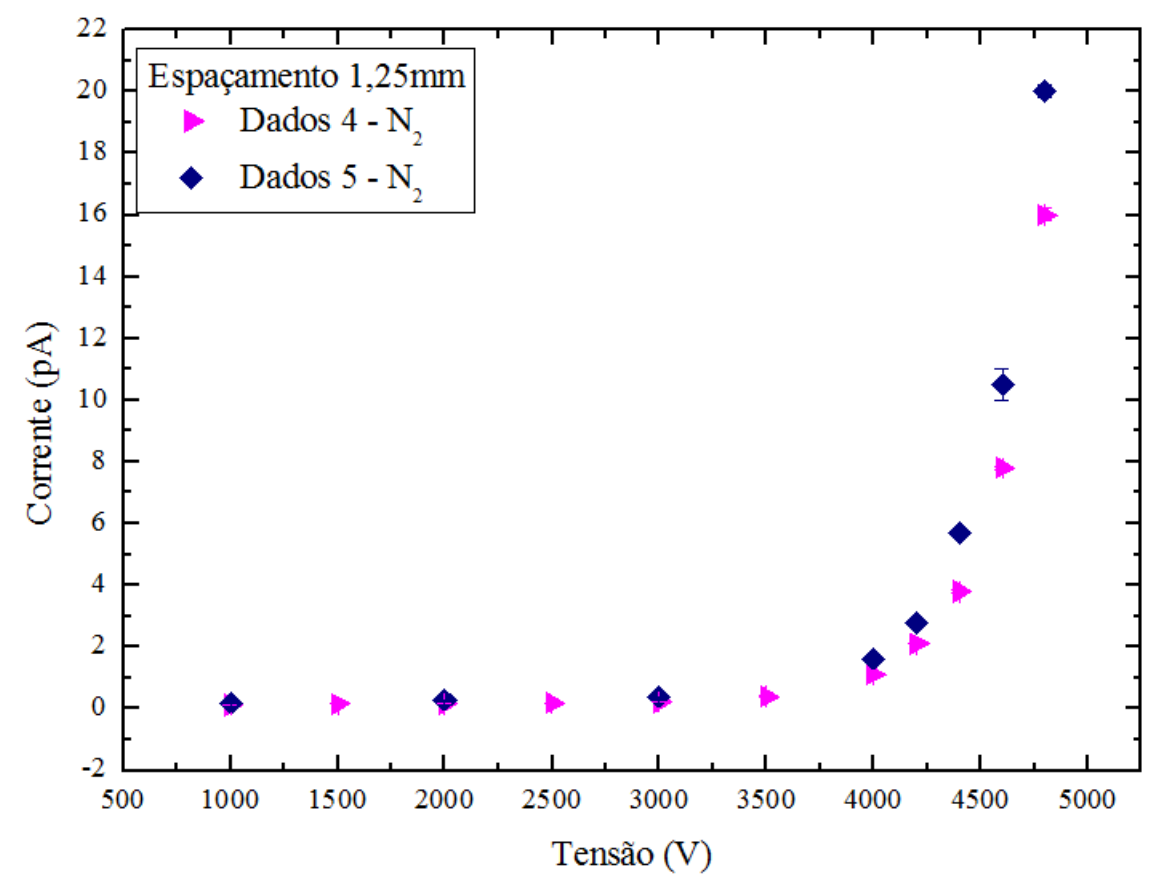

FIGURA 39: Corrente em função da tensão, para 1,25mm entre os eletrodos.

A partir dos valores de corrente elétrica, utilizando a Eq. (40), determinou-se o coeficiente de multiplicação gasosa no nitrogênio para este espaçamento entre os eletrodos. Os valores obtidos são apresentados na TAB.10.

TABELA 10: Coeficiente de multiplicação gasosa $(\alpha)$ em função do campo elétrico reduzido $(\mathrm{E} / \mathrm{N})$ para nitrogênio.

\section{Espaçamento 1,25mm}

\begin{tabular}{cccc}
\hline \multicolumn{2}{c}{ Dados 4 } & \multicolumn{2}{c}{ Dados 5 } \\
$\mathbf{E} / \mathbf{N}(\mathbf{T d})$ & $\boldsymbol{\alpha} / \mathbf{N ~}\left(\mathbf{1 0}^{-\mathbf{2 0}} \mathbf{m}^{\mathbf{2}}\right)$ & $\mathbf{E} / \mathbf{N}(\mathbf{T d})$ & $\boldsymbol{\alpha} / \mathbf{N}\left(\mathbf{1 0}^{-\mathbf{2 0}} \mathbf{m}^{\mathbf{2}}\right)$ \\
\hline 121 & $0,00355(5)$ & 138 & $0,00716(5)$ \\
138 & $0,00697(3)$ & 145 & $0,00909(6)$ \\
145 & $0,00921(3)$ & 152 & $0,01153(4)$ \\
152 & $0,01123(5)$ & 158 & $0,01364(17)$ \\
159 & $0,01374(3)$ & 165 & $0,01585(4)$ \\
166 & $0,01623(5)$ & & \\
\hline
\end{tabular}

Na FIG.40 é apresentada a curva de coeficiente de multiplicação em função do campo elétrico reduzido, para os dois conjuntos de dados com 1,25mm entre os eletrodos, e para conjunto "Dados 1" com 1,50mm de espaçamento. 
Com a curva a seguir verifica-se que, para esta configuração da câmara, os valores de coeficiente de multiplicação obtidos com diferentes espaçamentos entre os eletrodos apresentam comportamento reprodutivo e boa concordância com os dados de Haydon e Williams [44] e os valores da simulação.

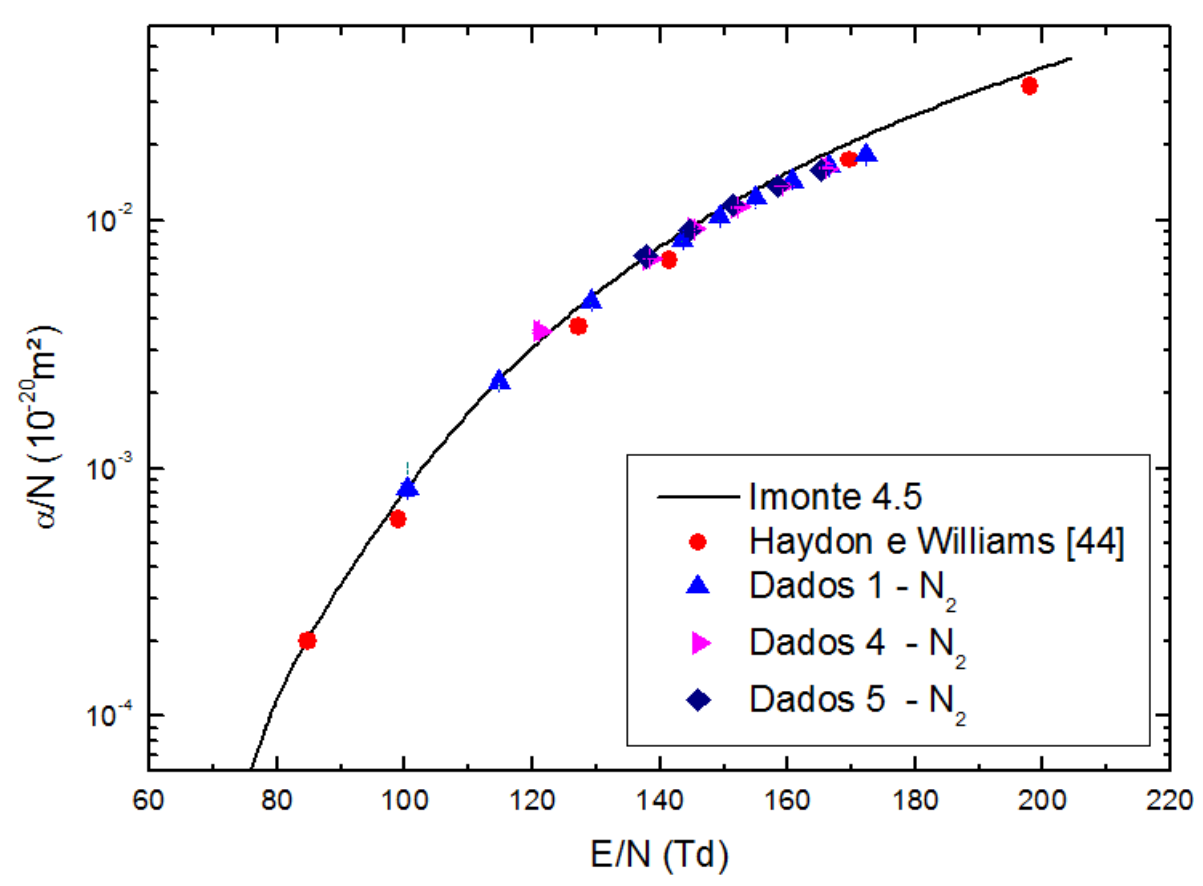

FIGURA 40: Coeficiente de multiplicação para os espaçamentos estudados.

Como discutido anteriormente, modelos são apresentados na literatura para descrever o comportamento do coeficiente $\alpha$, em diferentes gases. Os parâmetros de cada modelo dependem basicamente do tipo de gás e da região de campo elétrico estudada. Entre as parametrizações mais utilizadas está a semi-empírica proposta por Williams e Sara [29]. Segundo a Eq. (22)

$$
\frac{\alpha}{N}=A e^{-\frac{B N}{E}}
$$

onde:

$\mathrm{A}, \mathrm{B} \rightarrow$ constantes que dependem do tipo de gás 
Como para o nitrogênio se dispõe na literatura de valores para os parâmetros $A$ e $B$, aplicou-se a parametrização anterior aos dados obtidos.

A partir da Eq.(22):

$$
\ln \left(\frac{\alpha}{N}\right)=\ln \mathrm{A}-\mathrm{B} \frac{\mathrm{N}}{\mathrm{E}}
$$

Assim, com a curva do coeficiente de multiplicação $(\alpha / N)$ em função do inverso campo elétrico reduzido, em escala logarítmica, se obtém o parâmetro $B$ pelo coeficiente angular da curva e o parâmetro $A$ a partir do seu coeficiente linear.

Na FIG.41 são apresentadas as curvas de parametrização para os cinco conjuntos de dados, a partir das quais foram determinados os parâmetros $A$ e $B$ mostrados na TAB.11. Na tabela também são apresentados os valores de potencial de ionização efetivo, calculados a partir da razão entre o coeficiente $B$ e o coeficiente $A$.

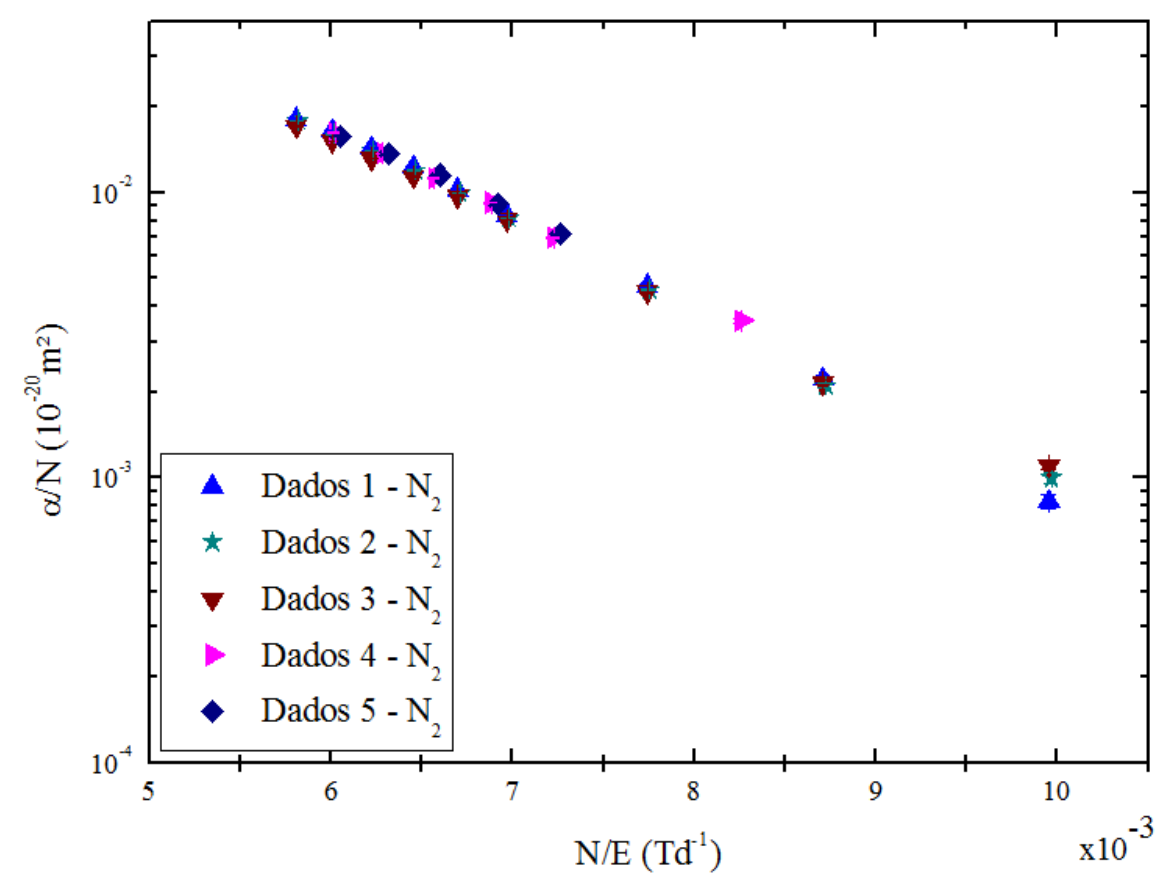

FIGURA 41: $\alpha / \mathrm{N}$ em função do inverso do campo elétrico reduzido para o nitrogênio. 
TABELA 11: Parâmetros $A$ e $B$ da equação de Williams e Sara e intervalo de campo elétrico reduzido empregado na parametrização.

\begin{tabular}{lllll}
\hline & $\mathbf{A}\left(\mathbf{1 0}^{-\mathbf{2 0}} \mathbf{m}^{\mathbf{2}}\right)$ & $\mathbf{B}(\mathbf{T d})$ & $\mathbf{V}_{\text {ef }}(\mathbf{e V})$ & $\begin{array}{c}\text { Intervalo } \\
\text { de E/N (Td) }\end{array}$ \\
\hline Daniel e Harris [21] & 2,33 & 802 & 34 & $85-152$ \\
Cookson et al. $[24]$ & 1,55 & 770 & 47 & $89-166$ \\
Haydon e Williams & & & & $85-198$ \\
Dados 1 & 1,64 & 771 & 47 & $100-172$ \\
Dados 2 & $1,55(5)$ & $753(4)$ & $48,6(16)$ & $100-172$ \\
Dados 3 & $1,18(4)$ & $715(4)$ & $60,6(21)$ & $100-172$ \\
Dados 4 & $0,90(3)$ & $685(4)$ & $76(3)$ & $121-166$ \\
Dados 5 & $1,00(5)$ & $683(5)$ & $68(3)$ & $138-165$ \\
\hline
\end{tabular}

Com a tabela anterior verifica-se que os parâmetros $A$ e $B$ da série "Dados 1" apresentam boa concordância com os dados de Cookson [24]. Porém, vale ressaltar que as referências anteriores empregam diferentes métodos para determinar o coeficiente de multiplicação gasosa, além de considerarem processos secundários de produção de carga, como ionização no catodo por moléculas metaestáveis [44].

Os valores de potencial efetivo de ionização são compatíveis com os valores previstos, já que o nitrogênio possui potencial de ionização de 15,58eV [36]. Apesar do valor tabelado de energia média de elétrons para produzir um par de íons $(W)$ no nitrogênio ser $36,5 \mathrm{eV}$ [37], este valor depende da energia dos elétrons. Para elétrons com energia de $15,8 \mathrm{eV}$ a $1,0 \mathrm{keV}$ o valor de $W$ varia de $1030,38 \mathrm{eV}$ a $36,68 \mathrm{eV}[49]$.

\subsubsection{Isobutano}

O isobutano é um gás poliatômico, largamente utilizado no domínio dos detectores gasosos como gás quenching ou em misturas Penning. As seções de choque para os principais processos colisionais neste gás são apresentadas no ANEXO I.

O potencial de ionização do isobutano é $10,68 \mathrm{eV}$ [50] e a energia de dissociação da molécula por impacto eletrônico é 7,0eV [51]. Por essa razão, a utilização deste gás em grandes proporções, por longos períodos de operação, e sob elevado campo

\footnotetext{
${ }^{1} \mathrm{O}$ intervalo de campo elétrico reduzido estudado por Haydon e Williams é de 85 a 3400 Td. Neste trabalho determinaram-se os parâmetros A e B para o intervalo de 85 a 198 Td.
} 
elétrico pode causar o envelhecimento dos eletrodos [52]. A energia média para se produzir um par de íons no isobutano é $26,17 \mathrm{eV}$ [53]

Em contrapartida, pequenas quantidades de isobutano em gases nobres aumentam o coeficiente de multiplicação gasosa da mistura, diminuindo a tensão de operação dos detectores. Além disso, a adição de isobutano contribui para redução de instabilidades e perdas de resposta induzidas por fótons de desexcitação.

Nos últimos anos, a inclusão deste gás em misturas empregadas nos detectores dos grandes aceleradores de partículas motiva o estudo de parâmetros físicos de descargas em gases, como o coeficiente de multiplicação gasosa, para um amplo intervalo de campo elétrico reduzido [54].

Na TAB.12 a seguir são apresentadas algumas referências que determinaram o coeficiente de multiplicação no isobutano, com o respectivo intervalo de campo elétrico reduzido estudado. Dada a semelhança nas secções de choque do isobutano e do butano, na literatura é comum a comparação dos resultados de coeficiente $\alpha$ no isobutano com valores obtidos para o butano. As seções de choque dos principais processos colisionais no butano são apresentadas no ANEXO I.

TABELA 12: Trabalhos nos quais o coeficiente de multiplicação no isobutano é determinado com a respectiva região de $\mathrm{E} / \mathrm{N}$ investigada.

\begin{tabular}{cc}
\hline Autor & Intervalo de E/ N (Td) \\
\hline K. Tsumaki [55] & $568-1276$ \\
A. Sharma e F. Sauli [56] & $87-130$ \\
C. Lu, K.T. McDonald e Y. Zhu [57] & $543-1242$ \\
I. K. Bronic e B. Grosswendt ${ }^{2}$ [58] & $745-6003$ \\
M. Nakhostin, et al. [59] & $568-1360$ \\
\hline
\end{tabular}

\footnotetext{
${ }^{2}$ Neste trabalho o coeficiente de multiplicação foi determinado em condições de não-equilíbrio por meio de uma configuração de geometria cilíndrica, discutida na seção 3.2.1.
} 
A técnica de medida adotada para o nitrogênio foi estendida para o isobutano. Os valores de corrente obtidos para duas tomadas de dados, com espaçamento de $1,50 \mathrm{~mm}$, são apresentados na TAB.13. A fim de estudar os regimes de operação da câmara, construiu-se a curva de corrente em função da tensão aplicada mostrada na FIG.42.

Por se tratar de um hidrocarboneto com estrutura complexa, a tensão de transição de regime de câmara para regime de avalanche com o isobutano é maior do que para o nitrogênio, como se verifica com a FIG.42. Assim, o intervalo de campo elétrico reduzido alcançado com isobutano é maior do que o obtido com o nitrogênio.

TABELA 13: Valores de tensão aplicada e corrente medida para o espaçamento de $1,50 \mathrm{~mm}$ entre os eletrodos. As incertezas nos valores de corrente correspondem a incertezas instrumentais.

\begin{tabular}{cccc}
\hline \multicolumn{4}{c}{ Espaçamento 1,50mm } \\
\hline Tensão (V) & Corrente (pA) & Tensão (V) & Corrente (pA) \\
\hline 2500 & $0,2200(20)$ & 2000 & $0,2100(20)$ \\
3000 & $0,2500(20)$ & 2500 & $0,2400(20)$ \\
3500 & $0,2500(20)$ & 3000 & $0,2000(20)$ \\
4000 & $0,3000(20)$ & 3500 & $0,2500(20)$ \\
4500 & $0,2500(20)$ & 4000 & $0,2500(20)$ \\
5000 & $0,350(20)$ & 4500 & $0,2800(20)$ \\
5500 & $0,600(20)$ & 5000 & $0,370(5)$ \\
6000 & $2,000(20)$ & 5500 & $0,600(5)$ \\
6500 & $13,50(20)$ & 6000 & $2,100(20)$ \\
6600 & $19,00(20)$ & 6500 & $14,50(20)$ \\
6700 & $27,00(20)$ & 6600 & $21,00(20)$ \\
6800 & $35,0(5)$ & 6800 & $38,0(5)$ \\
6900 & $48,0(20)$ & 7000 & $64,0(5)$ \\
7000 & $62,0(20)$ & & \\
\hline
\end{tabular}




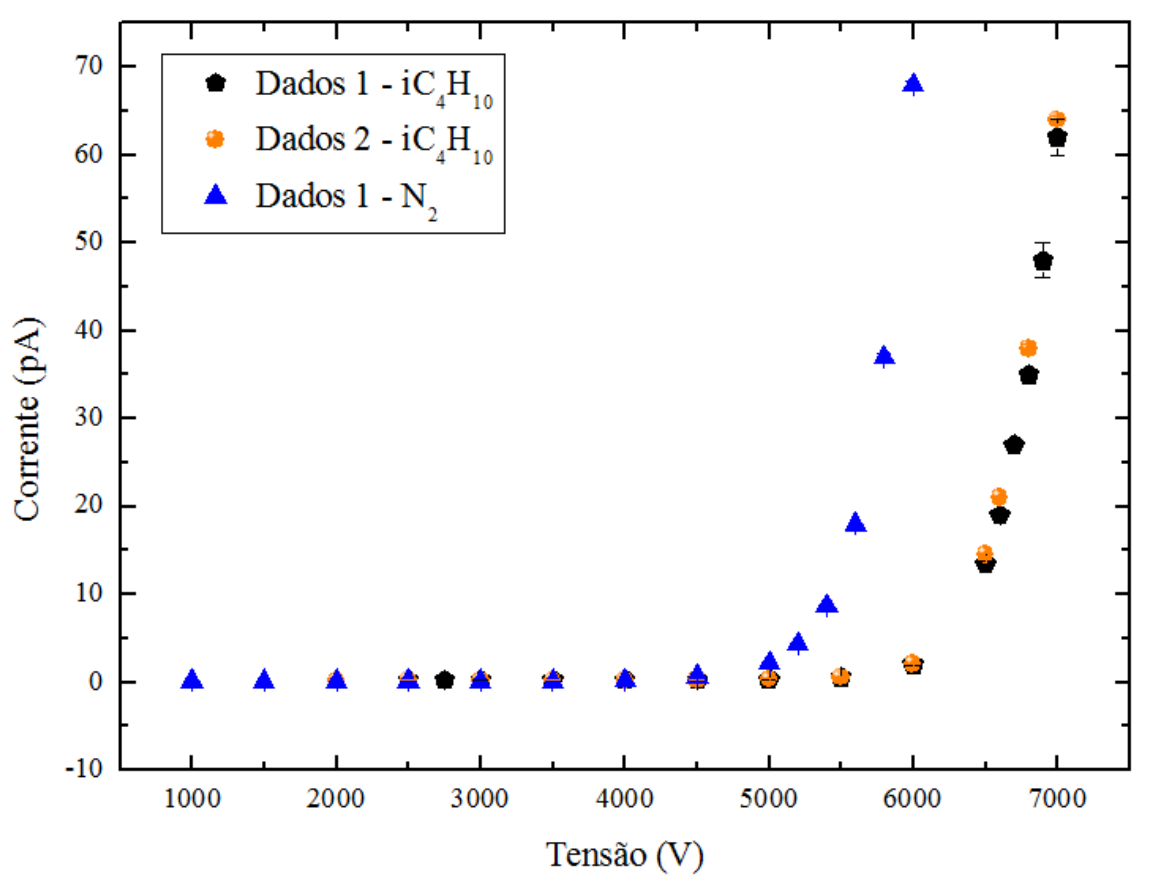

FIGURA 42: Corrente em função da tensão aplicada à câmara.

Com a distância de $1,25 \mathrm{~mm}$ entre os eletrodos, foram efetuadas medidas de corrente em função da tensão, cujos valores são mostrados na TAB.14 a seguir. A curva característica obtida para este espaçamento é apresentada na FIG.43.

TABELA 14: Valores de corrente em função da tensão aplicada à câmara para o espaçamento de $1,25 \mathrm{~mm}$. As incertezas nos valores de corrente correspondem a incertezas instrumentais.

\begin{tabular}{cccc}
\hline \multicolumn{3}{c}{ Espaçamento 1,25mm } \\
\hline Dados 3 & \multicolumn{2}{c}{ Dados 4 } \\
\hline Tensão (V) & Corrente (pA) & Tensão (V) & Corrente (pA) \\
\hline 3000 & $0,3500(20)$ & 2000 & $0,2100(20)$ \\
3500 & $0,3500(20)$ & 3000 & $0,2600(20)$ \\
4000 & $0,3800(20)$ & 3500 & $0,2600(20)$ \\
4500 & $0,4600(20)$ & 4000 & $0,300(5)$ \\
5000 & $2,7100(20)$ & 4500 & $0,470(5)$ \\
5500 & $11,00(20)$ & 5500 & $0,940(5)$ \\
6000 & $50,0(5)$ & 6000 & $6,50(5)$ \\
\end{tabular}




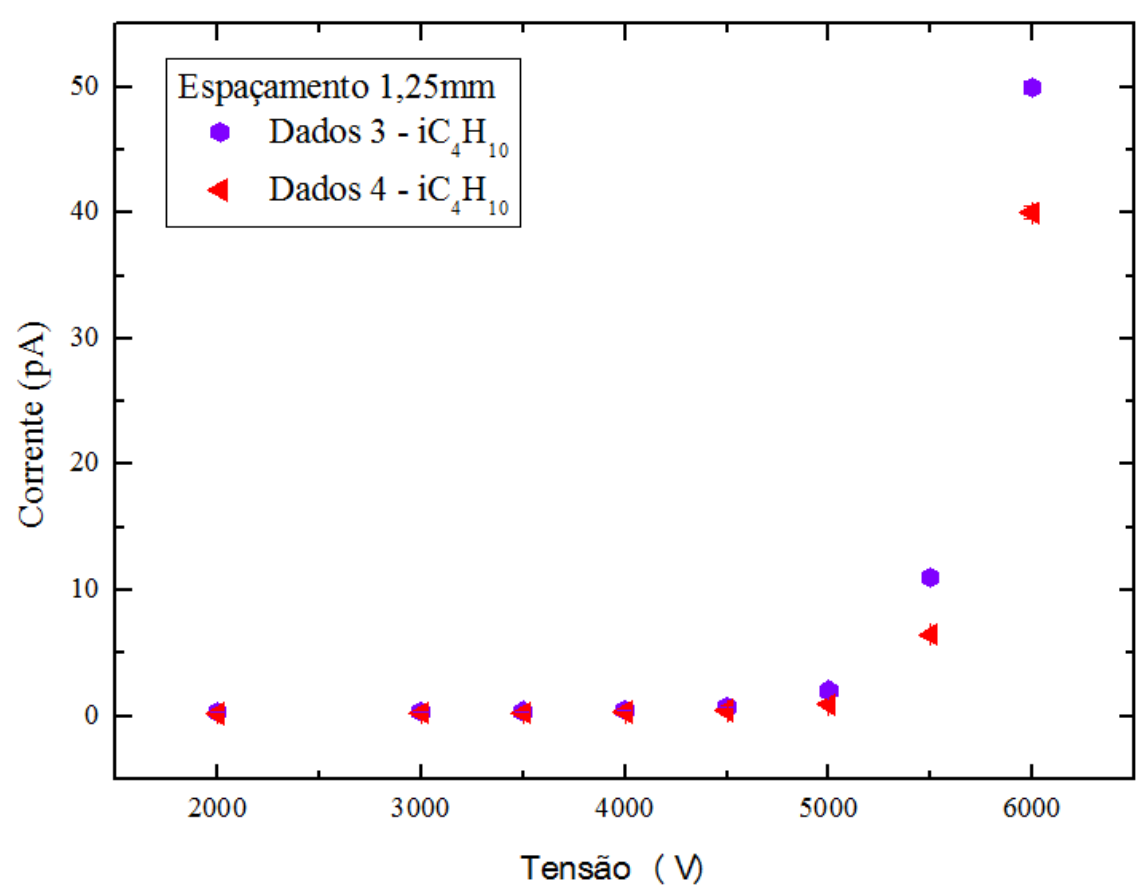

FIGURA 43: Corrente em função da tensão para 1,25mm de espaçamento.

Determinada a corrente de ionização, com a Eq. (40) calculou-se o coeficiente de multiplicação para o isobutano. Os valores obtidos são mostrados nas TAB.15 e 16 abaixo.

TABELA 15: Coeficiente de multiplicação gasosa em função do campo elétrico reduzido para isobutano para $1,50 \mathrm{~mm}$ de espaçamento entre os eletrodos.

\begin{tabular}{cccc}
\hline \multicolumn{4}{c}{ Espaçamento 1,50mm } \\
\hline E/N (Td) & $\boldsymbol{\alpha} / \mathbf{N}\left(\mathbf{1 0}^{-\mathbf{2 0}} \mathbf{m}^{\mathbf{2}}\right)$ & $\mathbf{E} / \mathbf{N}(\mathbf{T d})$ & $\boldsymbol{\alpha} / \mathbf{N}\left(\mathbf{1 0}^{-\mathbf{2 0}} \mathbf{m}^{\mathbf{2}}\right)$ \\
\hline 144 & $0,00097(16)$ & 144 & $0,00124(4)$ \\
158 & $0,00252(10)$ & 158 & $0,00263(3)$ \\
173 & $0,00599(3)$ & 172 & $0,00623(3)$ \\
187 & $0,01148(4)$ & 187 & $0,01177(4)$ \\
190 & $0,01247(3)$ & 189 & $0,01284(3)$ \\
193 & $0,01348(3)$ & 195 & $0,01454(4)$ \\
196 & $0,01422(4)$ & 201 & $0,01628(3)$ \\
199 & $0,01528(12)$ & & \\
202 & $0,01601(9)$ & & \\
\hline
\end{tabular}


TABELA 16: Coeficiente de multiplicação gasosa em função do campo elétrico reduzido para isobutano para $1,25 \mathrm{~mm}$ de espaçamento entre os eletrodos.

\begin{tabular}{cccc}
\hline \multicolumn{4}{c}{ Espaçamento 1,25mm } \\
\hline E/N (Td) & $\boldsymbol{\alpha} / \mathbf{N}\left(\mathbf{1 0}^{-\mathbf{2 0}} \mathbf{m}^{2}\right)$ & E/N (Td) & $\boldsymbol{\alpha} / \mathbf{N}\left(\mathbf{1 0}^{-\mathbf{2 0}} \mathbf{m}^{\mathbf{2}}\right)$ \\
\hline 139 & $0,00085(19)$ & 139 & $0,00077(6)$ \\
156 & $0,00236(15)$ & 156 & $0,00233(4)$ \\
173 & $0,00603(4)$ & 173 & $0,00474(3)$ \\
191 & $0,01186(6)$ & 191 & $0,01144(3)$ \\
208 & $0,01712(4)$ & 208 & $0,01775(5)$ \\
\hline
\end{tabular}

A seguir, na FIG.44 são apresentadas as curvas do coeficiente de multiplicação em função do campo elétrico reduzido para os conjuntos dados obtidos neste trabalho, juntamente com dados simulados com o Imonte 4.5, e dados obtidos anteriormente pelo grupo [60] por meio de análise de sinais. Vale ressaltar que, para a região de E/N analisada, não existem dados experimentais disponíveis na literatura para se comparar com os obtidos no trabalho.

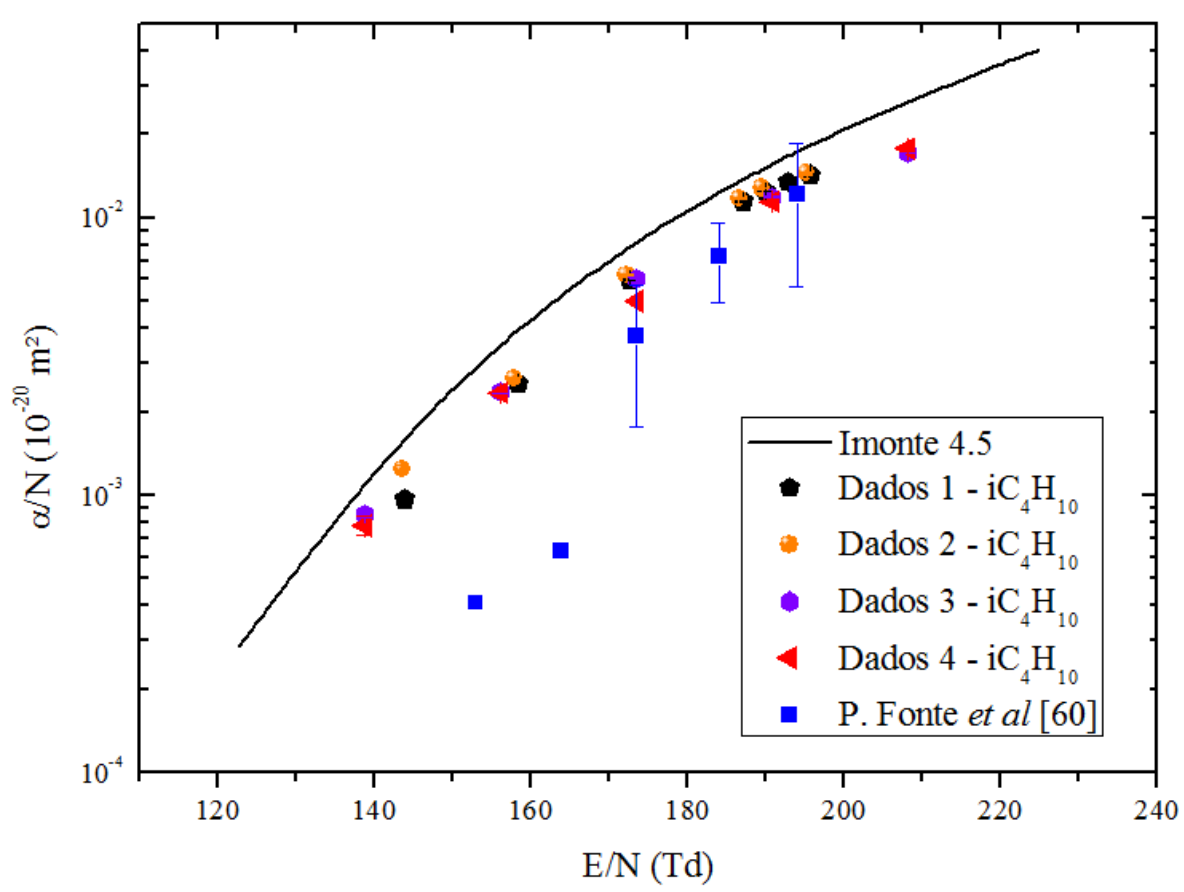

FIGURA 44: Coeficiente de multiplicação gasosa no isobutano. 
Para fins comparativos, a seguir é mostrado o comportamento do coeficiente de multiplicação gasosa no isobutano e no nitrogênio (FIG.45). Como o isobutano é um hidrocarboneto com molécula complexa, e em processos de descargas em gases sofre dissociação molecular, para um mesmo valor de campo elétrico reduzido, o coeficiente de multiplicação gasosa para este gás é menor do que para o nitrogênio. Além disso, devido às secções de choque vibracionais e de excitação do isobutano, parte da energia dos elétrons da avalanche é perdida em processos não ionizantes.

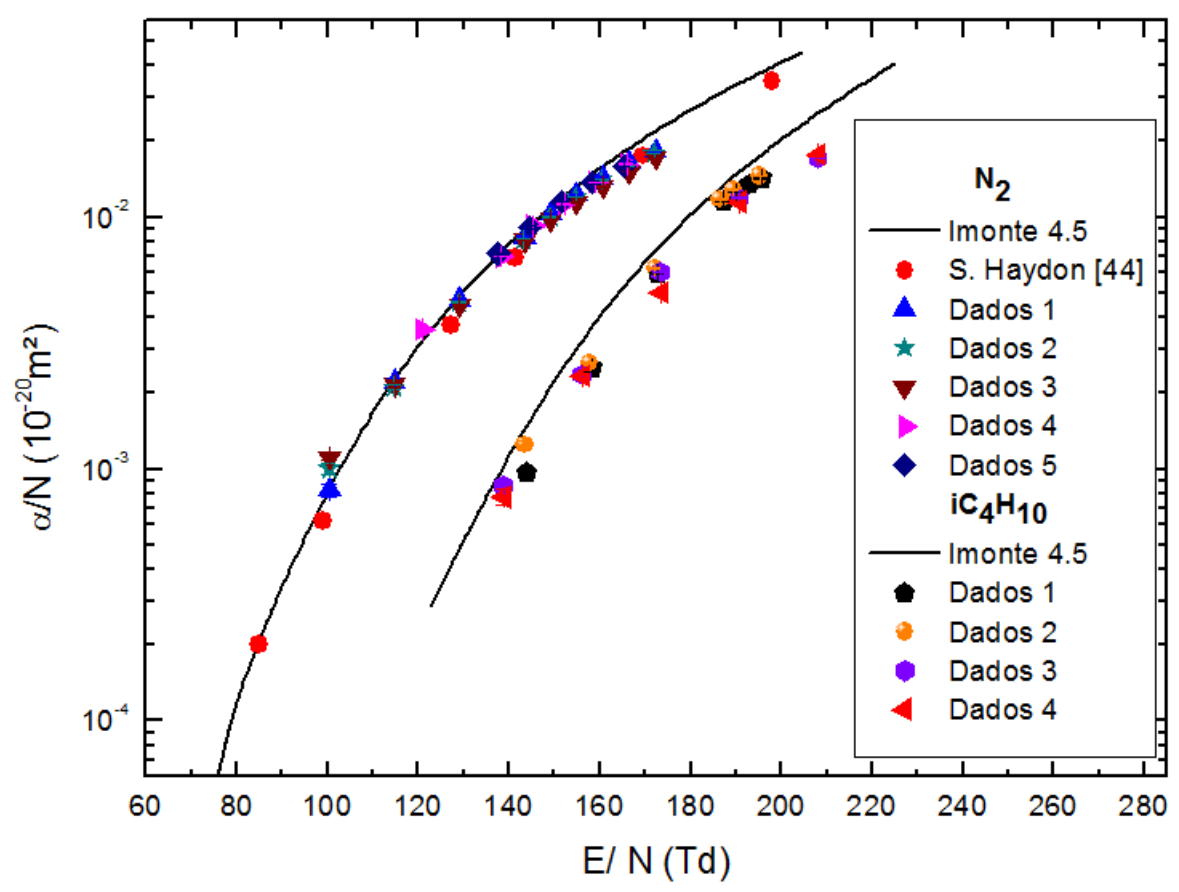

FIGURA 45: Coeficiente de multiplicação do nitrogênio e do isobutano.

Analogamente aos estudos com nitrogênio, aplicou-se a parametrização de Williams e Sara aos dados com isobutano. As curvas empregadas nas parametrizações são apresentadas na FIG.46. Os valores dos coeficientes $A$ e $B$, assim como os de potencial de ionização efetivo, e intervalo de campo elétrico reduzido considerado são mostrados na TAB. 17.

Na TAB.17 também são apresentados valores dos parâmetros $A$ e $B$ para o isobutano, obtidos por trabalhos que estudam diferentes regiões de campo elétrico reduzido. 


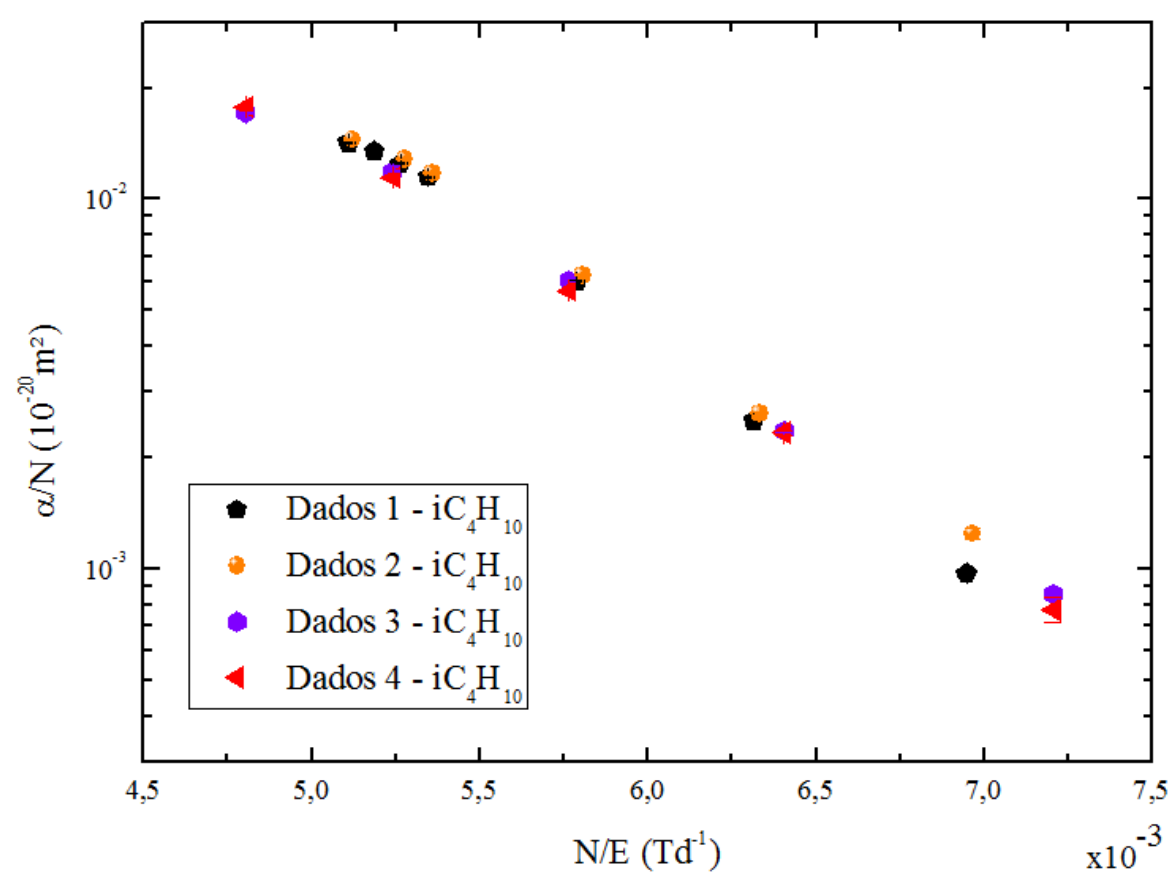

FIGURA 46: Coeficiente $\alpha$ reduzido em função de N/E no isobutano.

TABELA 17: Parâmetros $A$ e $B$ e potencial de ionização efetivo do isobutano, com o respectivo intervalo de campo elétrico reduzido.

\begin{tabular}{|c|c|c|c|c|}
\hline & $A\left(10^{-20} m^{2}\right)$ & B (Td) & $V_{\text {ef }}(e V)$ & $\begin{array}{c}\text { Intervalo de } \mathrm{E} / \mathrm{N} \\
\text { (Td) }\end{array}$ \\
\hline Tsumaki [55] & 7 & 1373 & 20 & $568-1276$ \\
\hline Sharma e Sauli [56] & 55 & 1130 & 21 & $87-130$ \\
\hline Nakhostin et al.[59] & 8 & 1217 & 15 & $568-1360$ \\
\hline Dados 1 & $16,1(6)$ & $1377(13)$ & $9(3)$ & $144-202$ \\
\hline Dados 2 & $9,93(19)$ & $1267(9)$ & $12,8(26)$ & $144-201$ \\
\hline Dados 3 & $9,00(17)$ & $1278(11)$ & $14,2(29)$ & $139-208$ \\
\hline Dados 4 & $10,78(22)$ & $1320(7)$ & $12,2(24)$ & $139-208$ \\
\hline
\end{tabular}

Como o potencial de ionização do isobutano é 10,68 eV [50] e a energia média para produzir um par de íons é $26,17 \mathrm{eV}$ [53], os valores obtidos de potencial de ionização efetivo apresentam comportamento compatível com o esperado teoricamente. 


\section{CONCLUSÕES}

Neste trabalho estudou-se o comportamento do coeficiente de multiplicação no isobutano, em função do campo elétrico reduzido, com uma configuração semelhante à de uma câmara de placas paralelas resistivas. A técnica empregada foi validada por meio de medidas com nitrogênio, que é um gás amplamente estudado, e para o qual se tem dados bem estabelecidos na literatura.

Os estudos iniciais incluíram análise de sinais e simulações do campo elétrico entre os eletrodos com o programa Comsol Multiphysics ${ }^{\circledR}$ v.3.5. A partir destes estudos verificou-se a influência de efeitos de não-uniformidade de campo elétrico para a configuração inicialmente utilizada. Como estes efeitos relacionam-se com as dimensões dos eletrodos em comparação ao espaçamento entre eles, estas análises resultaram em alterações dos eletrodos da câmara.

Com eletrodos de área efetiva maior, a partir de medidas de corrente elétrica e estudos do regime de operação da câmara, determinou-se inicialmente o coeficiente de multiplicação gasosa do nitrogênio. As medidas com nitrogênio incluíram estudos do comportamento do coeficiente $\alpha$ em função do campo elétrico reduzido, por meio da parametrização de Williams e Sara, e determinação do potencial de ionização efetivo $\left(V_{e f}\right)$

a partir dos coeficientes da parametrização. Estes estudos possibilitaram concluir que, para o intervalo de campo elétrico reduzido analisado, os dados obtidos apresentam comportamento reprodutivo e boa concordância com os da literatura [44], permitindo assim, estender a técnica para o isobutano.

Como para a região de campo elétrico reduzido analisada neste trabalho (139 a 208Td) não existem valores experimentais na literatura de coeficiente $\alpha$ no isobutano, os valores obtidos foram comparados com os da simulação Imonte 4.5 e com dados obtidos anteriormente pelo grupo. Com a FIG.44 verifica-se que a configuração atual de eletrodos e a técnica de medida do trabalho resultaram em um melhor comportamento do coeficiente $\alpha$, em comparação com os resultados anteriores do grupo [60]. Vale destacar que os dados de P. Fonte et al. [60] foram obtidos com a configuração de eletrodos descrita na seção 4.1 e por meio de análises de sinais. 
Em virtude de a simulação computacional utilizar aproximações para o cálculo dos parâmetros de transporte, valores do coeficiente $\alpha$ da simulação apresentam comportamento superestimado em comparação com os dados experimentais do nitrogênio (FIG.45). Por essa razão, os dados obtidos neste trabalho de coeficiente $\alpha$ no isobutano apontam para um acordo satisfatório com a teoria.

É importante ressaltar que entre as dificuldades experimentais do projeto está a focalização do laser no catodo, dada as distâncias entre os eletrodos analisadas no trabalho $(1,25$ e $1,50 \mathrm{~mm})$, e o alinhamento dos eletrodos, essencial para a confiabilidade das medidas. Por fim, vale salientar que este trabalho contribui com informações relevantes para a compreensão de fenômenos físicos envolvidos em descargas gasosas e validam a utilização da técnica em futuros estudos. 


\section{ANEXO I}

A seguir é apresentado o gráfico de secção de choque para os principais processos colisionais com elétrons do nitrogênio (FIG.47). Já a porcentagem de energia perdida por elétrons em função do campo elétrico reduzido para alguns processos é mostrada na FIG.48.

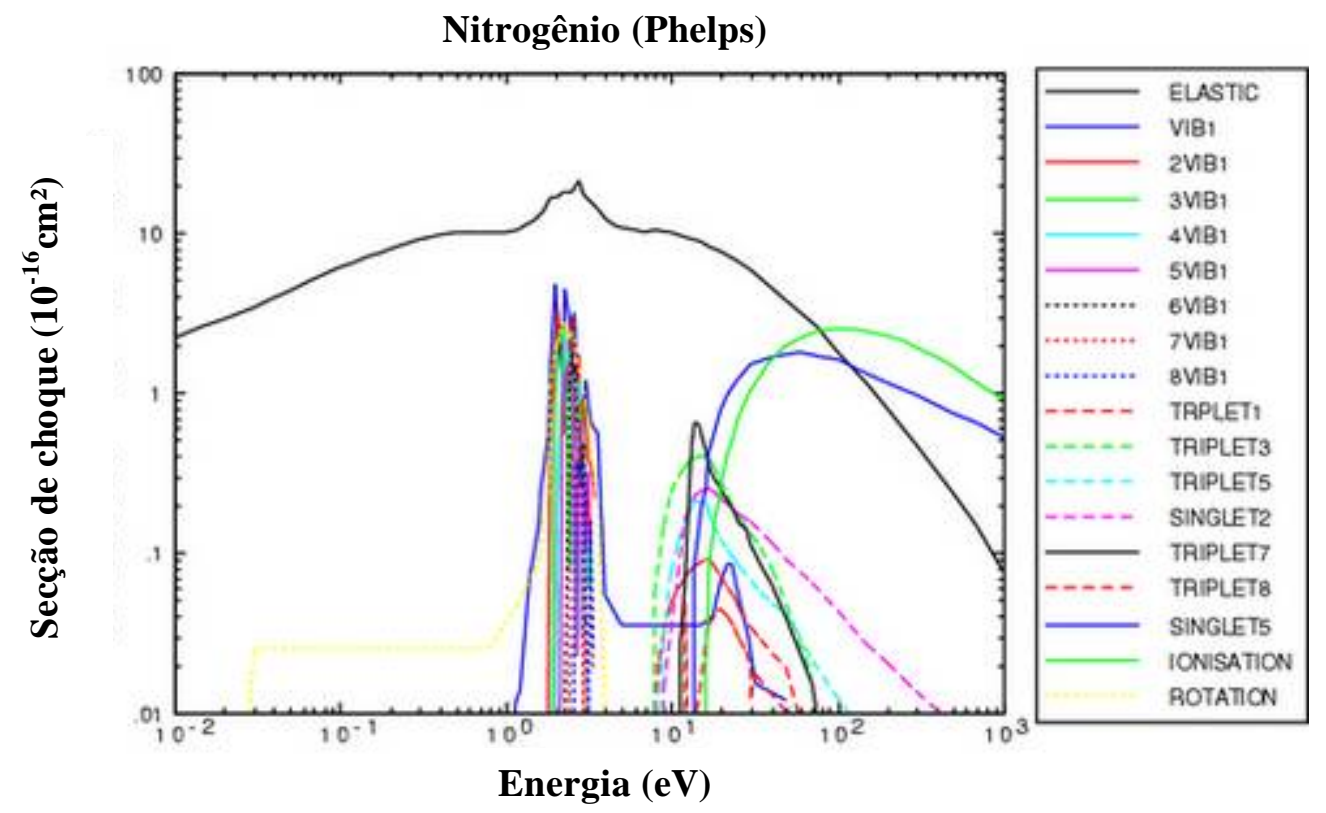

FIGURA 47: Seções de choque no nitrogênio [61].

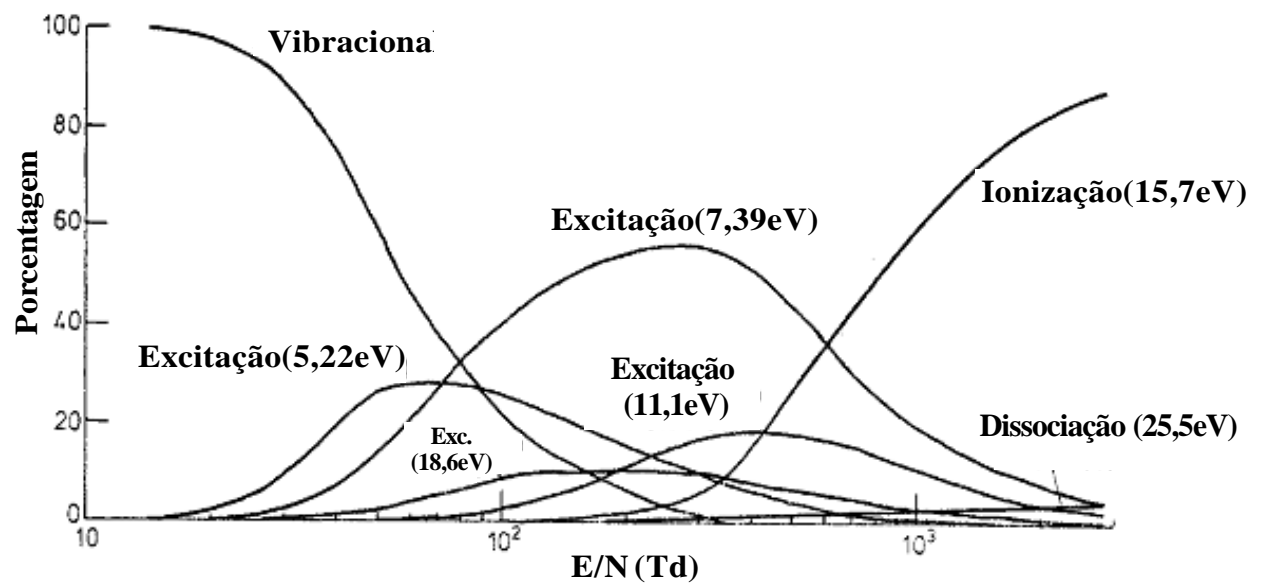

FIGURA 48: Porcentagem de energia perdida por elétrons em $\mathrm{N}_{2}$ em função de $E / N[62]$. 
As secções de choque de colisões com elétrons no isobutano e no butano são apresentadas nas FIG.49 e 50 abaixo.

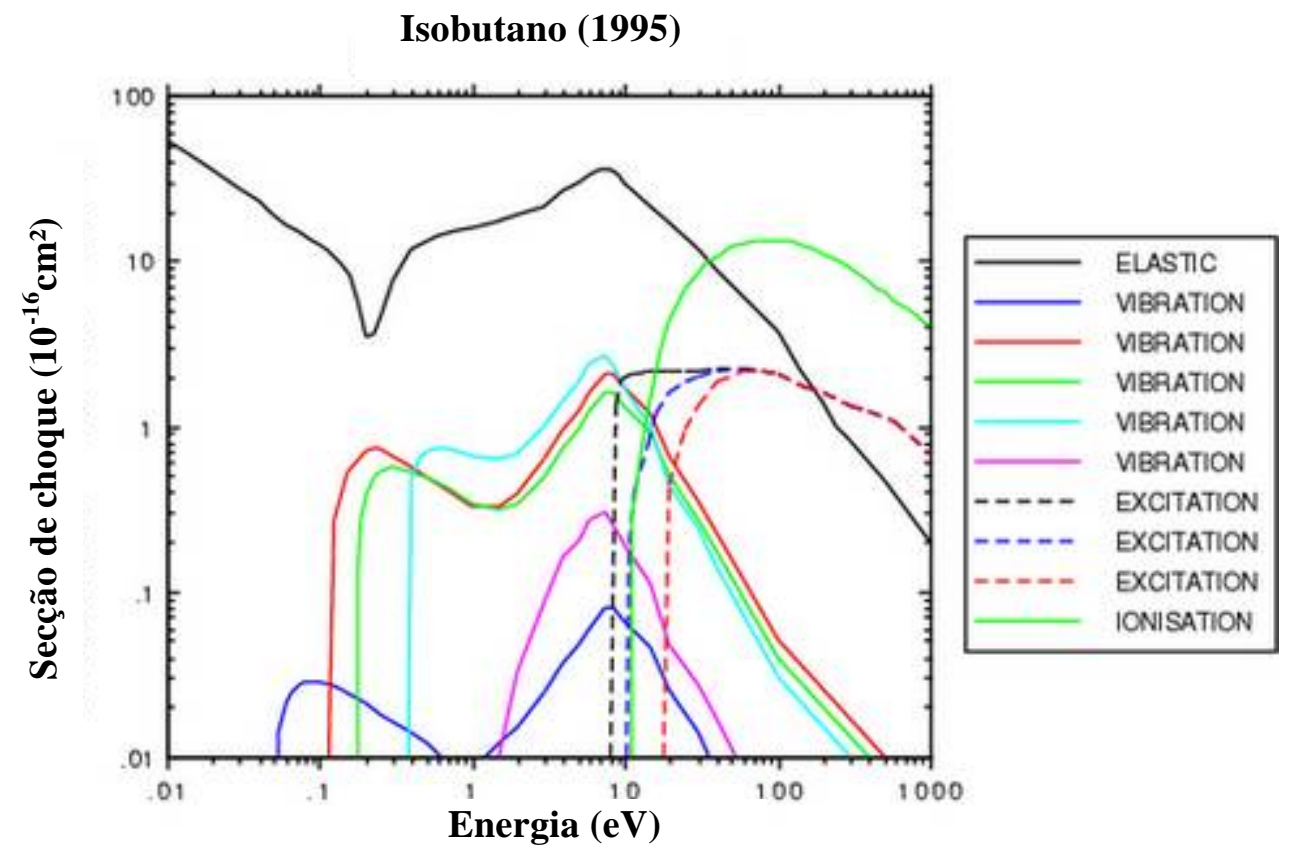

FIGURA 49: Seções de choque no isobutano [63].

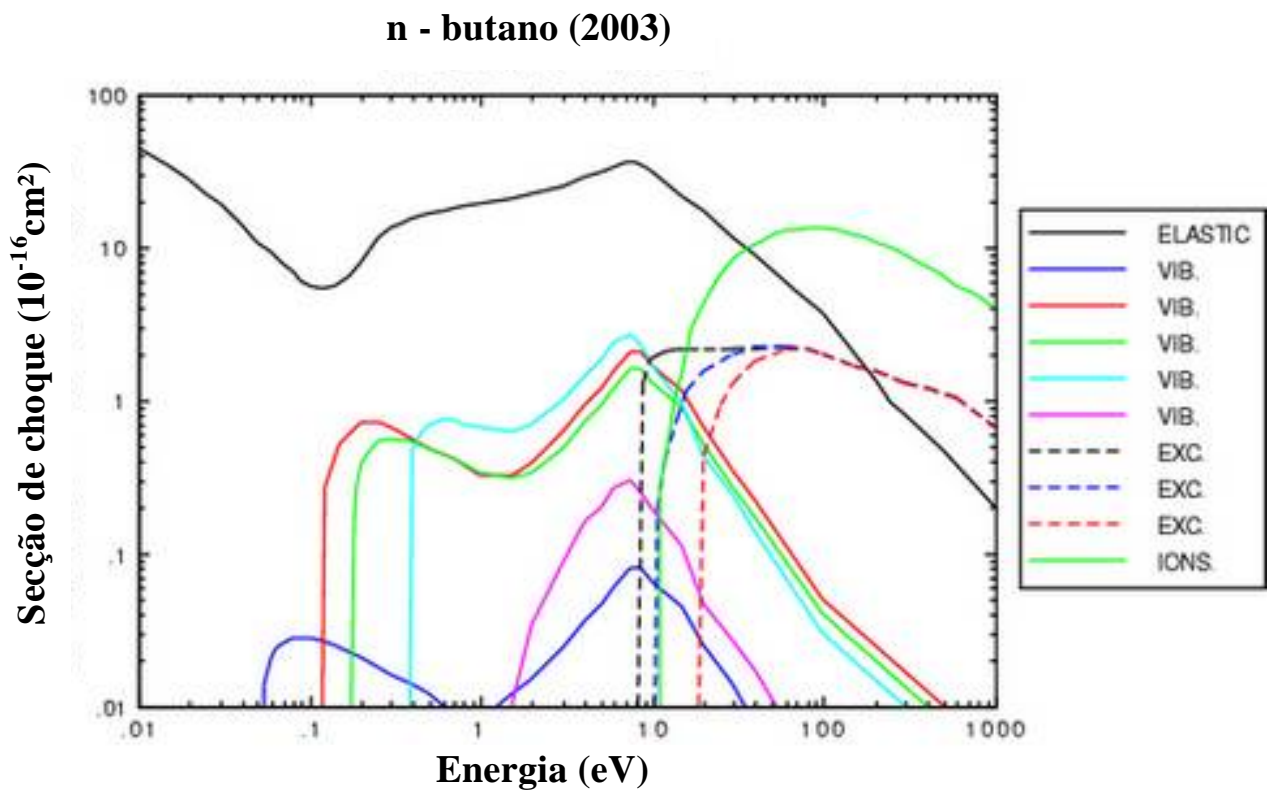

FIGURA 50: Seções de choque no butano [64]. 


\section{REFERÊNCIAS BIBLIOGRÁFICAS}

1. MCDANIEL, E. W. Collision phenomena in ionized gases. NY: Wiley, 1964.

2. RAJU, G. G. Gaseous electronics: theory and practice. Boca Raton: Taylor and Francis Group, 2006.

3. RAJU, G. G. Collision cross sections in gaseous electronics. part II. inelastic collisions. IEEE Electrical Insulation Magazine, v. 23, p. 17-30, 2007.

4. LIEBERMAN, M. A.; LICHTENBERG, Principles of plasma discharges and materials processing. $2^{\text {nd }}$ ed. NJ: John Wiley \& Sons, 2005.

5. MAKABE, T.; PETROVIC, Z. Plasma electronics: Applications in microelectronic device fabrication. Boca Raton: Taylor and Francis Group, 2006.

6. RAETHER, H. Electron avalanches and breakdown in gases. London: Butterworth, 1964.

7. THOMSON, J. J.; THOMSON, G. P. Conduction of electricity through gases. $3^{\text {rd }}$ ed. v. II, Cambridge, 1933.

8. LOEB, L. B., Basic processes of gaseous electronics. Berkeley: University of California Press, 1955.

9. COBINE, J. D. Gaseous conductors: theory and engineering applications. $1^{\text {st }}$ ed. NY: Dover Publication, 1958.

10. MEEK, J. M.; CRAGGS J. D. Electrical breakdown of gases. London: Oxford Press, 1953.

11. SAKAI, Y.; TAGASHIRA, H.; SAKAMOTO, S. The development of electron avalanches in argon at high E/N: I. Monte Carlo simulation. J. Phys. D: Appl. Phys., v.10, p.1035-1049, 1977.

12. TAGASHIRA, H.; SAKAI, Y.; SAKAMOTO, S. The development of electron avalanches in argon at high E/N: II. Boltzmann equation analysis. J. Phys. D: Appl. Phys., v.10, p.1051-1063, 1977. 
13. RIEGLER, W.; LIPPMANN, C. Detailed models for timing and efficiency in resistive plate chamber. Nucl. Instr, and Meth. A, v. 508, p. 14-18, 2003.

14. RIEGLER, W.; LIPPMANN, C. The physics of resistive plate chambers. Nucl. Instr. and Meth. A, v. 518, p. 86-90, 2004.

15. BLANCO, A.; CAROLINO, N.; CORREIA, C. M. B. A.; FERREIRA-MARQUES, R.; FONTE, P.; GOBBI, A.; GONZÁLEZ-DÍAZ, D.; LOPES, M. I.; LOPES, L.; MECEDO,M.P.; MANGIAROTTI, A.; PESKOV, V.; POLICARPO, A. Progress in timing resistive plate chambers. Nucl. Instr. and Meth. A, v. 535, p. 272-276, 2004.

16. GONZÁlEZ-DÍAZ, D.; FONTE, P.; GARZÓN, J.A.; MANGIAROTTI, A. An analytical description of rate effects in timing RPCs. Nucl. Phys. B, v. 158, p.111-117, 2004.

17. MIYAMOTO, J.; KNOLL, G. F. The statistics of avalanche electrons in micro-strip and micro-gap gas chambers. Nucl. Instr. and Meth. A, v. 399, p. 85-93, 1997.

18. BOWLS, W. E. The effect of cathode material on the second Townsend coefficient for ionization by collision in pure and contaminated $\mathrm{N}_{2}$ gas. Phys. Rev. v. 53, p. 293-301, 1937.

19. RAIZER, Y. P. Gas discharge physics. $1^{\text {st }}$ ed. Berlin: Springer-Verlag, 1991.

20. PHELPS, A. V.; PETROVIC, Z. Lj. Cold-cathode discharges and breakdown in argon: surface and gas phase production of secondary electron. Plasma Sources Sci. Technol. v. 8, p. R21-R44, 1999.

21. DANIEL. T. N.; HARRIS, F.M. The spatial growth of ionization current in nitrogen at voltages up to 500kV. J. Phys. B.: Atom. Molec. Phys. v.3, p.363-368, 1970.

22. WEDDING, A. B. Electron swarm parameters in a $\mathrm{CO}_{2}: \mathrm{N}_{2}: \mathrm{He}$ : $\mathrm{CO}$ gas mixture. J. Phys. D: Appl. Phys. v. 18, p. 2351-2359, 1985.

23. BLEVIN, H. A.; FLETCHER, J. Optical studies of pre-breakdown electron avalanches. Aust. J. Phys. v. 45, p. 375-386, 1992.

24. COOKSON, A. H.; WARD, B. W.; LEWIS, T. J. Townsend's first ionization coefficient for methane and nitrogen. Brit. J. Phys. v. 17, p. 891-903, 1966.

25. URQUiJO, J.; ARRIAGA, C. A.; CISNERO, C.; ALVAREZ, I. A time-resolved study of ionization electron attachment and positive-ion drift in methane. J. Phys. D: Appl. Phys. v. 32, p. 41-45, 1999. 
26. HERNÁNDEZ-ÁVILA, J. L.; URQUIJO, J; Pulsed Townsend measurement of electron transport and ionization in $\mathrm{SF}_{6}-\mathrm{N}_{2}$ mixtures. J. Phys. D: Appl. Phys. v. 36, p. L51-L54, 2003.

27. BLEVIN, H. A.; NYGAARD, K. J; SPRIGGS, K. R. Analysis of transient voltage measurements from electron swarm experiments including ionization and attachment, $\boldsymbol{J}$. Phys. D: Appl. Phys. v. 14, p. 841-850, 1981.

28. HUNTER, S. R.; CARTER, J. G.; CHRISTOPHOROU, L. G. Electron transport measurements in methane using an improved pulsed Townsend technique. J. Appl. Phys.. v. 60, p. 24-35, 1986.

29. WILlIAMS, A.; SARA, R. I. Parameters affecting the resolution of a proportional counter. Int. J. Appl. Radiat. Isotopes. v.13, p. 229-238, 1962.

30. VON ENGEL, A. Ionized gases. $1^{\text {st }}$ ed. NY: American Institute of Physics, 1997.

31. SMIRNOV, B. M. Physics of ionized gases. John Wiley \& Sons, 2001.

32. CHARleS, M. W. Gas gain measurements in proportional counters. J. Phys. E: Scientific Instruments. v. 5, p. 95 - 100, 1972.

33. SANTONICO, R.; CARDARELLI, R. Development of resistive plate counters. Nucl. Intr. and Meth., v. 187, p. 377-380, 1981.

34. CARDARELLI, R.; SANTONICO, R.; DI BIAGIO, A.; LUCCI, A. Progress in resistive plate counters. Nucl. Intr. and Meth. A, v. 263, p. 20-25, 1988.

35. FONTE, P.; PESKOV, V. High-resolution TOF with RPCs. Nucl. Instr. and Meth. A, v.447, p. 17-22, 2002.

36. NATIONAL INSTITUTE OF STANDARDS AND TECHNOLOGY - NIST $<$ http://physics.nist.gov/cgi-bin/Ionization/table.pl?ionization=N2 $>$ Acesso em: 10 jan. 2010 .

37. INTERNATIONAL COMMISION ON RADIATION UNITS AND MEASUREMENTS: Average energy required to produce an ion pair. ICRU Report 31, 1979.

38. POSIN, D. Q. The Townsend coefficients and spark discharge. Phys. Rev, v. 50, p. 650$658,1936$.

39. DUTTON, J.; HAYDON, S. C.; JONES, F. L. Electrical breakdown of gases II Spark mechanism in nitrogen. Proc. Roy Soc. A, v. 213, p. 203-214, 1952. 
40. JONES, J. Ionization coefficients in nitrogen. Brit. J. Appl. Phys (J. Phys. D.). v. 1, p. 769-774, 1967.

41. MALLER, V. N.; NAIDU, M. S. Growth of ionization currents in nitrogen. J. Phys. D: Appl. Phys. v. 7. p. 1406-1411, 1974.

42. FOLKARD, M. A.; HAYDON, S. C. Experimental investigations of ionization growth in nitrogen I. J. Phys. B: Atom. Molec. Phys. v. 6, p. 214-226, 1972.

43. HAYDON, S. C.; WILLIAMS O. M. Experimental investigations of ionization growth in nitrogen II. J. Phys. B: Atom. Molec. Phys. v. 6, p. 214-226, 1972.

44. HAYDON, S. C.; WILliAMS O. M. Combined spatial and temporal studies of ionization growth in nitrogen. J. Phys. D: Appl. Phys. v. 9. p. 523-536, 1976.

45. SPRIGGS, K. R.; FLETCHER, J. Transient voltage measurements of primary ionization in nitrogen. J. Phys. D: Appl. Phys. v. 15, p. 1935-1941, 1982.

46. WEDDING, A. B.; BLEVIN, H. A.; FLETCHER, J. The transport of electrons through nitrogen gas. J. Phys. D: Appl. Phys. v. 18, p. 2361-2373, 1985.

47. ROZNERSKI, W. The transport parameters of electron swarms in nitrogen at moderate and elevated E/N. J. Phys. D: Appl. Phys. v. 29, p. 614-617, 1996.

48. CWETANSKI, P.; ROMANIOUK, A.; SOSNOVTSEV, V. Studies of wire offset effects on gas gain in the ATLAS TRT straw chamber. CERN, ATL-INDET-2000-016, 2000.

49. COMBECHER, D. Measurements of W values of low-energy electrons in several gases. Radiat. Res. v. 84, p. 189-218, 1980.

50. NATIONAL INSTITUTE OF STANDARDS AND TECHNOLOGY - NIST $<$ http://webbook.nist.gov/cgi/cbook.cgi?ID=C75285\&Units=SI $>$. Acesso em 10 jan. 2010 .

51. VA'VRA, J. Physics and chemistry of aging - early developments. Nucl. Instr. And Meth. A. v. 515, p. 1 - 14, 2003.

52. VA'VRA, J. Review of wire chamber aging. Nucl. Instr. And Meth. A. v.252, p. 547563, 1986.

53. KLOTS, C. E. Energy-partition parameters in radiation studies of molecular gases. $\boldsymbol{J}$. Chem. Phys. v. 44, p. 2715-2718, 1966. 
54. COLUCCI, A.; GORINI, E.; GRANCAGNOLO, F.; PRIMAVERA, M. Measurement of drift velocity and amplification coefficient in $\mathrm{C}_{2} \mathrm{H}_{2} \mathrm{~F}_{4}$ - isobutane mixtures for avalancheoperated resistive-plate counters. Nucl. Instr. And Meth. A. v. 425, p.84-91, 1999.

55. TSUMAKI, K. Determination of the Townsend primary ionization coefficient using a parallel plate avalanche counter. Jap. Jour. Appl. Phys. v. 27, p. 393-396, 1988.

56. SHARMA, A.; SAULI, F. A measurement of the first Townsend coefficient in argon based mixtures at high fields. Nucl. Instr. and Meth. A. v. 334, p. $420-424,1992$.

57. LU, C.; MCDONALD, K. T.; ZHU, Y. Helium gas mixtures for ring imaging Cherenkov detectors with CsI photocathodes. Nucl. Instr. and Meth. A. v. 334, p. 328 - 338, 1993.

58. BRONIC, I. K.; GROSSWENDT, B. Gas amplification and ionization coefficients in isobutane and argon-isobutane mixtures at low gas pressures. Nucl. Instr. and Meth. B. v. 142 , p. 219-244, 1998.

59. NAKHOSTIN, M.; BABA, M.; OHTSUKI, T.; OISHI, T.; ITOGA, T. Precise measurements of first Townsend coefficient, using parallel plate avalanche chamber. Nucl. Instr. and Meth. A. v. 572, p. 999 - 1003, 2007.

60. FONTE, P.; MANGIAROTTI, A.; BOTELHO, S.; GONÇALVES, J. A. C; RIDENTI, M.; BUENO, C. C. A dedicated setup for the measurement of the electron transport parameters in gases at large electric fields. Nucl. Instr. Meth. A. v. 613, p. $40-45,2010$.

61. CERN. Magboltz 2 v.7.1: cross section plots. Nitrogen. Disponível em: $<$ http://rjd.web.cern.ch/rjd/cgi-bin/cross?update>. Acesso em: 12 jan. 2010.

62. KUCUIKARPACI, H. N.; LUCAS, J. Simulation of electron swarm parameters in carbon dioxide and nitrogen for high E/N. J. Phys. D: Appl. Phys. v. 12, p. 2123 - 2138,1979.

63. CERN. Magboltz 2 v.7.1: cross section plots. Isobutane. Disponível em: $<$ http://rjd.web.cern.ch/rjd/cgi-bin/cross?update $>$ Acesso em: 12 jan. 2010.

64. CERN. Magboltz 2 v.7.1: cross section plots. n-butane. Disponível em: $<$ http://rjd.web.cern.ch/rjd/cgi-bin/cross?update $>$ Acesso em: 12 jan. 2010. 